\title{
Internalized Heterosexism, Outness, Athletic Identity, and Perceived Stress Among Queer Female Athletes
}

Olivia C. Scott

West Virginia University, ocscott@mix.wvu.edu

Follow this and additional works at: https://researchrepository.wvu.edu/etd

Part of the Counseling Psychology Commons, Gender and Sexuality Commons, and the Sports

Studies Commons

\section{Recommended Citation}

Scott, Olivia C., "Internalized Heterosexism, Outness, Athletic Identity, and Perceived Stress Among Queer Female Athletes" (2019). Graduate Theses, Dissertations, and Problem Reports. 4084.

https://researchrepository.wvu.edu/etd/4084

This Dissertation is protected by copyright and/or related rights. It has been brought to you by the The Research Repository @ WVU with permission from the rights-holder(s). You are free to use this Dissertation in any way that is permitted by the copyright and related rights legislation that applies to your use. For other uses you must obtain permission from the rights-holder(s) directly, unless additional rights are indicated by a Creative Commons license in the record and/ or on the work itself. This Dissertation has been accepted for inclusion in WVU Graduate Theses, Dissertations, and Problem Reports collection by an authorized administrator of The Research Repository @ WVU.

For more information, please contact researchrepository@mail.wvu.edu. 
Internalized Heterosexism, Outness, Athletic Identity, and Perceived Stress Among Queer Female Athletes

Olivia Scott, M.S.

Dissertation submitted to the College of Education and Human Services

at West Virginia University

In partial fulfillment of the requirements for the degree of

Doctor of Philosophy

in

Counseling Psychology

Lisa Platt, Ph.D., Chair

Jeffrey Daniels, Ph.D., Co-Chair

James Bartee, Ph.D.

Ed Etzel, Ed.D.

Monica Leppma, Ph.D.

Department of Counseling, Rehabilitation Counseling, And Counseling Psychology

\section{Morgantown, West Virginia}

2019

Keywords: Internalized Heterosexism, Outness, Athletic Identity

Copyright 2019 Olivia Scott 


\begin{abstract}
Internalized Heterosexism, Outness, Athletic Identity, and Perceived Stress

Among Queer Female Athletes
\end{abstract}

\title{
Olivia Scott
}

The historical presence of heterosexism in sport has been discussed in numerous publications, with unique considerations for female athletes (Anderson, Magrath, \& Bullingham, 2016; Cahn, 1993; Griffin, 1998; Rankin, 1998). Unfortunately, few studies have examined the impact of this climate on female athletes with minoritized sexual identities. Most research pertaining to this population has been qualitative and largely focused on lesbian athletes (Fynes \& Fisher, 2016; Stoelting, 2011). Consequently, more generalizable conclusions about queer female athlete experiences has been limited. The present study was an attempt to address this research gap, by assessing the internalized heterosexism, outness, athletic identity, and perceived stress of queer women competing at the college level. Two mediation models were proposed. The first situated internalized heterosexism as a mediator of the relationship between athletic identity and perceived stress. The second situated internalized heterosexism as a mediator between outness and perceived stress. Participants were recruited via online webpages and email advertisement. Only cisgender women over 18, competing in the National Collegiate Athletic Association (NCAA), and identifying with a minoritized sexual identity were eligible to participate. Athletes were administered a demographic questionnaire, the Revised Internalized Homophobia Scale (IHP-R; Herek, Gillis, \& Cogan, 2009), the Athletic Identity Measurement Scale (AIMS; Brewer \& Cornelius, 2001), the Nebraska Outness Inventory (NOS; Meidlinger \& Hope, 2014), and the Perceived Stress Scale (PSS; Cohen \& Williamson, 1988). Results indicate support for the first mediation model but not for the second. Additional analyses revealed a regression model in which athletic identity, sexual orientation, and religiosity predicted internalized heterosexism. Findings related to demographics offer insight into athletes who may be at greater risk for negative outcomes. Applications and directions for future research are discussed to aid coaches, mental health professionals, and university administrators in better serving queer female athletes. 


\section{Dedication}

For all the queer women who have shared their strength and talent in sport. 


\section{Acknowledgements}

Completion of this dissertation would not have been possible without the support and guidance of faculty and mentors. I am especially grateful for my Dissertation Chair, Dr. Lisa Platt, who not only believed in my project, but in my future as a psychologist. I am also thankful for each of the members of my Dissertation Committee. Each has influenced my doctoral journey of learning, scholarship, and growth over the last five years.

I want to thank my program peers, Taylor Allen and Catherine Kepner, for assisting me with participant recruitment. Without your time and energy I would not have found my sample. I also extend my gratitude to West Virginia University's College of Education and Human Services, for providing me with funding for this project through the Berlin B. Chapman Graduate Student Award. This allowed me to compensate my participants.

Finally, I want to thank all those who have inspired and encouraged me throughout my education. Thank you to my mother, who taught me drive, independence, and an appreciation for intellect. Thank you to my family, who have supported me throughout my academic pursuits and showed up when I needed them. Thank you to Dr. Charles Jantzi, for valuing who I was holistically as an undergraduate student-athlete and taking the time to invest in me. Thank you to Dr. Heather Lyons, for seeing my potential and helping me realize that my journey in higher education was not over after my master's degree. Thank you to all of my supervisors, who have helped me integrate the personal and professional in meaningful and powerful ways. Lastly, thank you to Nicole, Jeneice, Chelsea, and all of my peers, who taught me lessons in selfacceptance and vulnerability. Without you, I would not have the courage to be myself. 
Table of Contents

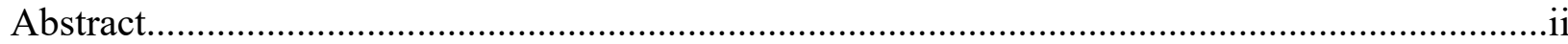

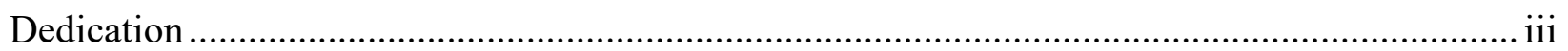

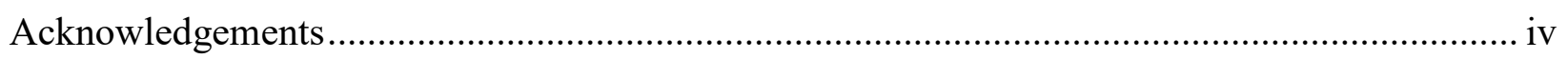

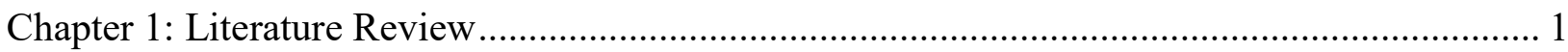

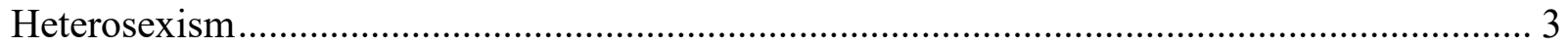

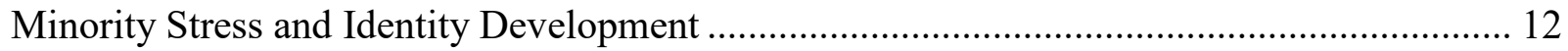

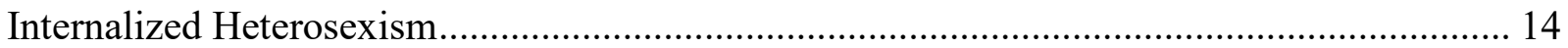

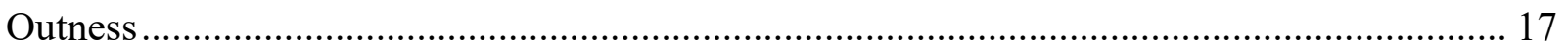

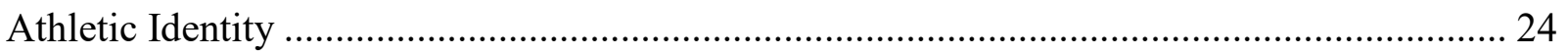

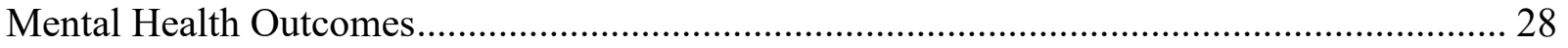

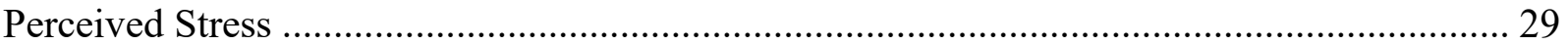

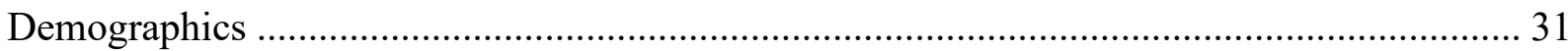

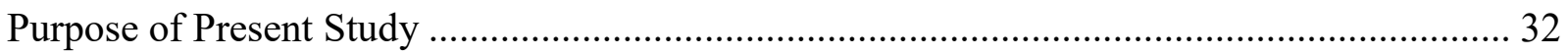

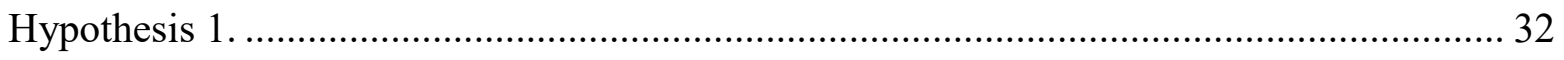

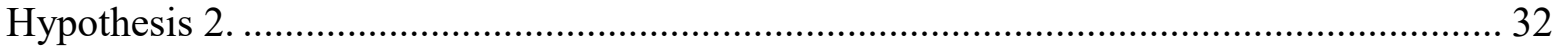

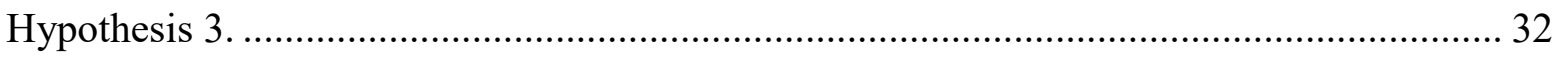

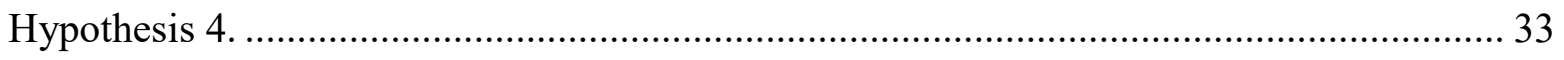

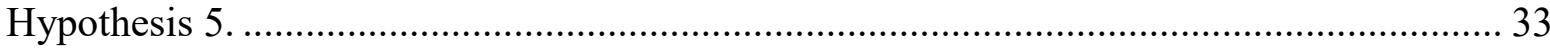

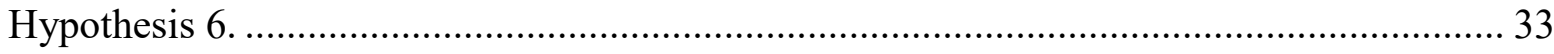

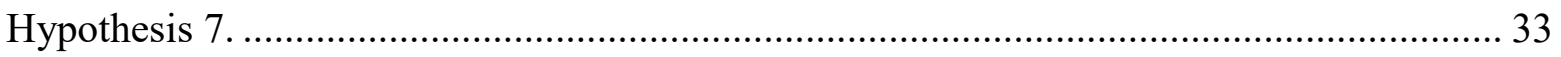

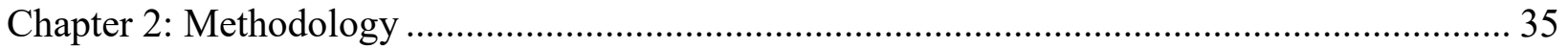

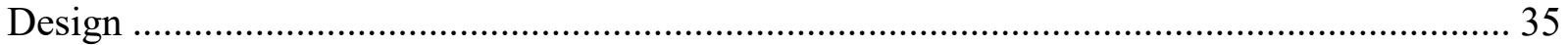

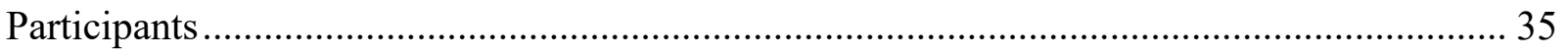

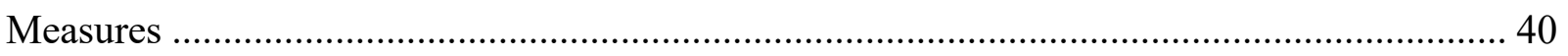

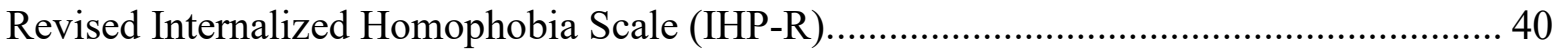

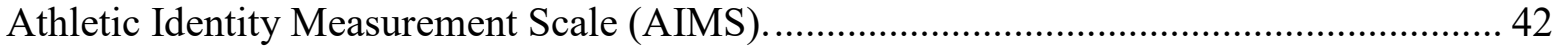

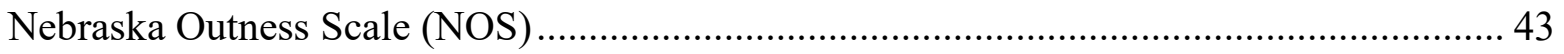

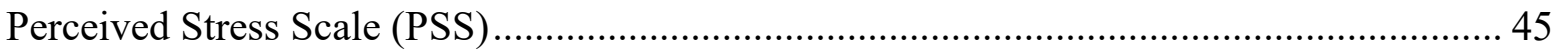

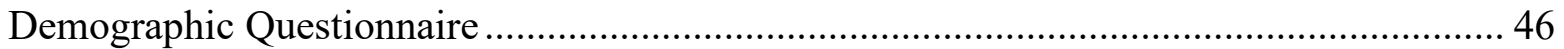

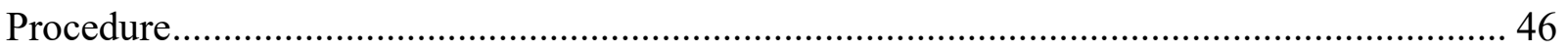




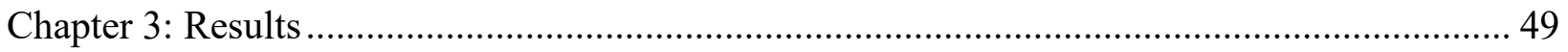

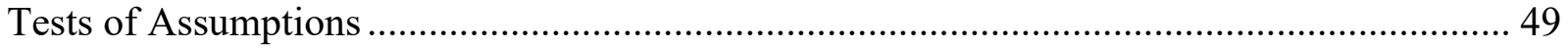

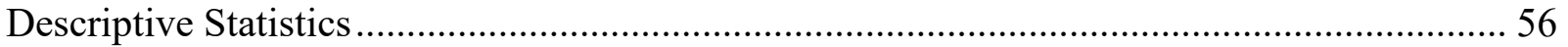

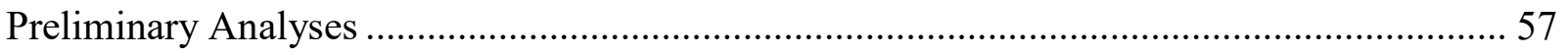

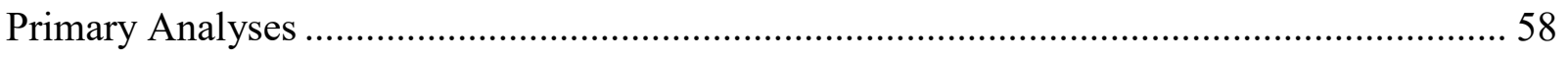

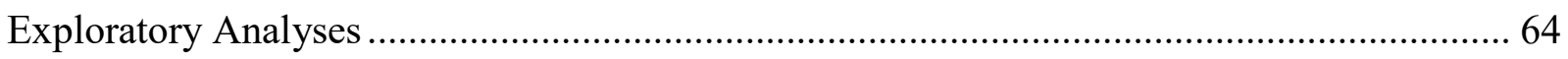

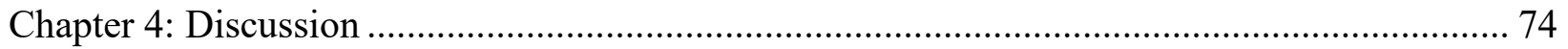

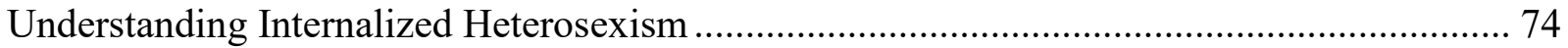

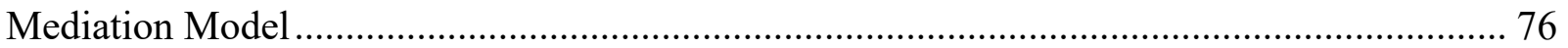

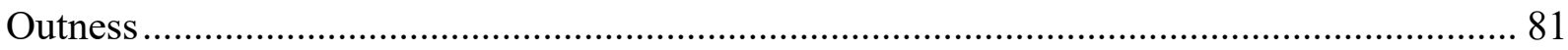

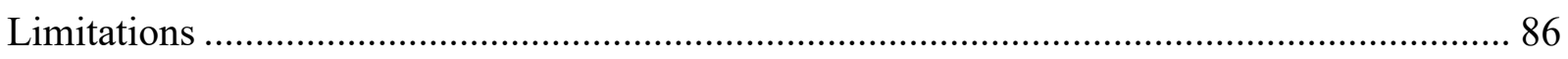

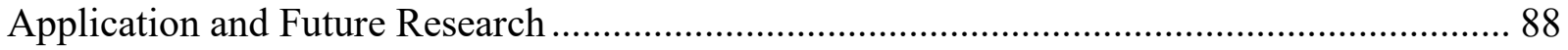

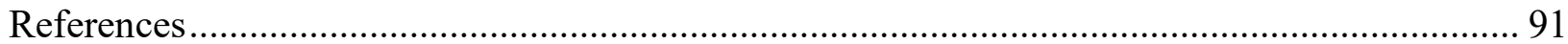


Appendices

APPENDIX A: REVISED INTERNALIZED HOMOPHOBIA SCALE .................................... 121

APPENDIX B: ATHLETIC IDENTITY MEASUREMENT SCALE..................................... 122

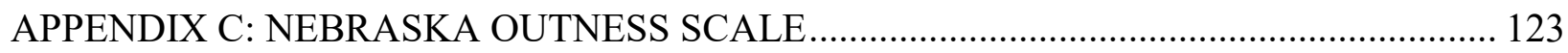

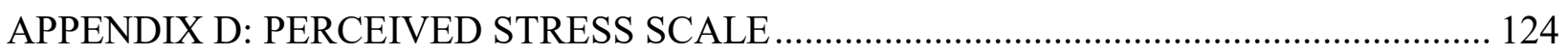

APPENDIX E: DEMOGRAPHIC QUESTIONNAIRE ..................................................... 125

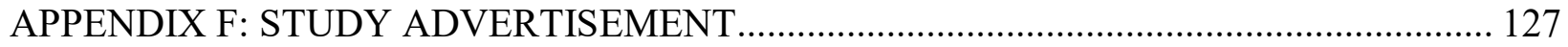

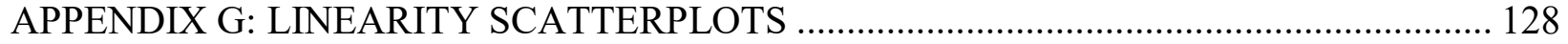

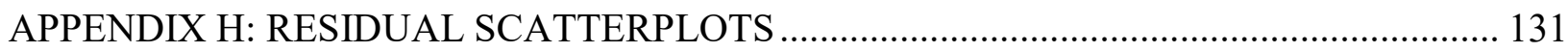

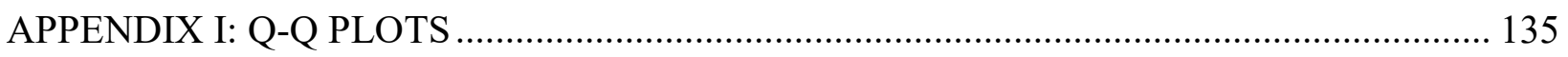

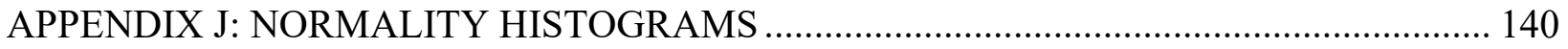




\section{List of Tables}

Table 1: Participant Demographics.......................................................................................... 39

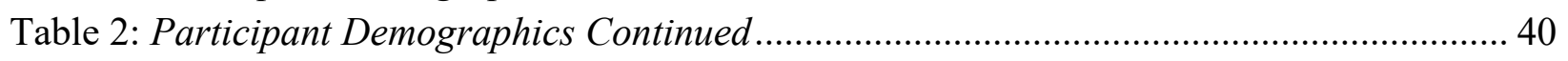

Table 3: Descriptive Statistics for Study Variables ................................................................ 57

Table 4: Correlations Among Internalized Heterosexism, Athletic Identity, Outness, and

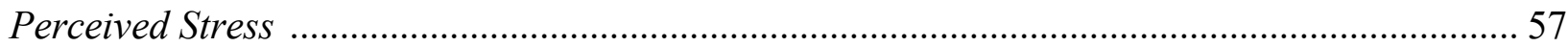

Table 5: Internalized Heterosexism as a Mediating Variable between Predictor Variable of Athletic Identity and Outcome Variable of Perceived Stress.

Table 6: Internalized Heterosexism as a Mediating Variable between Predictor Variable of Outness and Outcome Variable of Perceived Stress.

Table 7: Summary of Demographic Variables Tested as Predictors of Perceived Stress..... 65

Table 8: Summary of Demographic Variables Tested as Predictors of Internalized

Heterosexism 66

Table 9: Summary of Multiple Regression Analyses for Variables Predicting Internalized Heterosexism 68

Table 10: Summary of Demographic Predictors of Athletic Identity ......................................... 70

Table 11: Summary of Demographic Predictors of Outness ...................................................... 71

Table 12: Summary of Multiple Regression Analyses with Perceived Stress as the Outcome Variable and Racial Identity as an Added Predictor.

Table 13: Summary of Multiple Regression Analyses with Perceived Stress as the Outcome Variable and Sport as an Added Predictor. 73

Table 14: Summary of Multiple Regression Analysis with Perceived Stress as the Outcome Variable and Sport and Racial Identity as Added Predictors. 


\section{List of Figures}

Figure 1: Mediation model with internalized heterosexism mediating the relationship between athletic identity and perceived stress.

Figure 2: Mediation model with internalized heterosexism mediating the relationship between

outness and perceived stress.

Figure 3: Histogram of perceived stress scores ........................................................... 50

Figure 4: Histogram of internalized heterosexism scores................................................... 51

Figure 5: Histogram of athletic identity scores.................................................................... 51

Figure 6: Histogram of outness scores ............................................................................. 52

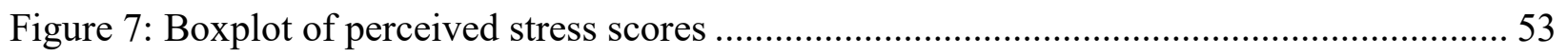

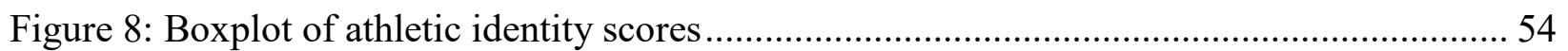

Figure 9: Standardized regression coefficients for the relationship between athletic identity and

perceived stress, mediated by internalized heterosexism ................................................. 60 


\section{Chapter 1: Literature Review}

Historically, the world of sport has been an unfriendly space for individuals with minoritized sexual identities ${ }^{1}$ (Fynes \& Fisher, 2016; Griffin, 1998, Rankin, 1998). Support for this claim has been documented in news accounts and academic literature. Perhaps the most famous example of a hostile athletic culture occurred under the authority of Rene Portland, who formerly coached the Pennsylvania State University women's basketball team. In 2006, one of Portland's players, Jennifer Harris, filed a discrimination lawsuit against Portland for her overt bias against lesbians (Associated Press, 2007). Portland allegedly had a "no lesbians policy" on her team, and mistreated Harris based on her presumed lesbian identity and lack of femininity (Associated Press, 2007). Harris claimed that Portland also tried to force her withdrawal from the team.

Not all cases of sexual orientation discrimination in sport are as public or blatant as that of Portland. The theoretical literature highlights a spectrum of prejudice and discrimination against queer athletes. Silence represents one indicator of negative climate present in sporting spaces. Anderson, Magrath, and Bullingham (2016) acknowledged the history of “don't ask don't tell" cultures in college athletic departments in the United States. Such imperatives of silence were often couched in the assertion that matters of sexual identity are not relevant to sport and should therefore be kept separate from the athletic world. Rankin (1998) addressed the culture of silence within women's athletics, commenting on how it encourages sexual identity concealment and preserves negative attitudes towards queer identities. 
The extant empirical literature on college athletes also reflects the silence and heterosexism in sport, in that few studies have attended to minoritized sexual identities. Ram, Starek, and Johnson (2004) exposed the lack of consideration of queer individuals in sport and exercise psychology research published between 1987 and 2000. They indicated that while more studies reported race and ethnicity variables during that timeframe, few studies included sexual identity in their participant demographics. The authors voiced the need for a collective commitment to capturing the experience of marginalized groups.

Over the last decade, research has been more inclusive of minoritized sexual identities. However, another issue in both the athletic and psychological literature is the lack of appreciation for diverse experiences among queer persons. Most studies that do include sexual orientation refer to lesbian, gay, and bisexual individuals, but do not illuminate the experiences associated with other sexuality labels (e.g., questioning, pansexual, mostly heterosexual). Furthermore, the research involving queer athletes is largely qualitative, involves small samples, and offers mixed conclusions. Some authors have documented reports of discrimination and adverse outcomes among queer athletes (e.g., Fynes \& Fisher, 2016; Melton \& Cunningham, 2012; Rankin \& Merson, 2012; Symons, O’Sullivan, \& Polman, 2017). Others have noticed improvements in acceptance and experience (e.g., Anderson et al., 2016; Fink, Burton, Farrell, \& Parker, 2012; Mann \& Krane, 2018; Stoelting, 2011).

In light of the conflicting findings about the contemporary experiences of queer athletes, additional research is needed to clarify current trends across teams, universities, and sports using quantitative analyses. Such research could be used to assist coaches, mental health practitioners, and university administrators in adequately serving student-athletes with minoritized sexual identities. Given that the scope of the present study could have exceeded practicality, only queer 
female athletes competing at the college level were recruited for the sample. This was partly due to the well-documented presence of queer women on collegiate sports teams (Rankin \& Merson, 2012). In the subsequent sections, a review of the literature pertaining to the experiences of queer women and female athletes is presented. Heterosexism is defined first, along with relevant "minority stress" and identity development models. Next, the extant research relating to the study variables of internalized heterosexism (IH), outness, athletic identity (AI), and perceived stress is reviewed. A rationale for selecting each variable for the study is also described in this chapter. Finally, the demographic variables included in this study are briefly discussed.

\section{Heterosexism}

Herek (1990) used the term heterosexism to capture the oppressive forces and prejudicial attitudes that impact lesbian, gay, and bisexual individuals at all levels of society. Understanding the nature and history of this term is important for conceptualizing the queer female athlete experience in ways that account for interpersonal, institutional, and cultural oppression.

In their review of the literature, Szymanski, Kashubeck-West, and Meyer (2008a) noted that the terms homophobia and homonegativity have been used to characterize discriminatory attitudes towards minoritized sexual identities. However, they pointed out these terms and the associated concepts are both problematic and narrow in scope. Homophobia is concerned with the fear of same-sex sexual behavior and those who engage in it, but researchers have demonstrated that disgust might be a more central feature of prejudicial attitudes, rather than fear (Szymanski et al., 2008a). Homonegativity circumvents some of the conceptual issues of homophobia, capturing the breadth of negative reactions toward queer people. Nevertheless, Szymanski et al. (2008a) argued that both terms are confined to individual and group prejudice, neglecting larger systems of oppression. Furthermore, neither term encompasses the sexist 
components of negative attitudes about minoritized sexual identities. Consequently, heterosexism is the most accurate term for the broad range of oppressive agents in society and the diversity of experiences within the queer community (Szymanski et al., 2008a).

Like racism, sexism, and other forms of oppression, heterosexism keeps minoritized persons in a disadvantaged position in society (Sue \& Sue, 2016). The function of any oppressive agent is to restrict the success and power of certain groups, while preserving the status of other group members (Goodman, 2011). However, there are differences between heterosexism and other forms of oppression. For one, sexual identity is a concealable identity status, unlike other social categories such as race and presumably sex. Thus, heterosexism can be expressed in both overt and covert ways. A lesbian girl who discloses her sexual identity to her parents and is subsequently disowned would be experiencing overt prejudice. But a gay male athlete who has never disclosed his sexual orientation and witnesses his teammates make homophobic remarks would be experiencing covert prejudice. Although his teammates are unaware of his sexual identity and may mean no direct offense, their comments establish a hostile climate for those with minoritized orientations. In response, the gay athlete can either remain silent or disclose his identity and risk facing rejection. Weighing the risks and benefits of identity disclosure is a unique and recurring burden for queer individuals in a heterosexist world (Riggle, Rostosky, Black, \& Rosenkrantz, 2017). Furthermore, the implications and results of coming out vary on a case by case basis.

Heterosexism also differs from other "isms" because it acknowledges the role of sexism in the discrimination of queer people (Szymanski et al., 2008a). In other words, heterosexism emphasizes an intersectional perspective of oppression that accounts for the impact of having multiple minoritized identities (Szymanski et al., 2008a). Heterosexism therefore recognizes that 
the lesbian experience differs from the gay male experience, and the bisexual female experience differs from the bisexual male experience. The disadvantaged position of women in society often leads to their objectification, which may contribute to the eroticization of same-sex sexual behavior between women (Louderback \& Whitley, 1997). However, this eroticization does not represent acceptance of queer female identities, but the restrictive value of female-female sexual behavior as an agent of male arousal.

In addition, heterosexism embodies the inherent assumption that queer identities are often considered to be abnormal and immoral, which is distinct from the features of racism, sexism, and ageism (Sue \& Sue, 2016). This is due to historical understandings of sexual orientation as a lifestyle choice, rather than an immutable identity. Others have also viewed queer people as a perversion of natural order. Haldeman (1994) described the position of many conversion therapy advocates and ex-gay ministries, noting the continual appraisal of same-sex attraction and sexual behavior as pathological, despite the American Psychological Association's (APA; 2012) assertions of the contrary. While women, people of color, and older adults can experience oppression and otherhood, they are less likely to be viewed as unnatural or be condemned for their identities. Ableism might be most comparable to heterosexism, in light of its underlying assumption that people with disabilities are broken or abnormal. Additionally, individuals with physical or cognitive limitations were historically viewed as those punished by God (Sue \& Sue, 2016).

Understandings of normality are important when considering the manifestation of heterosexism in attitudes, standards, and systems. The concept of heteronormativity captures the role of norms in shaping prejudice against sexual orientation diversity. First coined by Warner (1991), heteronormativity represents the prevailing standard and assumption of heterosexuality, 
which is ascribed privilege and normalcy in society. It is important to recognize that heteronormativity is not limited to attitudes about sexual behavior, but encompasses societal expectations related to marriage, family, and gender roles (Herz \& Johansson, 2015). Thus, heteronormativity is embedded within the institutions, traditions, beliefs, and laws of society.

\section{Predictors of Heterosexism}

In spite of the heteronormative foundation of most societies, different people and environments vary in their level of heterosexism. Researchers have explored the predictors and correlates of heterosexism within different groups. Most have found more affirming attitudes among Americans who identify as White, female, atheist, or politically liberal (e.g., Herek, 2002; Woodford, Silverschanz, Swank, Scherrer, \& Raiz, 2012), while negative attitudes have been associated with religious fundamentalism and right-wing authoritarianism (Nagoshi et al., 2008). However, the complexity of how these identities interact is less understood. Contact with queer people has been associated with reduced heterosexism (Hinrichs \& Rosenberg, 2002), although the level, context, and type of contact matters. Woodford et al. (2012) found that having queer friends or immediate family members was related to more accepting attitudes, but having queer acquaintances or extended family was not. Some researchers have noted that traditional gender roles partially explain negative attitudes about sexual orientation diversity (e.g., Harbaugh \& Lindsey, 2015; Jewell \& Morrison, 2012). In other words, those who promote gender stereotypes are more likely to discriminate. Underlying this prejudicial perspective is the assumption that those who deviate from heteronormativity and masculine or feminine ideals pose a threat to the values, structure, and patriarchal hierarchy of western society. Warriner, Nagoshi and Nagoshi's (2013) findings provide some support for this notion. They found that aggression was associated with heterosexism in heterosexual men but not heterosexual women, gay men, or 
lesbians. Thus, it may be that heterosexual men who embody traits that are hypermasculine are more heterosexist as well.

Kilianski (2003) suggests that individuals who observe discrepancies between their actual identity and the masculine or feminine ideal may compensate by espousing prejudicial attitudes. This strategy serves to assert or preserve masculinity and femininity in the face of personal identity threats. Regardless of the level of analysis, traditional views of masculinity and femininity may influence levels of discrimination.

The intersection between heterosexism and gender norms is particularly relevant in sport, where traditional masculinity is a dominant value. In fact, theorists have emphasized the role of hegemonic masculinity within the culture of athletics in promoting heterosexism (e.g., Anderson, 2002; Kauer \& Krane, 2006; Worthen, 2014). The idealization of hypermasculinity in sport informs the attitudes of male and female athletes in different ways (Roper \& Halloran, 2007; Worthen, 2014). Male athletes experience pressure to achieve an acceptable level of masculinity to assert their athletic identities. Female athletes, however, are torn between developing athletic identities that are consistent with traditional masculinity and maintaining feminine ideals. For both sets of athletes, rejecting queer identities may serve the function of meeting their identity needs (Anderson et al., 2016), which can promote hostility on sports teams.

While heteronormativity and traditional gender roles help explain the existence of heterosexism, it is worth noting the ways in which it manifests in the lives of queer people. The type of prejudice and discrimination people have experienced as a result of their sexual orientation will be described next, followed by what is known from queer athlete reports. 


\section{The Manifestation of Heterosexism}

Heterosexism, as it is experienced by queer people, comes in many forms. Herek (2009) examined the prevalence of discriminatory experiences among a sample of self-identified gay, lesbian, and bisexual adults $(n=662)$. Twenty percent of respondents reported experiencing a person or property crime due to their sexual identity, while $50 \%$ reported verbal harassment. Ten percent reported employment or housing discrimination. Both were significantly more likely among gay men and lesbians than bisexual individuals.

Woodford, Kulick, Sinco, and Hong (2014) noted that modern heterosexism is more covert than previously reported. In their sample queer college students, environmental micoraggressions, or the negative messages embedded in laws, policies, and social norms that target minoritized groups (Sue, 2010), were the most prominent feature of the heterosexism they experienced. Thus, heterosexism may be subtler than blatant victimization enacted by identifiable offenders.

In regard to sex differences, researchers have found that queer men endorse greater experiences of prejudice than queer women (e.g., Puckett, Maroney, Levitt, \& Horne, 2016). This makes sense considering the greater degree of prejudicial attitudes documented among heterosexual men in comparison to heterosexual women (Worthen, 2014). However, research findings on sex differences are mixed. Some researchers have found no differences in experienced discrimination among men and women (Feinstein, Goldfried, \& Davila, 2012; Fingerhut, Peplau, \& Gable, 2010), while other theorists have proposed a compounding effect in discrimination for queer women (Brooks, 1981). In other words, having two or more minoritized identities may result in increased stress due to greater volume and variability in type of discriminatory experiences. Szymanski, Dunn, and Ikizler (2014) found support for this theory 
in their study of 761 queer women. They found that heterosexist events and sexist events were unique predictors of psychological distress, over and above general stress in their sample. Queer women are also susceptible to unique forms of prejudice, such as male-perpetrated sexual assault or harassment as a result of nonconformity to heteronormative expectations (Fernald, 1995; Friedman \& Leaper, 2010).

Queer women might also be more susceptible to prejudice than queer men, due to their multiple minoritized status. Burn, Kadlec, and Rexler (2005) provided heterosexist vignettes to 175 lesbian, gay, and bisexual college students and asked them to rate their reactions and perceptions. The authors found that lesbian women rated the vignettes as more prejudicial and offensive than gay men in the sample. They posited that gay men might be more habituated to heterosexism, due to its high prevalence within "male culture." Bisexual participants also provided higher ratings for prejudice and offensiveness than gay men, but no significant differences between the responses of lesbians and bisexuals were apparent. While this comparison suggests that bisexuals also perceive greater prejudice, it should be noted that the bisexual group included both men and women due to the low number of bisexual male participants $(n=9)$ in the study. Additional research is needed to appreciate the distinct experiences of bisexual men and women.

The mixed findings associated with sex differences in experienced prejudice may have to do with varying types of discrimination. The Pew Research Center (2013) surveyed 1,197 lesbian, gay, and transgender adults and found that there were some forms of discrimination that were equally experienced by gay men and lesbians, including rejection by a family member and workplace discrimination. However, gay men were more likely to experience verbal and physical attacks than the lesbians surveyed. The culmination of this research points to the 
diverse experiences of queer people according to gender. Some forms of prejudice may be more prevalent among men than women and vice versa. Other forms of prejudice may be experienced by men and women at similar rates. Researchers should appreciate these differences when designing studies and drawing conclusions about the discrimination of minoritized sexual identities.

In regard to differences in experienced prejudice across sexual identities, there is some evidence that lesbians and gay men report more discrimination than other queer individuals (Bostwick, Boyd, Hughes, West, \& McCabe, 2014; Herek, 2009). Friedman and Leaper (2010) observed greater reported discrimination among lesbian and queer women when compared to bisexual women. Similarly, Puckett et al. (2016) found that bisexual and questioning individuals reported experiencing less prejudice than gay and lesbian people. The authors concluded that this might be related to the greater identity concealment reported by bisexual and questioning participants. Hong, Woodford, Long, and Renn (2016) surveyed 530 queer college students and found that bisexual and pansexual (those who are sexually and/or romantically attracted to individuals of all genders, not only men and women) students reported less interpersonal microaggressions and verbal threats than their gay and lesbian peers. Additionally, these students were less likely to experience others avoiding them. Such findings might also be related to identity concealability, as the authors noted how atypical gender expression was associated with greater overt discrimination.

The literature summarized thus far has some overlap with reported heterosexism in sport. Similar to research involving non-athletes, Rankin and Merson (2012) found that lesbian, gay, and bisexual college athletes $(n=394)$ reported more harassment and perceived a more negative campus climate than the heterosexual athletes $(n=7,625)$ they surveyed. Some qualitative 
studies have also exposed the discrimination of queer female athletes. Melton and Cunningham (2012) interviewed lesbian athletes of color $(n=12)$ regarding their experience of having multiple marginalized identities. Common themes gleaned from athlete responses included witnessing overt heterosexism within athletic departments and making an effort to conform to heteronormative standards. The athletes also reported feeling as though their racial and athletic identities were more accepted than their sexual identities. In another study, lesbian athletes ( $n=$ 10) reported greater comfort with their sexuality and greater acceptance on their teams, but still found their athletic departments unsupportive (Fynes \& Fisher, 2016). As was mentioned previously, a historically prominent feature of heterosexism in sporting cultures is the imperative of silence or "don't ask don't tell" (Anderson et al., 2016). Cahn (1993) described the lesbian athlete stereotype as a driving force in the push to conceal queer identities and project feminine heterosexuality when women participation in athletics was increasing in the $20^{\text {th }}$ century. This history likely contributes to the unique heterosexism experienced by queer female athletes, given that men are rarely assumed to be queer for participating in sports. Unfortunately, there is little research capturing experiences across queer identities among female athletes, due to the small sample sizes of existing qualitative inquiries. The present study was one attempt to address this research gap.

Now that the presence of heterosexism in society and sporting cultures has been reviewed, it is important to address the impact it has on individuals with minoritized sexual identities. To set the foundation for this body of literature, relevant theoretical models related to stress and identity development among queer people are presented. 


\section{Minority Stress and Identity Development}

Given that a central aspect of the present study is focused on what it means to identify as queer, an athlete, or both, identity development literature offers an appropriate framework for conceptualizing the queer female athlete experience. One theory and two models formed the theoretical basis of this dissertation. Marcia's (1966) theory of general identity development was considered pertinent due to the emphasis on negotiating and exploring identities, with some consideration of social forces. Marcia described four possible identity statuses that are experienced as part of the identity development process. According to his research, identity achievement is associated with adopting a particular life role or choice. Marcia deemed this identity status as most desirable, due to its association with self-esteem and autonomy. Identity moratorium, however, is a state of crisis marked by exploration and a lack of commitment. Identity diffusion is also characterized by a lack of commitment, but is associated with a lack of exploration. This could be related to a lack of interest or self-awareness. Identity foreclosure involves a level of commitment that is influenced by the expectations of others, particularly those in authority. Consequently, those in identity foreclosure have typically engaged in limited exploration. When applied to queer female athletes, it may be helpful to understand under what circumstances they experience achievement, moratorium, diffusion, or foreclosure related to their sexual and athletic identities.

The sexual identity development literature also offers pertinent guidance related to the present study. McCarn and Fassinger's (1996) model of lesbian identity development was considered most helpful, due to its emphasis on women, group membership, and appreciation for flexibility in the sexual identity formation process. The authors suggested four phases for individual sexual orientation development. The awareness phase involves a realization of 
attraction or desires towards women. The exploration phase is characterized by deeper feelings and relationships with women, but may not include an exploration of sexual behavior. The deepening/commitment phase involves greater exploration and intention around finding sexual clarity. McCarn and Fassinger noted that this phase may or may not involve selecting sexual identity labels. The internalization/synthesis phase is defined by greater self-acceptance and typically coincides with addressing group membership (i.e., identification with the queer community) through a second branch of the model. The authors applied the same four phases for group membership identity development as well. When considering McCarn and Fassinger's model, it is conceivable that queer female athletes might relate to the phases or processes described. For example, Davis-Delano (2014) observed the ways in which sporting climates both nurtured and hindered female athletes' same-sex attractions and relationships. The present study sought to elucidate additional factors that my influence or coincide with the sexual identity development process for this population. To guide the selection of these variables, literature regarding the stress of minoritized groups was consulted.

Meyer (2003) proposed a minority stress model specific to queer people. Underlying his theory is the notion that stress caused by one's minoritized status and social environment produces negative health outcomes. Meyer (2003) identified several minority stress processes that operate at distal and proximal levels. The former refers to external and objective sources of stress, such as harassment or discriminatory work policies reflective of heterosexism. The latter refers to individual and subjective processes that produce stress, including self-concealment of one's sexual orientation and negative appraisals of life events. The present study focused on proximal and subjective stressors, namely internalized heterosexism (IH), athletic identity (AI), and outness, all of which will be defined in the subsequent sections. 


\section{Internalized Heterosexism}

While heterosexist attitudes are views espoused by heterosexual people, internalized heterosexism $(\mathrm{IH})$ encompasses the beliefs and subjective internal experience of queer people (Szymanski et al., 2008a). More specifically, IH is the personal adoption and entrenchment of prejudicial messages about queer identities propagated by individuals, groups, institutions, and cultures that can lead to a negative view of the self and others with diverse sexual orientations (Szymanski et al., 2008a). According to Meyer's (2003) minority stress model, heterosexism represents a distal stressor while IH represents a proximal or subjective stressor. Not surprisingly, many researchers have observed a link between overt heterosexism and $\mathrm{IH}$ (Dragowski, Halkitis, Grossman, \& D’Augelli, 2011; Feinstein et al., 2012; Lewis, Derlega, Berndt, Morris, \& Rose, 2001; Szymanski and Henrichs-Beck, 2014). Based on the heterosexist and conformist culture of sport (Rankin, 1998), one might expect a high prevalence of IH among queer athletes. This is worth exploring, given that research has established an association between IH and negative outcomes (Frock, 2000; Szymanski, 2005; Szymanski et al., 2008b). For coaches, athletics staff, and university administrators, understanding the presence of $\mathrm{IH}$ among queer athletes could inform appropriate intervention. Unfortunately, IH has yet to be assessed in athlete populations outside of the present study. The subsequent review of the literature is presented to summarize what is currently known about IH in queer samples.

Researchers have observed relationships between IH and decreased sexual identity development, lower self-esteem, increased self-harm behaviors, greater disordered eating, and lower psychological wellbeing (Newcomb \& Mustanski, 2010; Szymanski et al., 2008b; Williamson, 2000; Wright \& Perry, 2006). Puckett, Levitt, Horne, and Hayes-Skelton (2015) observed a positive correlation between IH and psychological distress in their sample of 436 
gender and sexually diverse individuals. Psychological distress was measured in three ways: depression, anxiety, and general psychological distress. Internalized heterosexism was also correlated with greater self-criticism in their sample. Herek, Cogan, Gillis, and Glunt (1998) assessed IH in a community sample of lesbians and gay men. Overall, those with high IH endorsed greater depression and demoralization. Men with high IH also reported lower selfesteem. More recently, McLaren (2016) studied IH, depression, and suicidal ideation in a sample of gay men, lesbians, and bisexual women. She found that IH was significantly related to depression and suicidal ideation among gay men and lesbians.

Social variables have also been studied in relation to $\mathrm{IH}$. Most studies assert a correlation between IH and greater relationship problems, less social support, and low community connectedness with other queer individuals (Frost \& Meyer, 2009; Puckett et al., 2015 Szymanski et al., 2008b). Herek et al. (1998) found that IH was associated with less identity disclosure and less connection with queer people in their sample of lesbians and gay men $(n=$ 147). Wright and Perry (2006) found that queer youth $(n=156)$ who had disclosed their sexual identity to their support network reported less psychological distress associated with IH. Thus, it would appear that IH is related to one's social environment and can be reduced when one is involved in affirming relationships.

In regards to gender specific findings, a plethora of studies have been conducted to examine IH in queer men. Morandini, Blaszczynski, Ross, Costa, and Dar-Nimrod (2015) found that gay men who believed that sexual orientation is biologically-based reported less $\mathrm{IH}$, but those who believed in discrete identity categories endorsed greater IH. Thus, IH may be influenced by a person's beliefs about sexual identity. Other findings in the literature indicate that men with high levels of IH also experience shame, distrust, low self-confidence, sex guilt, 
less emotional stability, decreased sexual functioning, and gender role conflict (Allen \& Oleson, 1999; Brown \& Trevethan, 2010; Meyer \& Dean, 1998; Szymanksi et al., 2008b; Szymanski \& Ikizler, 2013). Kuerbis et al. (2017) assessed IH among 187 queer men struggling with alcohol abuse. They found that IH was positively associated with heavy drinking, negative consequences due to alcohol use, and psychological distress. In a few studies, men with minoritized sexual identities have reported higher levels of $\mathrm{IH}$ when compared to queer women (Bell \& Weinberg, 1978; Costa, Pereira, \& Leal, 2013; Feinstein et al., 2012; Herek et al., 1998). However, comparable levels of IH between men and women have also been observed (Barnes \& Meyer, 2012).

Several studies pertain to IH among queer women exclusively. Szymanski, Chung, and Balsam (2001) found that IH was significantly associated with depression, decreased social support, and decreased satisfaction with social support in a sample of 157 lesbians. Other researchers have corroborated the relationship between $\mathrm{IH}$ and negative mental health outcomes, noting some key mediators. For example, Szymanski and Kashubeck-West (2008) found that decreased social support and self-esteem mediated the relationship between IH and mental health in a sample of lesbians and bisexual women $(n=304)$. Alternatively, Kaysen et al. (2014) identified maladaptive coping, as defined by behavioral disengagement, denial, self-blame, selfdistraction, and substance use, as a mediator between IH and psychological distress in a large sample of queer women $(n=1,099)$. In another study, increased shame mediated the relationship between IH and binge eating among 138 lesbians and bisexual women (Bayer, Robert-McComb, Clopton, \& Reich, 2017). Additional negative correlates of IH among queer women include emotional intelligence, coping resources, and feminist identification (Szymanski \& Chung, 2003; Szymanski et al., 2008b). 
Sexual identity development and acceptance also appear negatively related to $\mathrm{IH}$ in women (Greywolf, 2007; Mildner, 2001; Mohr \& Kendra, 2011). For example, Hoang, Holloway, and Mendoza (2011) found that greater bisexual identity congruence, or the alignment of attractions, behaviors, and self-labels, was associated with less internalized biphobia in 87 women with self-reported attractions to both men and women. Similarly, Peterson and Gerrity (2006) found that IH decreased as sexual identity development progressed in a sample of undergraduate women $(n=35)$. Interestingly, the authors noted that 9 participants self-identified as heterosexual despite having reported being in a stage of queer sexual identity development.

Differences in IH based on sexual identity have been observed. Puckett et al. (2016) noted that bisexual and questioning participants in their sample reported greater IH than lesbian and gay participants. This is interesting in light of the greater prejudice reported by lesbians and gay men (Herek, 2009; Puckett et al., 2016). However, McLaren’s (2016) finding that IH significantly predicted depression and suicidal ideation among gay men and lesbians but not bisexual women points to the variable impact of IH on sexual minority people. McLaren (2016) also acknowledged the need for measures of IH that are sensitive to differences across sexual identities.

It is evident that IH is most often associated with harmful outcomes for queer people in terms of well-being, identity development, and social support. Some researchers have explored the connection between IH and other sexual identity processes, in order to better understand it. Outness is one of these variables, and will be described in the subsequent section.

\section{Outness}

Sexual identity disclosure, or coming out, has been a major construct within queer literature, dating back to the first models of sexual identity development (Cass, 1979; Troiden, 
1979). Historically, coming out about one's minoritized sexual identity was considered a developmental milestone important for achieving identity integration and facilitating positive well-being (Kosciw, Palmer, \& Kull, 2015; Vaughan \& Waehler, 2010). But more recent research has revealed that outness, or the degree to which one has disclosed one's sexual identity in different social environments (Feldman \& Wright, 2013), is a more complex variable than previously thought. Rather than solely represent a single event in a queer person's life, coming out is also a continuous process. The heteronormative nature of society perpetuates the assumption that all people are heterosexual, which imposes pressure on queer people to disconfirm this assumption with all those they know and will know in the future (Riggle, et al., 2017). Further complicating research on outness is the fact that a person may disclose their sexual orientation to some people and not others, and to varying degrees (Legate, Ryan, \& Weinstein, 2012). For example, a lesbian might be out to her family but not her co-workers. In addition, her closest friends might know about her partner but her religious community might not, despite both groups knowing about her sexual orientation. Understanding this nuanced meaning of outness is critical to examining the mixed findings of outness research. It is also important to consider that the varied meaning of outness can make it difficult to operationalize in research. Thus, different studies include different ways of measuring outness. These nuances will be described as findings are summarized.

Researchers have found that coming out is associated with both positive and negative outcomes for queer individuals. Kosciw et al. (2015) examined responses of gender and sexually diverse youth aged 13 to $20(n=7,816)$. They measured outness with two items, which asked students to rate how out they were to other students and teachers/school staff about being gay, lesbian, bisexual, transgender, questioning or queer $(0=$ out to none; $1=$ out to only a few; $2=$ 
out to most; $3=$ out to all). They found that although increased outness to peers and school staff was associated with greater in-school victimization, it was also associated with higher selfesteem and lower depression. The link between victimization and outness was more pronounced for rural youth when compared to urban and suburban students. In addition, rural youth demonstrated lower well-being and academic success, despite having comparable outness levels to students in more populated areas. The complex impact of outness was also apparent in Feldman and Wright's (2013) study of 192 lesbian, gay, and bisexual individuals. They used Mohr and Fassinger's (2000) Outness Inventory (OI) to measure the degree to which participants were out about their sexual identity to various people (mother, father, siblings, extended family, old and new heterosexual friends, strangers, work peers and supervisors, leaders and members of religious community). Feldman and Wright found that outness was positively associated with mental health, but not when controlling for sexual identity strength. The positive impact of outness on mental health was dependent on sexual identity development. The authors clarified this finding by referring to the possible negative consequences of outness, including discrimination and harassment. They argued that unless coming out coincides with identity strength, outness may have adverse effects because of the potential risks of disclosure. This interpretation may help explain the discrepancies between rural and urban youth in Kosciw et al.'s (2015) study. It might also explain the findings of Riggle et al. (2017), who found that outness (measured by OI) significantly predicted an increase in depressive symptoms among 373 queer participants.

Other researchers have noted the risks of coming out depending on the interpersonal context (Ryan, Legate, \& Weinstein, 2015). Frost and Meyer (2009) suggested that coming out might not be the best decision for all queer people at all times in all settings. Due to the potential 
for victimization, the authors pointed out that lack of outness might be a factor of the environment rather than an indication of IH or poor identity development. Sabat, Trump, and King (2014) highlighted the relevance of social variables and found that anticipated support from others was related to disclosure behaviors. In an effort to capture a more nuanced picture of outness, Legate et al. (2012) examined sexual identity disclosure and well-being within specific contexts (e.g., family, friends, religious community, etc.). They observed that queer people were more likely to disclose their sexual orientation in contexts that were autonomy-supportive (i.e., promoted self-expression and personal choices), rather than controlling. They also found that in autonomy-supportive environments, identity disclosure was related to positive well-being. This association was not present in controlling contexts.

The other side of identity disclosure is identity concealment. As was mentioned previously, concealment might be appropriate for queer people depending on their environment. Even so, the research regarding concealment points to its association with negative outcomes. In queer samples, concealing one's sexual orientation has been linked to less social support and lower life satisfaction (Pachankis, \& Bränström, 2018; Potoczniak, Aldea, \& DeBlaere, 2007). Interestingly, Critcher and Ferguson (2014) found that sexual identity concealment negatively affected a group of heterosexual undergraduates as well. Through a series of experiments, the authors found that monitoring and altering one's speech to conceal one's sexual identity decreased performance on both cognitive and physical tasks. Concealment also contributed to reduced interpersonal politeness. Taken together, these findings invite cause for concern if applicable to queer athletes, especially when considering the multiple performance domains pertinent to their lives (e.g., school, practice, competition). 
Outness and internalized heterosexism. Sexual identity disclosure has also been studied in relation to $\mathrm{IH}$. Most research is suggestive of a negative association between the two variables among samples of queer men and women (Singh, Dew, Hays, \& Gailis, 2006; Szymanski et al., 2008b). Herek et al. (1998) noted less disclosure among lesbians and gay men with increased IH, but specifically to heterosexual friends and acquaintances. Similarly, Szymanski et al. (2001), found that greater IH was associated with "passing" as heterosexual among lesbian women. In other words, lesbian women with high levels of IH reported more frequently posing as heterosexual in their social interactions. The sum of these findings suggests that queer people are less likely to come out when they harbor negative feelings and beliefs about their minoritized sexual identities.

Williams, Legate, Weinstein, and Rahman (2017) also noted that lesbian, gay, and bisexual individuals with greater IH obtained lower scores on the OI (Mohr \& Fassinger, 2000), but only in low autonomy-supportive environments $(n=156)$. They also found that autonomy support and outness predicted well-being, a relationship that was stronger for those high in IH. Such findings contribute to the body of evidence indicating that relational context influences outness and $\mathrm{IH}$.

Similarly, Walch, Ngamake, Bovornusvakool, and Walker (2016) examined experience of discrimination, $\mathrm{IH}$, anxiety, stress, and depressive symptoms among 474 lesbian, gay, and bisexual adults. They found that $\mathrm{IH}$ mediated the relationship between discrimination and mental health when participants reported sexual identity concealment. In other words, IH might be more detrimental to the mental health of those who actively conceal their sexual orientation. After all, one might presume that queer individuals who conceal their sexual identity are less 
exposed to affirming and supportive networks that can counteract internalized prejudicial attitudes.

\section{Outness of Queer Athletes}

Coming out as a queer athlete was once viewed as a dangerous decision (Krane \& Barber, 2003; Rankin, 1998). To do so was to invite alienation, prejudice, and negative consequences for one's athletic career. Rankin (1998) described the negative impact of the lesbian label on female athletes, noting how it often deterred women from sport participation and influenced coaches' recruiting practices. Rankin (1998) also described the connection between the culture of silence in women's athletics and the invisibility of minoritized sexual identities.

Recent qualitative studies have revealed that university athletic cultures still need improvement in terms of affirming and supporting queer athletes. The lesbian athletes in Fynes and Fisher's (2016) study $(n=10)$ described the “don't ask, don't tell” environments in their athletic departments, which ranged from quietly unsupportive to discriminatory. Fink et al. (2012) found that the queer female athletes in their sample $(n=14)$ valued having one ally on staff in facilitating their sexual identity disclosure. However, the authors noted the lack of institutional supports to ensure the equitable and affirmative treatment of queer athletes across athletic departments. In response to these unsupportive athletic cultures, athletes may associate negative consequences with being out and make efforts to conceal their sexual identities or conform to feminine ideals (Griffin, 1998; Rankin, 1998).

In spite of the unfavorable conditions prevalent in athletic departments, some positive changes in sports culture have been observed. In recent years, the National Collegiate Athletic Association (NCAA) has voiced its support of the inclusion of queer athletes in collegiate athletics (Coito, Bodensteiner, Feyerherm, \& Snider, n.d.), offering programming, education, and 
resources to NCAA member institutions. For example, Griffin and Taylor (2012) developed a comprehensive resource for coaches, athletes, and administrators that outlines policy and practice recommendations for promoting LGBTQ inclusion. More recently, the NCAA has taken active stances against the discrimination of queer people. In 2016, the organization declared its decision to prohibit states (e.g., North Carolina) and cities with discriminatory laws from hosting national championships (Gleeson, 2016). Although less has been done in the way of reprimanding individual institutions and athletic programs, the NCAA's inclusive values represent a step toward a more affirming climate for collegiate athletes.

Anderson et al. (2016) reviewed research regarding openly gay and lesbian athletes. They found that athletes with the greatest athletic capital, or the highest level of performance, skill, and importance on their teams, reported the most acceptance after coming out in the early 2000s. However, this was not true for a group of gay male athletes who reportedly came out between 2008 and 2010 (Anderson et al., 2016). These athletes reported positive coming out experiences, regardless of athletic capital. The authors concluded that ability is becoming less related to the acceptance of minoritized sexual identities, at least in men's sport. As another sign of progress, Anderson et al. (2016) cited the increasing number of visible queer athletes in professional sport who have received positive responses.

On women's teams, greater acceptance of out athletes has also been documented. Most of the participants in Fynes and Fisher's study (2016) reported that their teams were safe spaces to disclose their sexual identity. Several noted that there were older teammates who had come out before them, which increased their personal self-acceptance and disclosure. This finding has been corroborated by other queer female athletes as well (Fink et al., 2012). Fynes and Fisher 
(2016) also found that participants did not report any sport performance issues as a result of their minoritized status, given that they largely felt comfortable and supported on their teams.

Stoelting (2011) examined lesbian athletes' experiences of coming out to their teammates $(n=16)$. She found that multiple factors influenced participants' disclosure of their sexual identities. Several athletes expressed wanting to be honest and authentic with their teammates because lying was too difficult for them. They also wanted their teammates to know who their true selves were and either establish or maintain friendships. Some of the participants cited selfacceptance as a prerequisite and consequence of disclosure. For them, coming out was a factor of both identity acceptance and the expectation that one would gain self-acceptance by disclosing. Context also played a role in identity disclosure. The athletes mentioned that the accepting climates of their schools and teams reduced any fears associated with coming out. Additionally, the presence of other lesbians in sport and on the team facilitated their willingness to disclose.

Taken together, these findings suggest that queer female athletes are more comfortable coming out than they used to be, with teammate support and acceptance as contributing factors. However, little is known about the intrapersonal variables (e.g., IH) that may affect outness among queer athletes. Furthermore, most studies include samples of lesbian athletes and do not capture the experiences of other queer women in sports. The present study is one attempt to address these research gaps. The subsequent section will explore the third study variable, athletic identity, and its theoretical relevance to the sexual identity literature.

\section{Athletic Identity}

Brewer, Van Raalte, and Linder (1993) described athletic identity (AI) as a dimension of the self-concept that embodies the degree to which a person values being a sports participant. 
The authors believed that this element of the self is comprised of both social and cognitive components. Brewer and colleagues' (1993) conceptualization of AI has maintained popularity over the last two decades, which has created a unified research base. This conceptual clarity is a strength of the AI literature.

Researchers have studied athletic identity in relation to a number of variables, including academic performance, career maturity, injury rehabilitation, transition out of sport, and selfsatisfaction (e.g., Beamon, 2012; Brewer, Cornelius, Stephan, \& Van Raalte, 2010; Houle \& Kluck, 2015; Murphy, Brewer, \& Petitpas, 1996; Yopyk, 2007). Although having a strong athletic identity can coincide with greater commitment and performance in sport (Brewer et al., 1993), there can also be negative consequences for athletes who over-identify with their athlete role. For example, Antshel, VanderDrift, and Pauline (2016) found that NCAA athletes who identified more as athletes than students had more trouble thinking and concentrating in school. They were also less likely to use academic support resources to address these issues. Limited career exploration and poor career decision-making have also been connected to an overemphasis of AI (Murphy et al., 1996), highlighting the difficulty some collegiate athletes have when they transition out of competitive sport.

Some researchers have established a link between drinking behavior and athletic identity. Zhou, Heim, and O'Brien (2015) found that AI significantly predicted alcohol consumption in their sample $(n=1,785)$. Among athletes on team sports, the association between alcohol use and identity was positive. This was not so for athletes in individual sports, suggesting that athletes who play team sports may consume more alcohol due to team social events. Ludvigson (2014) also observed greater alcohol use on collegiate sports teams in her sample of Division I 
female athletes $(n=190)$. She also noted that higher levels of athletic identity were related to increased stress and depression.

The amassed findings appear to establish a connection between AI and negative outcomes, although no such connection has been quantitatively replicated in queer samples. While this was one reason underlying the inclusion of AI in the present study, there are other conceptually based rationales that will be clarified in the subsequent section.

Common threads between AI and sexual identity. One overlapping area of the AI and sexual identity literature relates to gender roles. Like IH, athletic identity appears correlated with traditional gender roles. In their study of 523 college football players, Steinfeldt and Steinfeldt (2011) found that strength of athletic identity was related to greater conformity to traditional masculinity, which included an element of "heterosexual self-preservation." Daltry (2012) observed that female athletes high in athletic identity reported greater gender role conflict $(n=$ 207). She postulated that these female athletes felt greater incompatibility with their socialized femininity as a result of their commitment to a traditionally masculine role. Similarly, Blinde and Taub (1992) commented on the association between lesbianism and female sport participation, noting how both are considered antithetical to traditional femininity. The authors argued that stereotyping all female athletes as lesbian is rooted in cultural norms about genderappropriate behavior. In other words, if female athletes already deviate from traditional femininity by playing sports, they must also be lesbian. Blinde and Taub (1992) interviewed 24 Division I female athletes about the generalized associations between female athleticism, masculinity, and lesbianism. Although proud to be athletes, many of their participants reported utilizing strategies to manage the stress of being perceived as cultural deviants. 
The impact of gender role conflict on the mental health of queer female athletes has not been studied explicitly. However, other studies using non-athlete samples provide some insights. Puckett et al. (2016) found that greater gender nonconformity was associated with greater expectations of prejudice and greater social anxiety in a community sample of queer adults $(n=$ 383). Hong et al. (2016) also noted the level of overt discrimination experienced by queer students with atypical gender expression. It is plausible that queer female athletes experience similar outcomes, depending on their level of perceived gender nonconformity.

Fynes and Fisher (2016) explored identity management strategies employed by the lesbian athletes in their sample. They found that athletes minimized the defining importance of sexual identity. By viewing themselves more holistically, they could set their sexual identity aside and focus on other parts of themselves. Furthermore, separating their personal and athletic selves was a strategy for maintaining sport performance. Even so, it is unclear how identity compartmentalization affects queer athletes' stress and health. The authors remarked that the effectiveness of this strategy requires further study, before deeming it ideal or necessary.

Based on this review of the AI and sexual identity literature, a few observations emerge that are relevant to the present study. First, AI may be related to outness, in light of the way athletes manage their various social identities. Outness might be considered less important if an athlete has a strong athletic identity. Additionally, if outness poses a threat to one's athletic standing or performance, it may be avoided. Second, it is unclear how athletic identity might relate to $\mathrm{IH}$, but gender-related stress incurred by the female athlete role could be relevant to their association. Finally, AI, IH, and outness are likely all related to athlete well-being. Due to this last point, the next section of this chapter will focus on why perceived stress was chosen as the outcome variable for the present study. 


\section{Mental Health Outcomes}

Throughout this review, mental health has been discussed in relation to internalized heterosexism, outness, and athletic identity. Queer people tend to endorse more negative outcomes than heterosexuals (Cochran, 2001; King et al., 2008), while athletes report similar rates of mental illness to the general population (Wolanin, Hong, Marks, Panchoo, \& Gross, 2016). However, athletes may engage in less help-seeking behavior than their non-athlete counterparts, suggesting that their mental health concerns often go untreated (Watson, 2005).

Some research has been conducted on the health and mental health of student-athletes with minoritized sexual identities. For example, Veliz, Epstein-Ngo, Zdroik, Boyd, and McCabe (2016) found that queer collegiate athletes were more likely to engage in binge drinking in the last two weeks, engage in marijuana use in the last 30 days, or be diagnosed with a substance use disorder in the last 12 months when compared to heterosexual athletes. Kroshus and Davoren (2016) also observed greater mental health difficulties among queer athletes. They determined that sexual orientation was the main factor in mental health disparities between heterosexual and queer people, regardless of athletic involvement. In other words, stress from one's minoritized status might be a more significant predictor of queer athletes' mental health than the stress of athletic participation.

In general, collegiate athletes encounter unique stressors when compared to their nonathlete counterparts, as they manage various roles and expectations (Surujlal, van Zyl, \& Nolan, 2013). However, athletes are less likely to grapple with discrimination stress related to athletic identity in the same way that queer people experience stress related to sexual identity. Fynes and Fisher (2016) cited sexual identity disclosure as one unique burden of stress for lesbian athletes. They noted the pressure athletes may feel from athletic departments, both spoken and unspoken, 
to remain quiet about their sexual identity. Fynes and Fisher (2016) also discussed the negotiation of expressed masculinity and femininity as a potentially stressful experience among lesbian athletes. Similarly, Fink et al. (2012) found that the female athletes in their sample often struggled with the lesbian label and its associated stereotypes. Given the challenges queer athletes face based on their sexual identities and sport participation, it was important to select an appropriate mental health outcome variable for the present study. In the next section, the literature on perceived stress will be summarized and connected to the study's other variables.

\section{Perceived Stress as a Mental Health Variable}

According to Cohen, Kamarck, and Mermelstein (1983), perceived stress refers to one's appraisal of life events in terms of how challenging, upsetting, or manageable they seem. Many researchers have used perceived stress as an indicator of well-being in medical and psychological research (e.g., Burton, Burgess, Dean, Koutsopoulou, \& Hugh-Jones, 2017; Ibrahim, Thearle, Krakoff, \& Gluck, 2016; Mathur et al., 2016). Its application in studies involving diverse samples, including people of color, queer individuals, older adults, and international populations, is also prevalent (e.g., Everett, Onge, \& Mollborn, 2016; Kwag, Martin, Russell, Franke \& Kohut, 2011; Riggle et al., 2017; Shakthivel et al., 2017; Shavitt et al., 2016).

A few researchers have examined associations between perceived stress and the other variables of the present study. Riggle et al., (2017) found that outness and perceived stress were negatively correlated, but that outness did not significantly predict perceived stress, demonstrating the role of potential third variables in their association. The authors noted that perceived stress is an indicator of general stress, while outness might be predictive of stress that is specific to queer people. Outness did predict depressive symptoms in their study, which may demonstrate the more specific impact of sexual identity disclosure on mental health. Riggle et 
al., (2017) also found that sexual identity authenticity was predictive of less perceived stress, noting its intrapersonal properties. Authenticity has also been identified as a negative correlate of IH (Riggle, Mohr, Rostosky, Fingerhut, \& Balsam 2014), which may indicate the greater role of IH in perceived stress over outness.

Sanders and Chalk (2016) connected IH and perceived stress in their study of negative psychological outcomes in queer adults $(n=940)$. They found that $\mathrm{IH}$ and overt discrimination significantly predicted perceived stress for gay and lesbian participants. However, for bisexual and pansexual participants, perceived stigma was the sole predictor of perceived stress.

Although perceived stress has been studied among college athletes (e.g., Chiu et al., 2016; Gerber et al., 2018; Moen, Wells, Firing, 2016), the direct relationship between athletic identity and perceived stress has been assessed less frequently. In one study, Watson (2016) found that level of athletic identity predicted perceived stress among 144 community college athletes. Other studies have included variables similar to AI and perceived stress, such as passion and burnout. Gustafsson, Hassmén, and Hassmén (2011) observed a link between obsessive passion and perceived stress, noting how some forms of passionate sport participation can be detrimental to athlete health. Similarly, Martin and Horn (2013) found that obsessive passion and some aspects of high athletic identity, namely exclusivity and negative affectivity, contributed to burnout in a sample of female adolescent athletes aged 16 to $18(n=186)$. Such studies allude to a connection between perceived stress and the athlete role.

In sum, perceived stress has widespread use as an indicator of mental well-being. There also appear to be associations between perceived stress and the other variables of the present study. However, no study to date has captured the relationships between perceived stress, IH, 
AI, and outness in one sample, or their collective relevance to queer female athletes. The present study was an attempt to address this research gap.

\section{Demographics}

In the interest of approaching this study with a consideration for intersecting identities, a number of demographic factors were included to make initial comparisons across different types of queer female athletes. Given that most research exclusively focuses on lesbian, gay, and bisexual individuals, more sexual identity labels were available for participants to choose from in the present study (e.g., queer, pansexual, mostly heterosexual, questioning). Ethnicity, race, sport, NCAA division, and year in school were also asked of participants. Finally, two items related to religion were included. The first pertained to school religious affiliation, in an effort to assess the religious climate that athletes may be situated in. The second was a measure of athlete religiosity, to determine more personal religious commitment.

A consideration for religion in the present study was deemed pertinent in light of extant literature regarding religion and minoritized sexuality. Hatzenbuehler, Pachankis, and Wolff (2012) found that religious climate was related to the health risk behaviors of queer youth, in that more supportive climates lead to lower risky behavior. Researchers have also noted a connection between increased IH and greater religiosity among queer people (e.g., Foster, Brewster, Velez, Eklund, \& Keum, 2017; Meladze \& Brown, 2015). With regard to religiosity among college athletes, there is some evidence of greater religious commitment compared to nonathletes, which may have associated benefits (Storch, Kolsky, \& Silvestri, 2001). Due to these findings and the lack of knowledge about religiosity among queer female athletes, the present study was intended to initiate this line of inquiry. 


\section{Purpose of the Present Study}

The main purpose of the present study was to explore the relationships among four constructs relevant to the queer female athlete experience. At present, most research regarding IH and outness among queer athletes has been qualitative, while the implications of these variables in non-athlete populations is well-established. Thus, there is a sizeable gap in the scientific literature regarding the assessment of otherwise well-known constructs among athletes with minoritized sexual identities. A study of IH, outness, athletic identity, and perceived stress within this population would potentially improve the ability of coaches, psychologists, and administrators to better support athlete success and wellbeing.

Two research questions guided the present study. The first was, "How are IH, outness, AI, and perceived stress connected among queer female athletes?" The second was, "What demographic variables predict the study variables?"

In light of the existing literature, several significant associations between IH, outness, AI, and perceived stress were expected. Thus, the following hypotheses were made as part of two mediation models:

\section{Mediation Model with Athletic Identity as the Predictor Variable (Figure 1).}

Hypothesis 1. It was hypothesized that greater AI would predict greater perceived stress, given the stressful nature of sport according to the literature.

Hypothesis 2. It was hypothesized that greater AI would predict greater IH. The basis of this prediction was derived from literature concerning the negative impact of the lesbian athlete stereotype on athletic cultures and queer female athletes.

Hypothesis 3. It was hypothesized that greater IH would predict greater perceived stress due the established relationship between IH and poor mental health outcomes in research. 
Hypothesis 4. It was hypothesized that $\mathrm{IH}$ would mediate the relationship between AI and perceived stress, due to the more established research base connecting IH to reduced wellbeing. Meyer's (2003) minority stress model also informed this hypothesis, given that IH is an established proximal stressor among queer individuals. Thus, it was presumed that AI would be more damaging when filtered through IH.

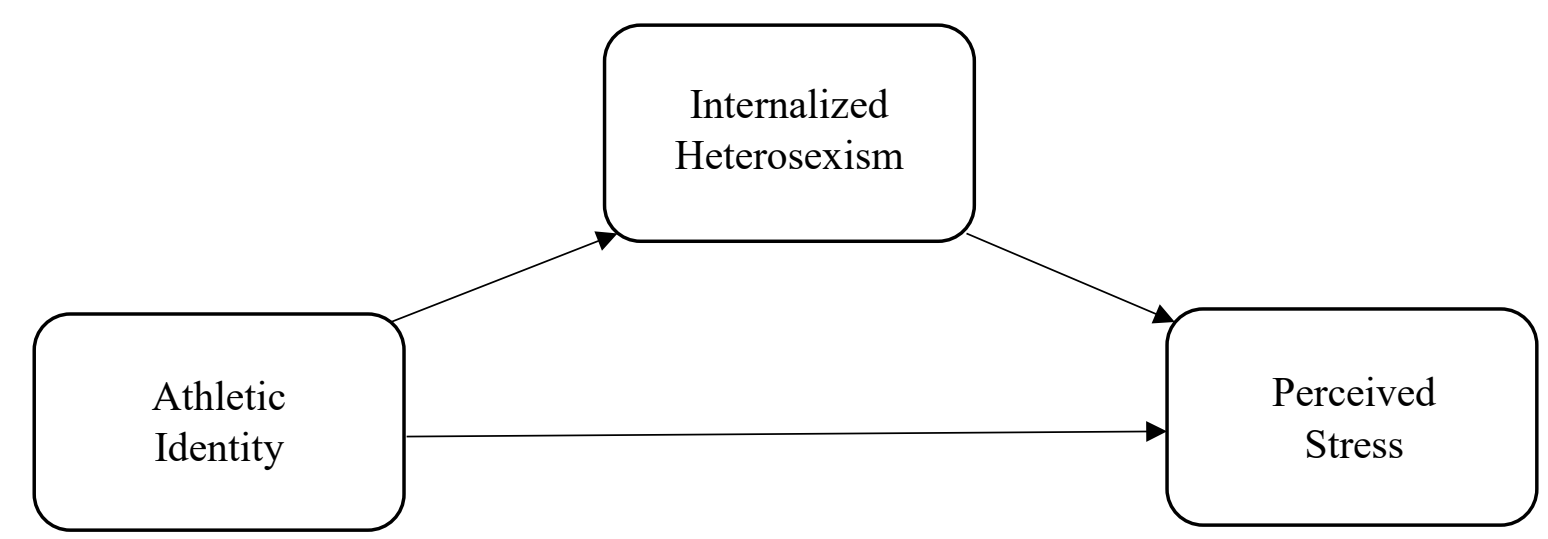

Figure 1. Mediation model with internalized heterosexism mediating the relationship between athletic identity and perceived stress.

\section{Mediation Model with Outness as the Predictor Variable (Figure 2).}

Hypothesis 5. It was hypothesized that less outness would predict greater perceived stress due to the damaging effects of identity concealment.

Hypothesis 6. It was hypothesized that less outness would predict greater IH due to the limited opportunities queer athletes might have to counteract internalized prejudice when others do not know about their sexual identity.

Hypothesis 7. It was hypothesized that IH would mediate the relationship between outness and perceived stress. Due to the complexity of outness as a predictor variable, it was 
assumed that less outness would promote stress through IH. It was presumed that in the absence of $\mathrm{IH}$, reduced outness may be less harmful to queer athletes.

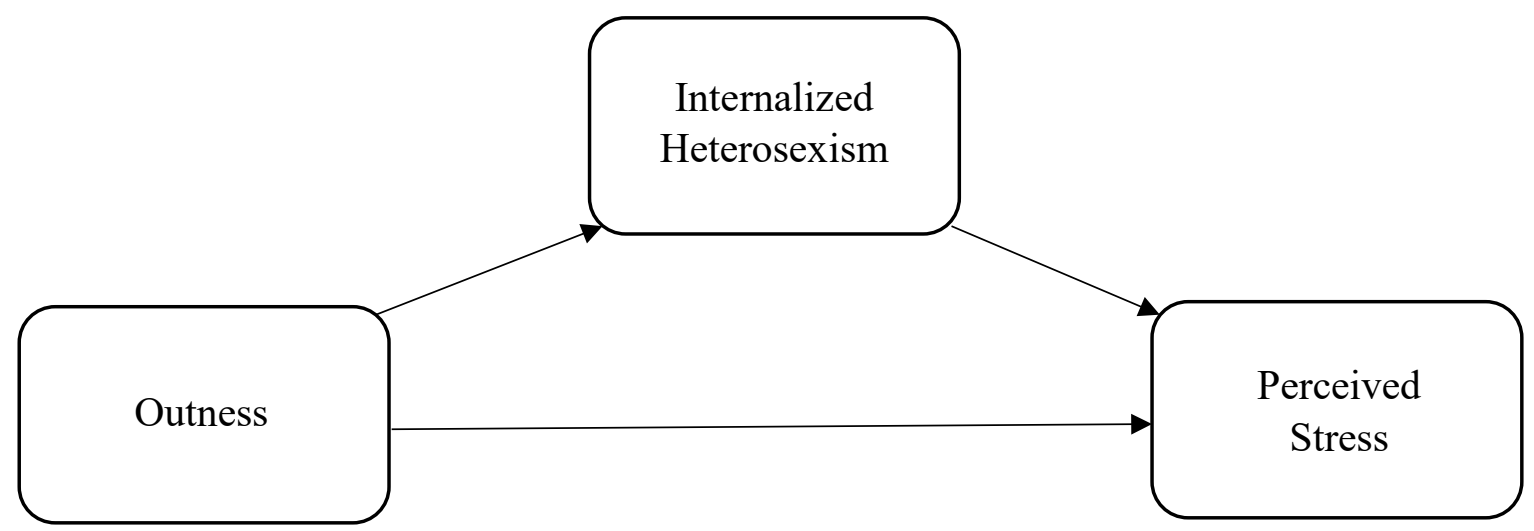

Figure 2. Mediation model with internalized heterosexism mediating the relationship between outness and perceived stress. 


\section{Chapter 2: Method}

The purpose of the present study was to examine the relationships among internalized heterosexism (IH), outness, athletic identity (AI), and perceived stress within a sample of queer female athletes competing at the collegiate level. Considering the qualitative nature of the extant research involving this population, the present study incorporated a quantitative methodology to establish more empirical conclusions.

\section{Design}

The present study used a non-experimental, correlational, survey, cross-sectional design. As such, the study did not involve the manipulation of independent variables, nor were participants randomly assigned to any conditions. Instead, relationships between study variables were observed after surveying participants at one point in time.

\section{Participants}

Inclusion criteria for the sample were as follows: (a) must identify as a cisgender and/or non-transgender female; (b) must play a collegiate sport at the varsity level at any of the three NCAA divisions; and (c) must identify with a minoritized sexual identity (e.g., lesbian, bisexual, non-heterosexual, queer, questioning, etc.). Athletes who had experienced same-sex attraction or intimacy but still identified as heterosexual were not included in the study. Only queer females were included, due to the extent of their documented presence in collegiate athletics compared to queer males (Rankin \& Merson, 2012). Males were also excluded to focus on the nuances of the queer female experience. Historically, researchers have grouped LGBT individuals together or used the same measures to capture their experiences, failing to appreciate gender and sexual identity differences (Szymanski, Kashubeck-West, \& Meyer, 2008a). This study focused on women of a variety of minoritized sexual identities, in order to move away from this trend. 
A G*Power analysis (Faul, Erdfelder, Buchner, \& Langwas, 2009) conducted to determine the minimum sample size necessary to perform multiple regression analyses. Per Cohen's (1988) recommendation, a power of 0.80 , an alpha of 0.05 , and a medium effect size (0.15) were inputted into $G^{*}$ Power. The number of tested predictors in this study was three: IH, AI, and outness. Based on this information, $\mathrm{G}^{*}$ Power indicated that a minimum sample size of 77 participants was necessary for multiple regression analyses. However, a total sample of 140 participants was pursued to account for missing data and duplicate responses. Seven cases were removed from the final sample due to incomplete data, thus 133 participant responses were included in data analyses.

Study recruitment was accomplished via three strategies. First, upon approval from the Institutional Review Board, social media message boards for LGBTQ student-athlete organizations based in the United States were contacted to post the study advertisement (see Appendix F) online. Pages and organizations that involved membership from coaches, studentathletes, and athletic administrators were sought out. Second, female athletes were emailed individually to participate in the study. Four lists of universities in the NCAA that possessed public online directories of rosters and student emails were created by U.S. census region (Northeast, Midwest, South, and West). In the interest of a geographically representative sample, recruitment began with selecting three institutions from each region at a time, one from each NCAA division. However, due to the uneven number of institutions with online directories between regions and divisions, some regions and divisions were overrepresented in the recruitment sample. At the conclusion of recruitment, female athletes from eight Division I schools, three Division II schools, and six Division III schools were contacted from the Northeast region. Athletes from five Division I schools, five Division II schools, and five Division III 
schools were contacted from the Midwest region. Athletes from 12 Division I schools, two Division II schools, and one Division I school were contacted from the South region. Finally, athletes from five Division I schools, three Division II schools, and two Division III schools were contacted from the West region. A total of 3,045 female athletes from these institutions were emailed a study advertisement and survey link (see Appendix F). A snowball technique was applied as the third recruitment strategy, and those who viewed the study advertisement were asked to forward the link to other queer female athletes they knew. The above three methods of recruitment were considered the most effective, while also being the most respectful of athlete privacy and autonomy in electing to participate. It was assumed that recruitment through coaches and university administrators would yield a lower response rate for several reasons. First, coaches could forget to pass the study advertisement along. Second, coaches and administrators might have biases that would preclude them from emailing the study to their players. Third, players may have felt pressured to complete or not complete the study, depending on the attitudes of athletics staff.

Demographics for the final sample are summarized in Tables 1 and 2. Participant age ranged from 18 to 25 years old $(M=20.19, S D=1.34)$. All participants identified as cisgender women. In terms of sexual orientation, nearly $10 \%(n=13)$ of athletes in the sample identified as mostly heterosexual, $40 \%(n=53)$ identified as bisexual, $11 \%(n=14)$ identified as mostly lesbian/gay, 27\% $(n=36)$ identified as lesbian/gay, 4\% $(n=5)$ identified as pansexual, 3\% $(n=$ 4) identified as queer, and $6 \%(n=8)$ identified as questioning. Six percent of participants $(n=$ 8) reported being of Hispanic, Latino, or Spanish origin. Ninety-four percent $(n=125)$ did not. With regard to racial identity, less than $1 \%(n=1)$ of participants identified as Asian, $8 \%(n=$ 11) identified as Black or African American, less than $1 \%(n=1)$ identified as Native 
Hawaiian/Pacific Islander, 77\% $(n=102)$ identified as White, and 14\% $(n=18)$ identified as multiracial. In terms of year in school, $26 \%(n=34)$ of participants in the study were first year students, $18 \%(n=24)$ were sophomores, $26 \%(n=35)$ were juniors, $27 \%(n=36)$ were seniors, almost $2 \%(n=2)$ were fifth years, and almost $2 \%(n=2)$ were graduate students. With regard to sport played, $26 \%(n=35)$ of participants were basketball players, $20 \%(n=26)$ were softball players, $17 \%(n=22)$ were soccer players, $18 \%(n=11)$ were volleyball players, and $7 \%(n=9)$ were ice hockey players. Remaining sports that had under nine participants were grouped into a sixth category composed of $23 \%(n=30)$ of the sample. In terms of NCAA division, $43 \%(n=$ 57) of athletes reported competing in Division I, 17\% $(n=22)$ reported competing in Division II, and $41 \%(n=54)$ reported competing in Division III. Athletes were also asked about the religious affiliation of their academic institutions. Eighty-five percent $(n=113)$ indicated that their school had no religious affiliation, 10\% $(n=13)$ reported attending a Catholic/Jesuit school, and 5\% $(n=7)$ reported attending a Protestant institution. Athletes were then asked to respond to the statement, "I consider myself a religious person." Nearly $29 \%(n=37)$ strongly disagreed with this statement, $18 \%(n=24)$ somewhat disagreed, $13 \%(n=17)$ neither agreed nor disagreed, $31 \%(n=41)$ somewhat agreed, and 11\% $(n=14)$ strongly agreed. 
Table 1.

Participant Demographics

\begin{tabular}{|c|c|c|}
\hline \multirow{2}{*}{ Variable } & \multicolumn{2}{|c|}{ Frequency } \\
\hline & $\%$ & $n$ \\
\hline \multicolumn{3}{|l|}{ Sexual Orientation } \\
\hline Bisexual & 39.8 & 53 \\
\hline Lesbian/Gay & 27.1 & 36 \\
\hline Mostly Lesbian/Gay & 10.5 & 14 \\
\hline Mostly Heterosexual & 9.8 & 13 \\
\hline Questioning & 6.0 & 8 \\
\hline Pansexual & 3.8 & 5 \\
\hline Queer & 3.0 & 4 \\
\hline \multicolumn{3}{|l|}{ Ethnicity } \\
\hline $\begin{array}{r}\text { Non-Hispanic, Latino, or Spanish } \\
\text { origin }\end{array}$ & 94.0 & 125 \\
\hline Hispanic, Latino, or Spanish origin & 6.0 & 8 \\
\hline \multicolumn{3}{|l|}{ Race } \\
\hline White & 76.7 & 102 \\
\hline Multiracial & 13.5 & 18 \\
\hline Black/African American & 8.3 & 11 \\
\hline Asian & .8 & 1 \\
\hline Native Hawaiian/Pacific Islander & .8 & 1 \\
\hline \multicolumn{3}{|l|}{ Year in school } \\
\hline Senior & 27.1 & 36 \\
\hline Junior & 26.3 & 35 \\
\hline First Year & 25.6 & 34 \\
\hline Sophomore & 18.0 & 24 \\
\hline Fifth Year & 1.5 & 2 \\
\hline Graduate & 1.5 & 2 \\
\hline
\end{tabular}

Note. $n=133$ 
Table 2 .

Participant Demographics Continued

\begin{tabular}{|c|c|c|}
\hline \multirow{2}{*}{ Variable } & \multicolumn{2}{|c|}{ Frequency } \\
\hline & $\%$ & $n$ \\
\hline \multicolumn{3}{|l|}{ Sport } \\
\hline Basketball & 26.3 & 35 \\
\hline Other & 22.6 & 30 \\
\hline Softball & 19.5 & 26 \\
\hline Soccer & 16.5 & 22 \\
\hline Volleyball & 8.3 & 11 \\
\hline Ice Hockey & 6.8 & 9 \\
\hline \multicolumn{3}{|l|}{ Division } \\
\hline DI & 42.9 & 57 \\
\hline DIII & 40.6 & 54 \\
\hline DII & 16.5 & 22 \\
\hline \multicolumn{3}{|l|}{ School religious affiliation } \\
\hline None & 85.0 & 113 \\
\hline Catholic/Jesuit & 9.8 & 13 \\
\hline Protestant & 5.3 & 7 \\
\hline \multicolumn{3}{|l|}{ "I consider myself a religious person" } \\
\hline Somewhat Agree & 30.8 & 41 \\
\hline Strongly Disagree & 27.8 & 37 \\
\hline Somewhat Disagree & 18.0 & 24 \\
\hline Neither Agree Nor Disagree & 12.8 & 17 \\
\hline Strongly Agree & 10.5 & 14 \\
\hline
\end{tabular}

Note. $n=133$

\section{Measures}

Revised Internalized Homophobia Scale (see Appendix A). The female version of the IHP-R (Herek, Gillis, \& Cogan, 2009) was used to assess participants' level of internalized heterosexism and homophobia. The female version of the IHP differs from the male version in 
that items reference attraction to women as opposed to men, and items that reference being gay include the term lesbian instead. It should also be noted that the original IHP was created in 1988, when homophobia was the only term used to describe prejudice against minoritized sexual identities (Szymanski, et al., 2008b). Although the nomenclature for the stigmatization of queer identities has evolved over the last few decades, the application of such terms bears significant overlap. The IHP-R was selected for this study due to its popularity and basic conceptualization of internalized stigma associated with having a minoritized sexual identity. Its brevity was also a strength, due to the demands placed on athletes' time that may deter them from research participation.

The IHP-R consists of 5 items that reflect individuals' attitudes about their sexual orientation (e.g., "I feel that being lesbian/bisexual is a personal shortcoming for me"). Respondents of this study rated their level of agreement with each statement on a 5-point Likert scale ranging from 1 (disagree strongly) and 5 (agree strongly). Higher scores reflected greater internalized prejudice. The original IHP consisted of 9 items and was drafted from face-to-face interview questions developed by Martin and Dean (1988). However, this version of the IHP was normed on gay men, which called into question its utility for lesbian and bisexual populations (Herek et al., 2009). Herek et al. (2009) found that scores on the IHP-R and the IHP were highly correlated for a large sample of lesbian, gay, and bisexual adults $(n=2,259)$. All correlation coefficients between the IHP-R and IHP were above .90 for each sexual identity group. Internal consistency reliability of the IHP-R was sufficient, with a Cronbach's alpha of .82. The authors also found that IHP-R scores significantly predicted self-esteem $(\beta=-2.14$, $t(2251)=-11.79, p<.001)$, depression $(\beta=6.82, t(2251)=11.52, p<.001)$, and anxiety $(\beta=$ $1.48, t(2251)=6.82, p<.001)$, after controlling for gender, sexual orientation, race, education, 
age, and victimization. Mason and Lewis (2015) provided evidence for initial validity of the IHP-R as measured by the correlation between its scores and sexual identity concealment $(r=$ .50). The male and female versions of the IHP-R have both been found adequately reliable in recent years. Szymanski and Ikizler (2013) reported Cronbach's alpha of .80 for internal consistency among a sample of queer men $(n=203)$. Likewise, Mason and Lewis (2015) observed a Cronbach's alpha of .86 in a sample of lesbian and bisexual women $(n=164)$. The above psychometric evidence provided further rationale for using the IHP-R in the present study. Cronbach's alpha was adequate $(\alpha=.79)$ in this sample as well, albeit slightly lower than previous findings.

Athletic Identity Measurement Scale (see Appendix B). The AIMS (Brewer \& Cornelius, 2001) was used to assess the athletic identity of participants. Respondents rated their level of agreement with seven items on a 7-point Likert scale of 1 (strongly disagree) to 7 (strongly agree). Scores for the AIMS were summed to produce a composite score ranging from 7 to 49 , with higher scores representing stronger athletic identity. The AIMS has one higher order factor of athletic identity and three first order factors: social identity (e.g., "Most of my friends are athletes"), exclusivity (e.g., "I spend more time thinking about sport than anything else"), and negative affectivity (e.g., "I feel badly about myself when I do poorly in sport"). These first order factors are purported to capture the social, cognitive, and emotional significance of athletic identity. Social identity is comprised of three items, while exclusivity and negative affectivity are comprised of two items each. Only the overall factor was considered in the results of this study.

The AIMS was originally constructed by Brewer, Van Raalte, and Linder (1993) as a 10item measure of athletic identity. They established adequate internal consistency reliability ( $\alpha=$ 
.81), which was corroborated in the present sample $(\alpha=.79)$. Brewer et al. also demonstrated evidence for convergent validity with the Self-Role Scale (Curry \& Weiss, 1989) and Sport Orientation Questionnaire (Gill \& Deeter, 1988). Correlation coefficients were .61 and .53, respectively with those instruments $(p<.005)$. Brewer and Cornelius $(2001)$ found that the 7-item version of the AIMS was adequately reliable $(\alpha=.81)$ in a sample of 2,856 individuals of varying athletic statuses. Through confirmatory factor analyses, this shorter version demonstrated acceptable model fit among males, females, athletes, and non-athletes. The authors also observed a significant difference between the mean scores of athletes $(M=38.21$, $S D=6.54)$ and non-athletes $(M=24.45, S D=9.56, t=-21.01, p<.01)$, providing evidence of the measure's predictive validity. Adequate psychometric properties of the AIMS have been demonstrated in other studies as well. Bimper (2014) observed an internal consistency of .86 in a sample of 255 Black collegiate athletes. Visek, Hurst, Maxwell, and Watson (2008) found that the AIMS had cross-cultural applicability in their study of American and English-speaking Hong Kong Chinese athletes. Cronbach's alpha for the internal consistency of the AIMS among the American athletes and Chinese athletes was .71 and .86, respectively. Confirmatory factor analysis revealed that the three-factor structure of the AIMS was supported in the American sample as well as the Chinese sample.

The widespread use of the AIMS in athlete populations and its consistent reliability and validity evidence were major factors in selecting it for the present study. The brevity of the measure was also a deciding factor.

Nebraska Outness Scale (see Appendix C). The NOS (Meidlinger \& Hope, 2014) was used to assess participants' level of outness, or the degree to which their sexual identity is known to those around them. The NOS is a 10-item measure consisting of two 5-item subscales: 
disclosure (NOS-D) and concealment (NOS-C). The NOS-D subscale pertains to the percentage of people within five groups (immediate family, extended family, friends, people at work or school, and strangers) that are aware of the respondent's sexual orientation. Participants indicated their response on an 11-point percentage scale ranging from $0 \%$ to $100 \%$. Higher mean scores were indicative of greater disclosure. The NOS-C subscale refers to the degree to which the respondent avoids discussing his or her sexual orientation with each of the five groups of people. This is also marked on an 11-point Likert scale ranging from 0 (never avoid) to 10 (always avoid). Higher mean scores were indicative of greater concealment. The full scale NOS score was determined by reverse scoring NOS-C responses, summing them with the NOS-D responses, and computing the mean score. Higher scores indicated greater outness. Only the full scale NOS was used in the results of this study.

Meidlinger and Hope (2014) sampled 149 queer people and found good internal consistency reliability for the NOS $(\alpha=.89)$, NOS-D $(\alpha=.82)$, and NOS-C $(\alpha=.80)$. They also found good internal consistency across genders and sexual orientations, with alphas ranging from .87 to .92 . The authors provided evidence for convergent validity between the NOS, its subscales, and the Outness Inventory (Mohr \& Fassinger, 2000). Evidence for discriminant validity was also demonstrated in comparison to the IHP and the Gay-Related Rejection and Sensitivity Scale (GRRSS; Pachankis, Goldfried, \& Ramrattan, 2008).

The NOS was selected for use in the present study in light of its more nuanced picture of outness. The NOS accounts for the fact that queer people can be out about their sexual identity to some people and not others. It also appreciates the differences between disclosure and concealment of sexual identity, which are different constructs within outness. The brevity and adequate psychometric properties of the NOS were other factors contributing to its selection. 
Internal consistency reliability of the NOS in the present study was consistent with previous literature. Cronbach's alphas for the NOS-D and NOS-C were .87 and .81 , respectively. The full scale NOS also demonstrated good internal reliability in the current study $(\alpha=.83)$.

Perceived Stress Scale (PSS-10; see Appendix D). Participants' perceived stress was evaluated using the PSS-10 (Cohen \& Williamson, 1988), a 10-item measure that assesses respondent perceptions of stressfulness during the past month. Athletes rated the occurrence of various experiences and feelings (e.g., "In the last month, how often have you felt nervous and “stressed"?) on a 5-point Likert scale of 0 (never) to 4 (very often). Four items were reverse scored $(4,5,7$, and 8$)$ before a total score of 0 to 40 was calculated by adding item scores. Higher total scores were indicative of greater perceived stress.

Although there are two other versions of the PSS (PSS-14 and PSS-4), the PSS-10 was selected per Cohen and Williamson's (1988) recommendation, which was derived from testing the psychometric properties of all three measures. Cohen and Williamson reported adequate internal consistency reliability $(\alpha=.78)$ for the PSS-10 among 960 male and 1,427 female respondents. Other studies have also demonstrated reliability of the measure in a variety of samples (e.g., Karam et al., 2012; Ramírez, \& Hernanzez, 2007; Reis, Hino, \& Rodriguez-Anez, 2010). Taylor (2015) recently obtained a Cronbach's alpha of .84 for the PSS-10 in a sample of 1,236 adults in the United States. Roberti, Harrington, and Storch (2006) also found favorable internal consistency reliability $(\alpha=.89)$ in a college student sample $(n=285)$.

Mitchell, Crane, and Kim (2008) provided some evidence for convergent validity of the PSS-10. They noted a moderate correlation $(r=.54)$ between the PSS-10 and the Impact of Event Scale (IES), which measures the degree of intrusion and avoidance symptoms respondents experience in response to a stressful psychological event. The authors also observed a positive 
correlation $(r=.69)$ between the PSS-10 and the Posttraumatic Stress-Arousal Scale (PTS-AS). Convergent validity was also recently demonstrated by Smith, Rosenberg, and Haight (2014), who observed correlations between the PSS-10 and the Stress Arousal Scale $4(r=.68)$ and the Anxiety Depression subscale $(r=.62)$ of the General Health Questionnaire.

The PSS-10 boasts widespread use in the literature as a measure of stress. Numerous authors have used it as an outcome measure (e.g., Everett, Onge, \& Mollborn, 2016; Riggle et al., 2017, Sanders \& Chalk, 2016; Watson, 2016). In light of its recurring presence in the literature and psychometric evidence, the PSS-10 was considered appropriate for the present study. Good internal consistency reliability $(\alpha=.88)$ for the PSS-10 was demonstrated in the present sample, which is comparable to previous studies.

Demographic questionnaire (see Appendix E). An 9-item demographic questionnaire was created for this study to gather specific data regarding participant age, gender identity, race, ethnicity, sexual orientation, year in school, NCAA division, sport, school religious affiliation, and religiosity. Participants typed in their age. Religiosity was measured on a 5-point Likert scale of 1 (strongly disagree) to 5 (strongly agree). All other items were in multiple choice format. Gender identity, sexual orientation, year in school, sport, and school religious affiliation also included a write-in option.

\section{Procedure}

As described previously, participants were recruited a number of ways. A study advertisement (see Appendix F) and Qualtrics link was posted to social media outlets for LGBTQ+ student athlete organization webpages, including Lehigh Athlete Ally and Athletes for Equality. Participants were instructed to distribute the study advertisement and survey link to queer female athletes they know. Athletes were also directly emailed with the study 
advertisement and survey link. Once participants opened the Qualtrics link, they were presented with a detailed study description and informed of the potential risks and benefits of participation. The websites and phone numbers for organizations that support and assist queer people, including Athlete Ally and the Trevor Project, were provided as resources on this page. At the bottom of the page, participants were asked to respond yes or no to the item, "I agree to participate."

Once participants reached the next page in Qualtrics, they filled out the demographic questionnaire. Any participant who endorsed a heterosexual identity or a gender identity other than female (i.e., male, trans, genderqueer/gender non-conforming) was redirected to the final page of the survey and did not complete the remainder of the study. Female athletes who endorsed a minoritized sexual identity, proceeded to fill out the IHP-R, AIMS, NOS, and PSS. The order of these measures was counterbalanced in Qualtrics. Upon completing the study, participants were redirected to a page where they were thanked for their participation. The websites and phone numbers of supportive organizations were listed again. Participants were then asked to voluntarily provide their email address to receive an electronic \$5 Starbucks gift card for their participation. Participants who provided their email address were sent an electronic gift card through the Starbucks website within one month of participating in the study.

\section{Data Analyses}

The primary analysis strategy used in the present study was multiple linear regression. This strategy was selected to draw more substantive conclusions about the relationships among IH, AI, outness, and perceived stress. To establish a basis for assessing prediction, correlation analyses were performed first. Subsequently, multiple regression analyses were conducted to 
test the two proposed mediation models described below. Finally, exploratory regression analyses were tested to reveal additional trends in the data.

Proposed Mediation Model with Athletic Identity as the Predictor Variable.

Hypothesis 1. It was predicted that AIMS scores would predict PSS scores in a simple linear regression.

Hypothesis 2. It was predicted that AIMS scores would predict IHP-R scores in a simple linear regression.

Hypothesis 3. It was predicted that IHP-R scores would predict PSS scores in a simple linear regression.

Hypothesis 4. It was predicted that IHP-R scores would mediate the relationship between AIMS scores and PSS scores, as demonstrated by multiple linear regression.

Proposed Mediation Model with Outness as the Predictor Variable.

Hypothesis 5. It was predicted that full scale NOS scores would predict PSS scores in a simple linear regression.

Hypothesis 6. It was predicted that full scale NOS scores would predict IHP-R scores in a simple linear regression.

Hypothesis 7. It was predicted that IHP-R scores would mediate the relationship between full scale NOS scores and PSS scores, as demonstrated by multiple linear regression. 


\section{Chapter 3: Results}

\section{Tests of Assumptions: Pearson Correlation}

To assess the interpretability of results using the statistical methods applied in this study, tests of assumptions were performed on the data. The assumptions of independence, normality, continuous variables, related pairs, linearity, and the absence of outliers ensure that conclusions can be drawn via correlation analyses. Each of these assumptions are addressed below.

Independence. When calculating a Pearson correlation, there is an assumption that participants possess singular group membership. In other words, observations associated with each participant should not be counted in more than one group (Schober, Boer, \& Schwarte, 2018). In the present study, there were several participants who indicated multiple group membership regarding race and sexual orientation. Twelve participants who endorsed multiple racial identities were included in the multiracial category and removed from other categories. Those who reported multiple sexual identities were included in the group that reflected the most identity specificity. For example, two participants who reported being both bisexual and queer were solely included in the bisexual category, in light of the broader application of queer as an identity.

Normality. For Pearson correlations, the distribution of values for each variable are assumed to be normally distributed (Ghasemi \& Zahediasl, 2012). Normality was assessed using histograms and statistical methods, namely the Shapiro-Wilk test (Shapiro \& Wilk, 1965) as well as skewness and kurtosis scores (Pearson, 1930). PSS scores appeared to meet the normality assumption (Figure 1). The Shapiro-Wilk test was consistent with this observation $(S W=.996, p$ $=.960)$, as were skewness (.03) and kurtosis (-.22) scores. According to West, Finch, and Curran (1996), skewness values below 2 and kurtosis values below 7 suggest normality. IH 
scores (Figure 2) were not normally distributed according to the Shapiro-Wilk test $(S W=.93, p=$ $.000)$. However, skewness (.58) and kurtosis (-.53) scores were acceptable. AIMS sores (Figure 3) also formed a non-normal distribution $(S W=.96, p=.001)$, despite skewness (-.68) and kurtosis (.44) scores appearing adequate. The same was true for NOS scores (Figure 4), with the Shapiro-Wilk test suggesting non-normality $(S W=.96, p=.001)$ and skewness $(-.23)$ and kurtosis (-.62) within acceptable limits. Some authors have noted the robustness of Pearson's correlation in spite of non-normal data (e.g., Havlicek \& Peterson, 1976; Nefzger \& Drasgow, 1957). Thus, alterations to the present data set were not made, nor were variables excluded from analyses.

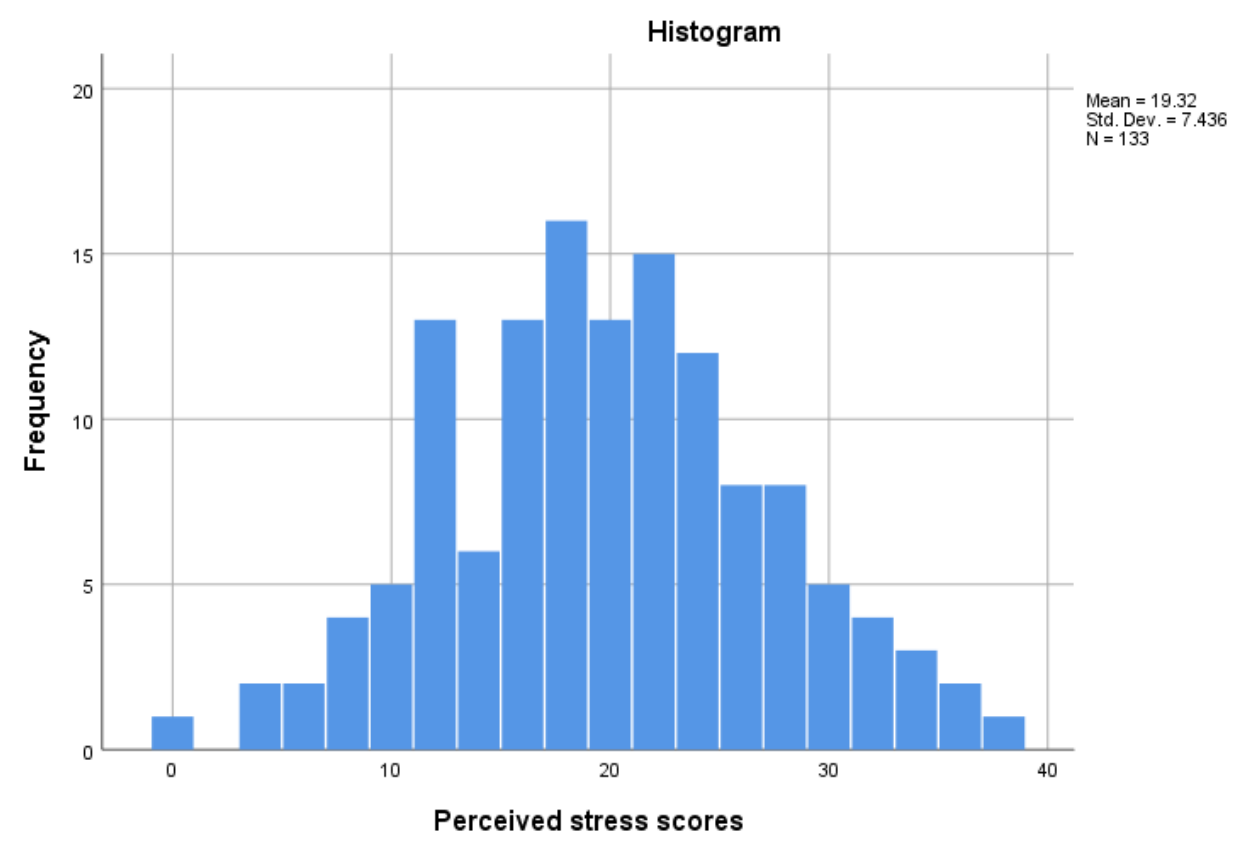

Figure 3. Histogram of perceived stress scores. 


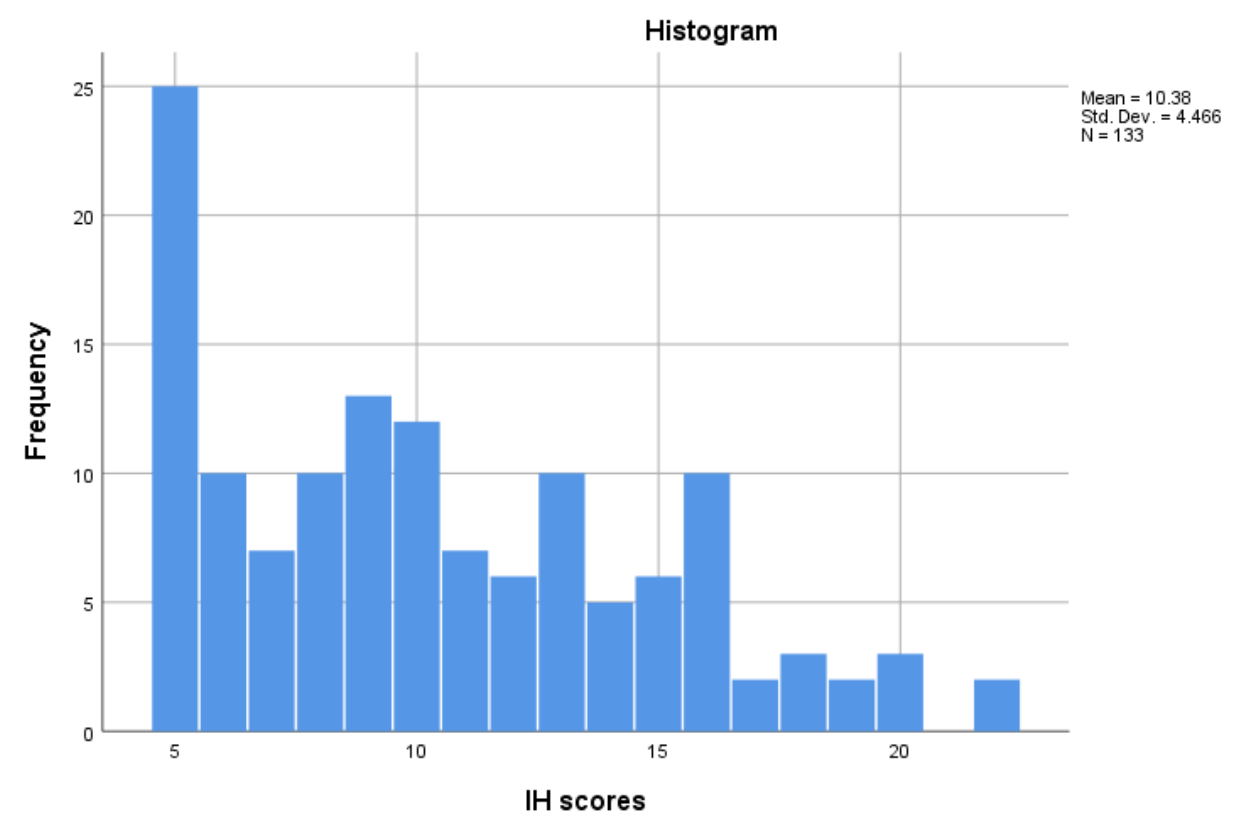

Figure 4. Histogram of internalized heterosexism scores.

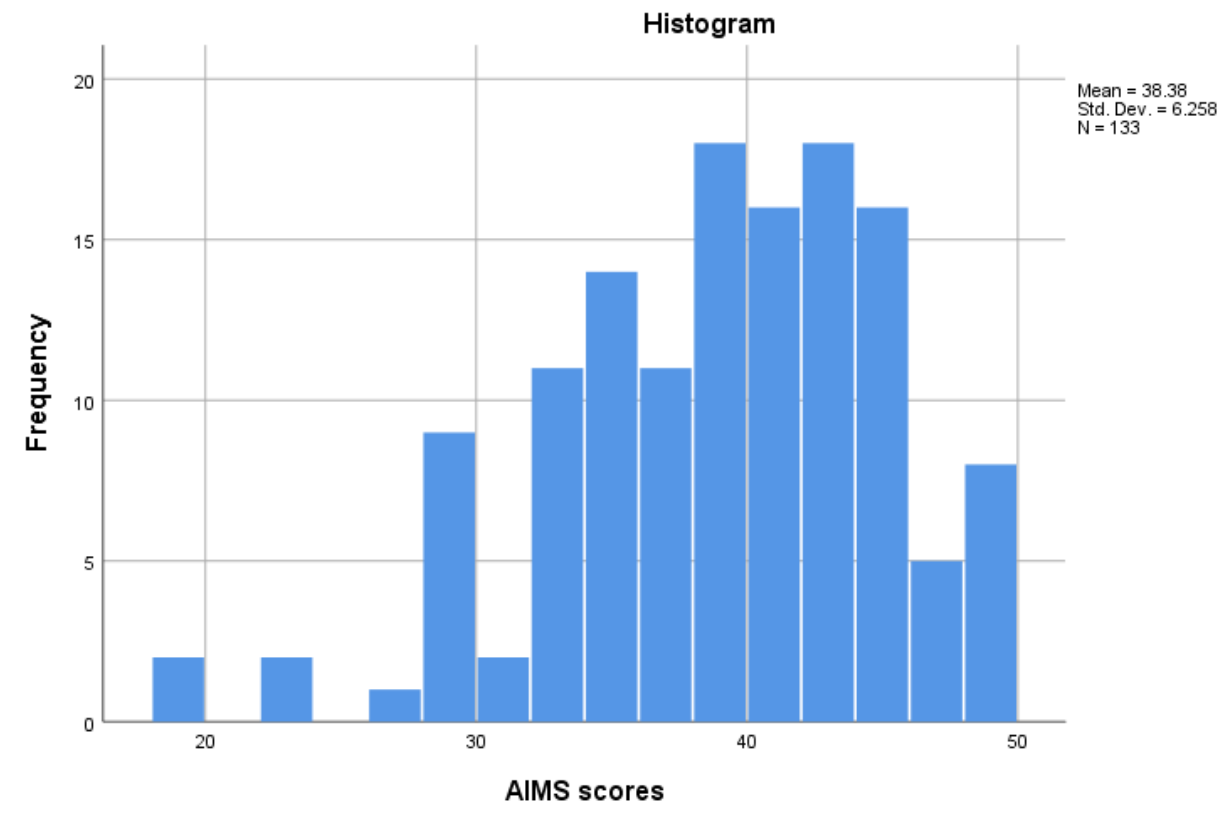

Figure 5. Histogram of athletic identity scores. 


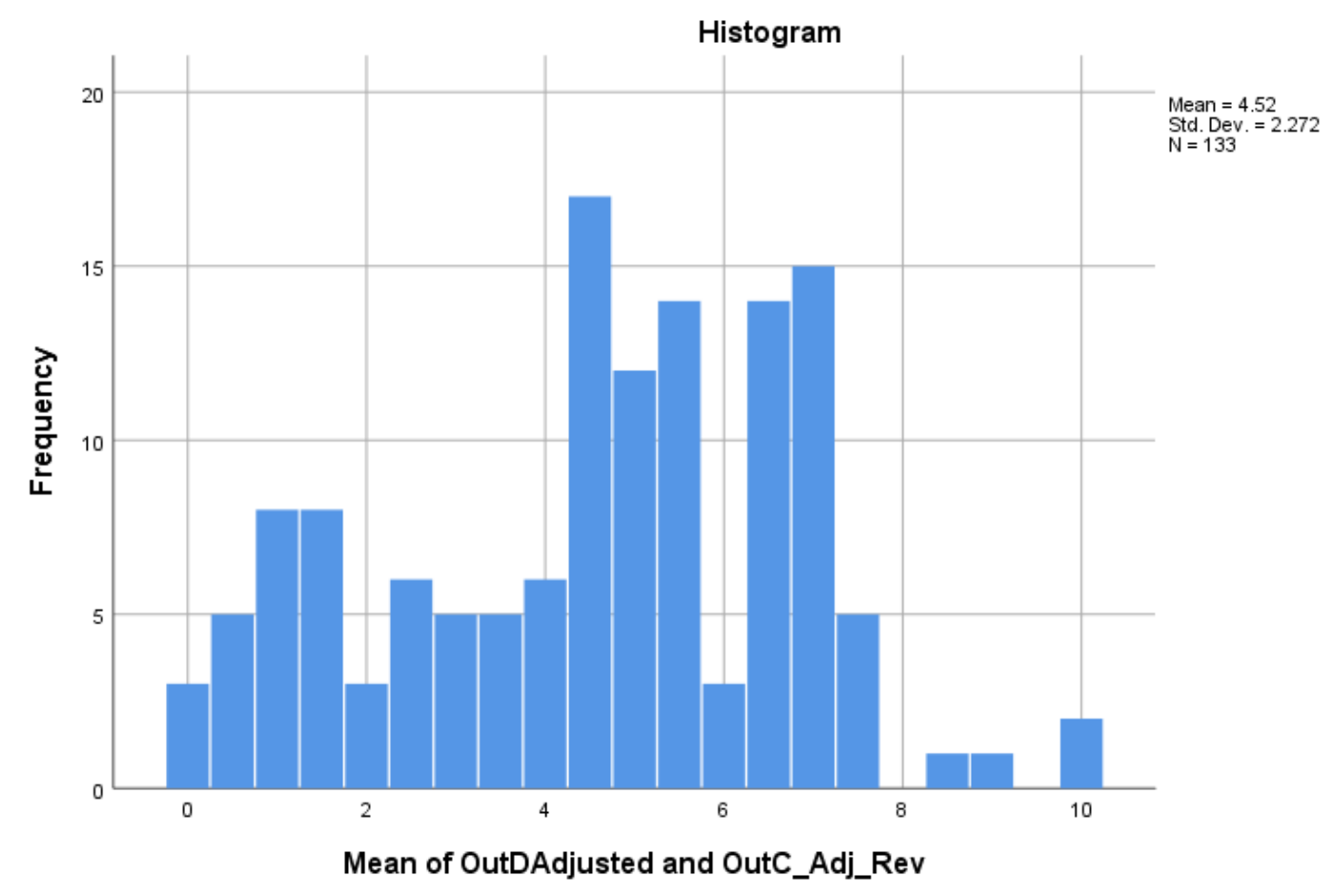

Figure 6. Histogram of outness scores.

Continuous variables. When using Pearson correlation, both variables must be continuous (Schober et al., 2018). All four variables in this study were continuous.

Related pairs. This assumption refers to each participant having a pair of values (Gogtay \& Thatte, 2017). Participants were only included in this study if they fully completed the IHP-R, NOS, AIMS, and PSS. This allowed for multiple pairs of values to be used for correlational analyses. Sixteen cases were removed from the sample due to incomplete data.

Linearity. Correlations also require that pairs of variables form a linear relationship (Schober et al., 2018). An examination of scatterplots (see Appendix G) confirmed the linearity of relationships between $\mathrm{IH}, \mathrm{AI}, \mathrm{NOS}$, and PSS scores. 
Absence of outliers. Pearson correlations can also be influenced by outliers, or data points that deviate significantly from the rest of the distribution (Schober et al., 2018). An examination of boxplots revealed that outliers were present among PSS scores and AIMS scores. Figure 5 depicts the two outliers in the perceived stress distribution. Figure 6 depicts the three outliers in the athletic identity distribution. None of the outliers seemed to be a product of error. To assess the impact of these outliers on correlation and regression coefficients in the present study, analyses were run with and without outliers included in the data per recommended practice (Stevens, 1984). Influential observations in the regression models were also assessed, using Cook's distance (Cook \& Weisberg, 1982). All values of Cook's distance were well below 1 (ranging from .000 to .180), which is consistent with Cook and Weisberg's (1982) recommendation for determining regression points of concern.

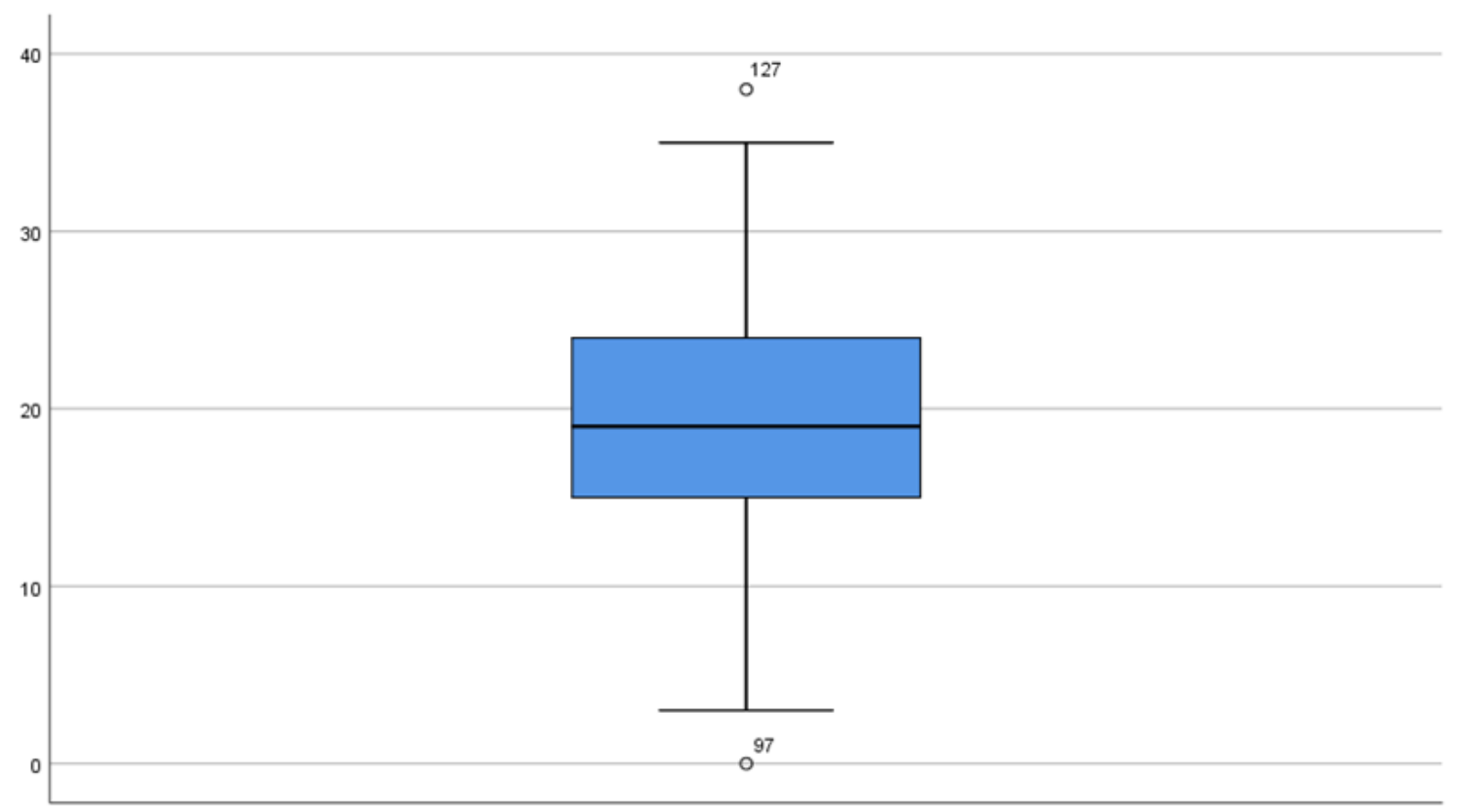

Perceived stress scores

Figure 7. Boxplot of perceived stress scores. 


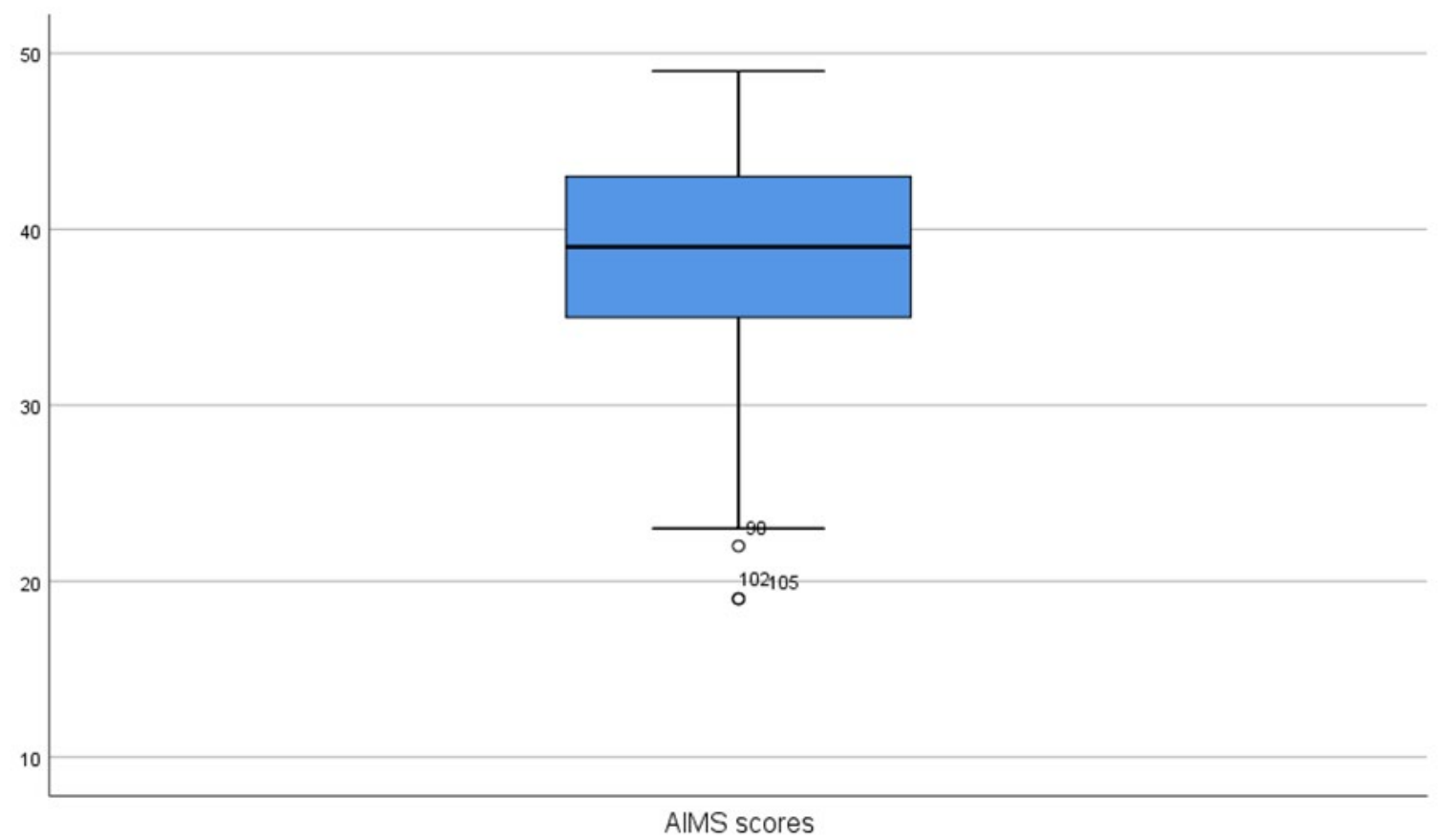

Figure 8. Boxplot of athletic identity scores.

\section{Tests of Assumptions: Regression Analyses}

In addition to the above assumptions of correlational analyses, the assumptions of regression analyses were tested to determine the interpretability of the data. Although there is some overlap in the assumptions of both statistical methods, regression assumptions are predominantly focused on the residuals of the data, rather than the variable scores.

Linearity. Similar to correlation, it is assumed that predictor and outcome variables form a linear relationship in regression models (Pedhazur, 1982). Scatterplots of the residuals plotted on the predicted values revealed linear relationships for each regression (see Appendix $\mathrm{H}$ ).

Homoscedasticity. Regression analyses involve the assumption that the variance of residuals be relatively similar (Pedhazur, 1982). Q-Q plots of the unstandardized residuals for the significant regression models are depicted in Appendix I. Variance around the regression line appears similar for the residuals in each Q-Q plot, suggesting that the data is appropriately homoscedastic. 
No Multicollinearity. Predictor variables included in regression models are also expected to be independent. In other words, it is important that predictors are not too highly correlated with one another, in order to confidently identify their unique contribution to predicting the outcome variable (Wampold \& Freund, 1987). The correlations between IHP-R, AIMS, and NOS scores were examined in a correlation matrix. All correlations were under .80 , suggesting that none of the variables were too closely related. Variance Inflation Factor (VIF) statistics were also used to determine the multicollinearity of the independent variables. Hair, Anderson, Tatham, and Black (1995) proposed that finding a VIF less than 10 is acceptable for satisfying the multicollinearity assumption. All of the multiple regressions conducted in this analysis yielded VIF statistics well below 10, ranging from 1.00 to 1.57 .

Multivariate normality. For multiple regression, the residuals of the regression are assumed to be normally distributed (Casson \& Farmer, 2014). Normality was assessed graphically (see Appendix J) and through statistical procedures. For the mediation of AI and perceived stress by $\mathrm{IH}$, residuals were assessed to be normal via the Shapiro-Wilk test ( $S W=$ $.996, p=.966)$ and skewness (-.023) and kurtosis (.023) statistics.

Normality statistics for the exploratory regressions were also calculated. Residuals appeared normal when AI, IH, and race predicted stress $(S W=.994, p=.833)$, and when AI, IH, and sport predicted stress $(S W=.996, p=.974)$. Residuals also appeared normal when AI, IH, race, and sport predicted stress $(S W=.995, p=.949)$. Skewness scores ranged from -.061 to .054 and kurtosis scores ranged from .007 to .119 for these distributions.

When AI and outness were predictor variables for $\mathrm{IH}$, residuals appeared to be nonnormal according to the Shapiro-Wilk test $(S W=.959, p=.001)$, but yielded acceptable skewness (.602) and kurtosis (-.268) scores. The same was true when outness and religiosity 
predicted $\mathrm{IH}(S W=.947, p=.000$; skewness $=.649$; kurtosis $=-.311)$, and when sexual orientation and AI predicted IH $(S W=.960, p=.001$; skewness $=.655 ;$ kurtosis $=.037)$.

Residuals of the regression in which AI, sexual orientation, and religiosity predicted IH produced similar statistics $(S W=.965, p=.002 ;$ skewness $=.556$; kurtosis $=-.275)$.

The normality assumption was met when sport played predicted AI based on the ShapiroWilk test $(S W=.984, p=.114)$ and skewness (-.392) and kurtosis (.208) scores. The distribution of residuals for sexual orientation predicting outness was not normal $(S W=.971, p=.005)$, but had suitable skewness (-.150) and kurtosis (.002).

Although there is some statistical evidence of non-normality among residual distributions, the degree of contamination for implicated regressions may not be concerning due to contrary evidence provided by histograms, skewness scores, and kurtosis sores. Furthermore, some authors have proposed that a large enough sample size (e.g., greater than 40) may minimize the importance of normality (Ghasemi \& Zahediasl, 2012) or yield misleading Shapiro-Wilk statistics (Casson \& Farmer, 2014).

\section{Descriptive Statistics}

As shown in Table 3, the mean IHP-R score of the present sample did not meet half of the total possible score on the IHP-R, suggesting relatively low to moderate levels of IH among the athletes surveyed. The present sample also reported high athletic identity, and low levels of outness. Regarding stress, the mean score of the sample fell just below half of the total possible score on the PSS. 
Table 3 .

Descriptive Statistics for Study Variables

\begin{tabular}{lcccc}
\hline Variable & $M$ & $S D$ & $\begin{array}{c}\text { Possible } \\
\text { Range }\end{array}$ & $\begin{array}{c}\text { Actual } \\
\text { Range }\end{array}$ \\
\hline IHP-R & 10.38 & 4.50 & 38 & 38 \\
AIMS & 38.38 & 6.26 & 22 & 17 \\
Full Scale NOS & 4.52 & 2.27 & 10 & 10 \\
PSS & 19.32 & 7.40 & 49 & 30
\end{tabular}

Note. $n=133$; IHP-R= Revised Internalized Homophobia Scale; AIMS= Athletic Identity Scale; Full Scale NOS= Full scale score of Nebraska Outness Scale; PSS= Perceived Stress Scale.

\section{Preliminary Analyses}

Correlational analyses were conducted first to identify associations between the study variables. The final matrix after removing outliers is depicted in Table 4. IHP-R scores were significantly correlated with each of the other three variables. A significant relationship was observed between PSS and AIMS scores as well. Full scale NOS scores were not correlated with AIMS scores or PSS scores.

Table 4.

Correlations Among Internalized Heterosexism, Athletic Identity, Outness, and Perceived Stress

\begin{tabular}{lrrrr}
\hline Variable & 1 & 2 & 3 & 4 \\
\hline 1. IHP-R & -- & & & \\
2. AIMS & $* .21$ & -- & & \\
3. Full Scale NOS & $* *-.27$ & -.09 & -- & \\
4. PSS & $* * .24$ & $* .17$ & -.06 & --
\end{tabular}

Note. $n=128$; IHP-R= Revised Internalized Homophobia Scale; AIMS $=$ Athletic Identity Scale; Full Scale NOS= Full scale score of Nebraska Outness Scale; PSS= Perceived Stress Scale. $* p<.05 ; * * p<.01$ 


\section{Primary Analyses}

\section{Proposed Mediation Model with Athletic Identity as the Predictor Variable.}

Baron and Kenny's (1986) four step approach for mediation analyses was used to test the significance of $\mathrm{IH}$ as a mediation variable for the relationship between athletic identity and perceived stress. The first four hypotheses of the present study correspond to Baron and Kenny's (1986) four steps, as outlined below. The results of each step are summarized in Table 5.

Hypothesis 1. It was predicted that AIMS scores would predict PSS scores in a simple linear regression.

Step 1. Baron and Kenny's (1986) first step for mediation requires that the predictor variable and the outcome variable be significantly related. The results of a simple linear regression demonstrated that AIMS scores significantly predicted PSS scores. AIMS scores also explained approximately $4 \%$ of the variance in PSS scores.

Hypothesis 2. It was predicted that AIMS scores would predict IHP-R scores in a simple linear regression.

Step 2. Baron and Kenny's (1986) second step, in which the predictor variable predicts the mediator, was also tested through simple linear regression. Results revealed that AIMS scores significantly predicted IHP-R scores. AIMS scores also explained approximately $5 \%$ of the variance in IHP-R scores.

Hypothesis 3. It was predicted that IHP-R scores would predict PSS scores in a simple linear regression.

Step 3. The results of a simple linear regression revealed IHP-R scores as a significant predictor of PSS scores, which is consistent with Baron and Kenny's (1986) third step. IHP-R scores explained approximately 5\% of the variance in PSS scores. 
Hypothesis 4. It was predicted that IHP-R scores would mediate the relationship between AIMS scores and PSS scores, as demonstrated by multiple linear regression.

Step 4. The final step for mediation was tested by conducting a multiple regression, using bootstrapping and Sobel methods to test the significance of the indirect effect (Bollen \& Stine, 1990; Shrout \& Bolger, 2002; Sobel, 1982). Results of the multiple regression indicated that the direct effect of athletic identity on perceived stress was no longer significant when controlling for IH. This finding suggests that IH fully mediates the relationship between athletic identity and perceived stress. To test the significance of the indirect effect, 5000 bootstrap resamples were obtained, consistent with the recommendation of Preacher and Hayes (2008). Results indicated that $\mathrm{IH}$ was a significant mediator for the relation between athletic identity and perceived stress $(\beta=.05 ; \mathrm{CI}=.003$ to .116$)$. A Sobel test was also conducted, considering its reputation as a more conservative test of indirect effects (MacKinnon, Warsi, \& Dwyer, 1995). Results demonstrated that the indirect effect of athletic identity on perceived stress through IH was not significant $(z=1.81, p=.07)$, which suggests that the mediation observed should be interpreted with some caution.

In sum, all four steps of Baron and Kenny's (1986) mediation procedure were met, suggesting a full mediation of the relationship between AIMS and PSS scores by IH scores (see Figure 7). Tests of the indirect effect yielded mixed results, but showed some support for the significance of $\mathrm{IH}$ as a mediator. 


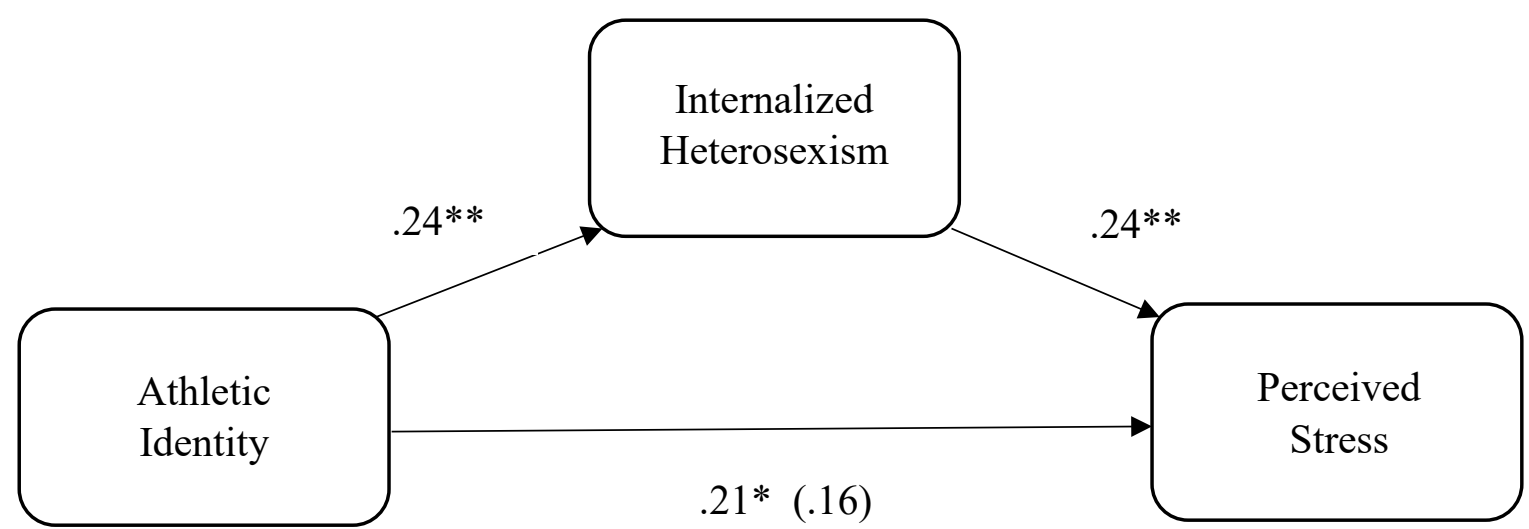

Figure 9. Standardized regression coefficients for the relationship between athletic identity and perceived stress, mediated by internalized heterosexism. The standardized regression coefficient between athletic identity and perceived stress when controlling for internalized heterosexism is in parentheses.

$* p<.05 ; * * p<.01$ 
Table 5.

Internalized Heterosexism as a Mediating Variable between Predictor Variable of Athletic Identity and Outcome Variable of Perceived Stress

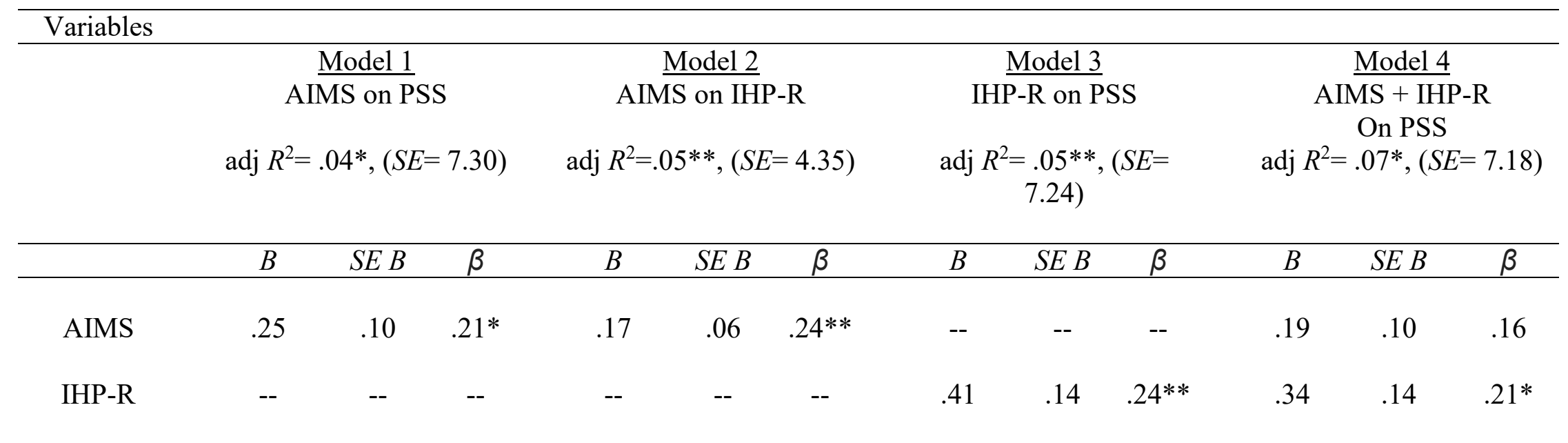

Note. $n=133$; AIMS= Athletic Identity Measurement Scale; IHP-R= Revised Internalized Homophobia Scale; PSS= Perceived Stress Scale.

$* p<.05 ; * * p<.01$ 


\section{Proposed Mediation Model with Outness as the Predictor Variable.}

Baron and Kenny's (1986) four step approach was also used to test the significance of IH as a mediator for the relationship between outness and perceived stress. The results of each step for this model are summarized in Table 6.

Hypothesis 5. It was predicted that full scale NOS scores would predict PSS scores in a simple linear regression.

Step 1. A simple linear regression revealed that full scale NOS scores did not predict PSS scores. Thus, Baron and Kenny's (1986) first step for mediation was not met.

Hypothesis 6. It was predicted that full scale NOS scores would predict IHP-R scores in a simple linear regression.

Step 2. A simple linear regression revealed that full scale NOS scores significantly predicted IHP-R scores, fulfilling Baron and Kenny's (1986) second step for mediation analysis. NOS scores explained approximately $6 \%$ of the variance in IHP-R scores.

Step 3. A simple linear regression already revealed IHP-R scores as a significant predictor of PSS scores in the previous mediation model.

Hypothesis 7. It was predicted that IHP-R scores would mediate the relationship between full scale NOS scores and PSS scores, as demonstrated by multiple linear regression.

Step 4. Given that step one of Baron and Kenny's (1986) model was not met, a mediation of NOS scores and PSS scores by IHP-R scores was not established. Table 4 provides the statistics for when NOS and IHP-R scores were entered as predictors of PSS scores together. Regarding the hypothesized regression models involving IHP-R scores, AIMS scores, NOS scores, and PSS scores, only the first hypothesized mediation model was supported. To further understand the study variables in the present sample, additional exploratory analyses were performed including demographic variables. 
Table 6.

Internalized Heterosexism as a Mediating Variable between Predictor Variable of Outness and Outcome Variable of Perceived Stress

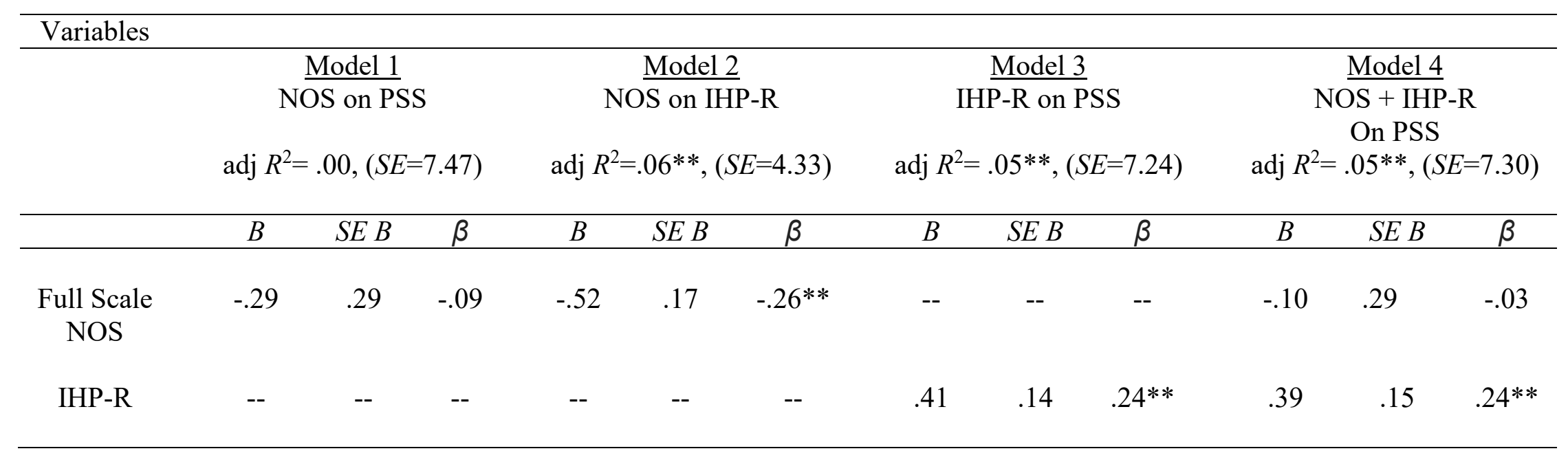

Note. $n=133$; IHP-R= Revised Internalized Homophobia Scale; AIMS= Athletic Identity Measurement Scale; Full Scale NOS= Full scale score of Nebraska Outness Scale; PSS= Perceived Stress Scale.

$* p<.05 ; * * p<.01$ 


\section{Exploratory Analyses}

After testing the hypothesized models, demographic variables were tested as possible predictors of the study variables individually and collectively. To do so, categorical demographic variables were dummy coded and one category was selected as a reference group for each. For sexual orientation, the reference group was lesbian/gay identity, given that it is often conceptualized as being on an opposing end of sexuality from heterosexual identity. For

racial identity, White identity was chosen as the reference category, given that most participants in the study identified as White. The Asian and Native Hawaiian/Pacific Islander categories were also removed, given that only one participant endorsed each of these identities. For year in school, first year students represented the reference group, as it was expected that they would yield the most interesting comparisons. Basketball players were the reference group for sport played, as they were the most numerous in the sample. Division I athletes were also chosen for being the greatest in number across NCAA divisions. Finally, most athletes in the sample attended schools without a religious affiliation. Therefore, no religious affiliation was selected as the reference category instead of Catholic or Protestant institutions.

PSS scores as outcome. Demographic variables were first tested individually as predictors of stress. Racial identity accounted for significant variance in PSS scores $\left(R^{2}=.05\right.$, adjusted $\left.R^{2}=.04, F(2,128)=3.38, p=.04\right)$ as seen in Table 7 , although no significant differences in scores were observed between racial identity groups. When controlling for sport, Black/African American athletes endorsed greater stress than White athletes $(\beta=.19, t(125)=$ $2.07, p=.04)$ 
Table 7.

Summary of Demographic Variables Tested as Predictors of Perceived Stress

\begin{tabular}{|c|c|c|c|c|c|c|}
\hline \multicolumn{7}{|l|}{ Variables } \\
\hline & \multirow{3}{*}{\multicolumn{3}{|c|}{$\begin{array}{c}\frac{\text { Model } 1}{\text { Racial Identity }} \\
\text { adj. } R^{2}=.04^{*},(S E=7.33)\end{array}$}} & \multirow{3}{*}{\multicolumn{3}{|c|}{$\begin{array}{l}\frac{\text { Model } 2}{\text { Racial Identity and Spor }} \\
\text { adj. } R^{2}=.03,(S E=7.37)\end{array}$}} \\
\hline & & & & & & \\
\hline & & & & & & \\
\hline & $B$ & $S E B$ & $\beta$ & $B$ & $S E B$ & $\beta$ \\
\hline $\begin{array}{l}\text { Black/African } \\
\text { American }\end{array}$ & 3.90 & 2.33 & .15 & 5.03 & 2.44 & $.19^{*}$ \\
\hline Multiracial & -3.32 & 1.88 & -.15 & -3.77 & 1.94 & -.18 \\
\hline Volleyball & -- & -- & -- & 1.89 & 2.69 & .07 \\
\hline Soccer & -- & -- & -- & 2.66 & 2.06 & .13 \\
\hline Softball & -- & -- & -- & 3.59 & 1.99 & .19 \\
\hline Ice Hockey & -- & -- & -- & 1.63 & 2.80 & .06 \\
\hline $\begin{array}{l}\text { Sports with under } 9 \\
\text { respondents }\end{array}$ & -- & -- & -- & 1.17 & 1.86 & .07 \\
\hline
\end{tabular}

Note. $n=133 ;{ }^{*} p<.05$

IHP-R scores as outcome. Significant differences in IHP-R scores were observed based on participants' sexual orientation (see Table 8). Sexual orientation variables on a whole accounted for approximately $9 \%$ of the variance in IHP-R scores $\left(R^{2}=.13\right.$, adjusted $R^{2}=.09$, $F(6,126)=3.18, p=.006)$. Mostly heterosexual and questioning participants reported greater IH relative to lesbian/gay participants. This study's religiosity item, "I consider myself a religious person" also predicted IHP-R scores. Approximately 7\% of the variance in IHP-R scores was explained by this item $\left(R^{2}=.08\right.$, adjusted $\left.R^{2}=.07, F(1,131)=11.04, p=.001\right)$. 
Table 8.

Summary of Demographic Variables Tested as Predictors of Internalized Heterosexism

\begin{tabular}{|c|c|c|c|c|c|c|}
\hline \multicolumn{7}{|l|}{ Variables } \\
\hline & \multicolumn{3}{|c|}{ Sexual Orientation } & \multicolumn{3}{|c|}{ Religiosity } \\
\hline & \multicolumn{3}{|c|}{ adj. $R^{2}=.09 * *,(S E=4.26)$} & \multicolumn{3}{|c|}{ adj. $R^{2}=.07^{* *},(S E=4.31)$} \\
\hline & $B$ & $S E B$ & $\beta$ & $B$ & $S E B$ & $\beta$ \\
\hline Mostly heterosexual & 3.84 & 1.38 & $.26^{* *}$ & -- & -- & -- \\
\hline Bisexual & 1.14 & .92 & .13 & -- & -- & -- \\
\hline Mostly lesbian/gay & -1.25 & 1.34 & -.09 & -- & -- & -- \\
\hline Queer & 2.36 & 2.25 & .09 & -- & -- & -- \\
\hline Questioning & 4.49 & 1.67 & $.24 * *$ & -- & -- & -- \\
\hline Pansexual & -1.39 & 2.03 & -.06 & -- & -- & -- \\
\hline Religiosity & -- & -- & -- & .88 & .27 & $.28 * *$ \\
\hline
\end{tabular}

Multiple regression analyses. Due to the above findings and those of previous

hypotheses involving IHP-R scores as the outcome variable, multiple regression analyses were conducted to further explain IH in the sample. To that end, NOS scores, AIMS scores, sexual orientation, and religiosity were all tested as predictors of IHP-R scores in various combinations (see Table 9). First, NOS scores and AIMS scores were tested as predictors of IHP-R scores. Together, they accounted for $11 \%$ of the variance in IHP-R scores $\left(R^{2}=.12\right.$, adjusted $R^{2}=.11$, $F(2,130)=9.14, p<.001)$. Both NOS scores and AIMS scores remained significant predictors even while controlling for the other. When NOS scores and sexual orientation were inputted as predictors for IHP-R scores, NOS scores were no longer significant. Furthermore, there was no significant change in the variance explained for IHP-R scores from when NOS scores were entered as a sole predictor $\left(\Delta R^{2}=.09, F(6,125)=2.10, p=.06\right)$. It was therefore assumed that NOS scores and sexual orientation carried significant overlap in predicting IHP-R scores. Consequently, NOS scores were excluded from the remaining multiple regression analyses. A multiple regression was then run with AIMS scores and sexual orientation as predictors of IHP-R scores. Together, AIMS scores and sexual orientation accounted for $14 \%$ of the 
variance in IHP-R scores $\left(R^{2}=.19\right.$, adjusted $\left.R^{2}=.14, F(6,125)=3.41, p=.004\right)$. AIMS scores remained a significant predictor of IHP-R scores when controlling for sexual orientation.

Religiosity was added as a third predictor, resulting in a 5\% increase in the variance explained by the predictor variables $\left(\Delta R^{2}=.05, F(1,124)=7.60, p=.007\right)$. Religiosity and AIMS scores were significant independent predictors of IHP-R scores in this final model. 
Table 9.

Summary of Multiple Regression Analyses for Variables Predicting Internalized Heterosexism

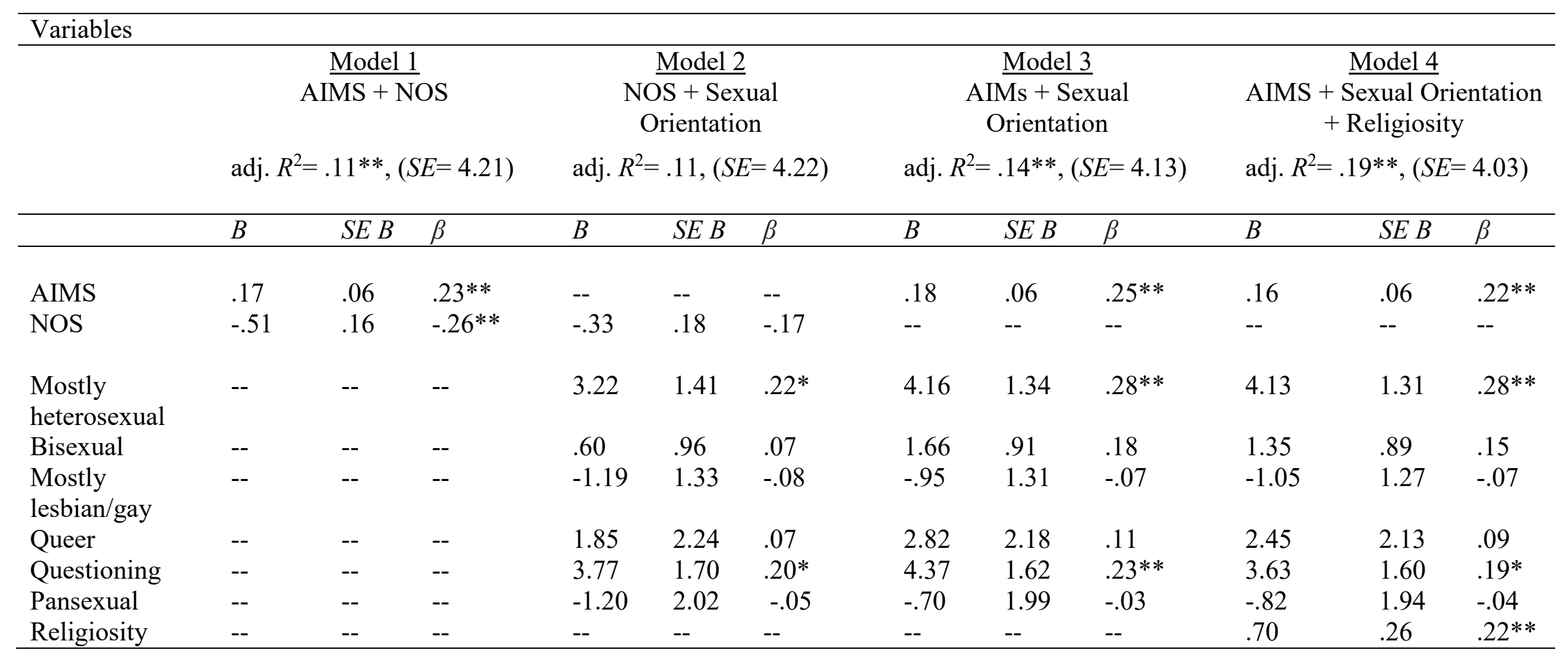

Note. $n=133$; AIMS = Athletic Identity Measurement Scale; NOS= Nebraska Outness Scale.

$* p<.05 ; * * p<.01$ 
AIMS scores as outcome. Significant differences in AIMS scores were observed in the sample based on sexual orientation, racial identity, and sport played (see Table 10). Although sexual orientation did not account for significant variance in AIMS scores $\left(R^{2}=.05\right.$, adjusted $R^{2}=.01$, $F(6,126)=1.10, p=.37)$, bisexual athletes endorsed significantly less athletic identity than lesbian/gay athletes in the sample. Similarly, racial identity did not account for significant variance in AIMS scores $\left(R^{2}=.05\right.$, adjusted $\left.R^{2}=.03, F(2,128)=3.02, p=.052\right)$, but Black and African American participants reported significantly higher athletic identity compared to White participants. Sport played explained $5 \%$ of the variance in AIMS scores $\left(R^{2}=.08\right.$, adjusted $R^{2}=$ $.05, F(5,127)=2.34, p=.045)$. When comparing sport affiliation, volleyball players endorsed significantly less athletic identity than basketball players, as did softball players. 
Table 10.

Summary of Demographic Predictors of Athletic Identity

\begin{tabular}{|c|c|c|c|c|c|c|c|c|c|}
\hline \multicolumn{10}{|l|}{ Variables } \\
\hline & \multicolumn{3}{|c|}{$\begin{array}{c}\text { Model 1 } \\
\text { Sexual Orientation } \\
\text { adj } R^{2}=.01,(S E=6.27)\end{array}$} & \multicolumn{3}{|c|}{$\begin{array}{c}\frac{\text { Model 2 }}{\text { Racial Identity }} \\
\text { adj } R^{2}=.03,(S E=6.20)\end{array}$} & \multicolumn{3}{|c|}{$\begin{array}{c}\frac{\text { Model 3 }}{\text { Sport Played }} \\
\text { adj } R^{2}=.05^{*},(S E=6.11)\end{array}$} \\
\hline & $B$ & $S E B$ & $\beta$ & $B$ & $S E B$ & $\beta$ & $B$ & $S E B$ & $\beta$ \\
\hline $\begin{array}{c}\text { Mostly } \\
\text { heterosexual }\end{array}$ & -1.78 & 2.02 & -.09 & -- & -- & -- & -- & -- & -- \\
\hline Bisexual & -2.93 & 1.35 & $-.23 *$ & -- & -- & -- & -- & -- & -- \\
\hline Mostly lesbian/gay & -1.66 & 1.97 & -.08 & -- & -- & -- & -- & -- & -- \\
\hline Queer & -2.58 & 3.29 & -.07 & -- & -- & -- & -- & -- & -- \\
\hline Questioning & .67 & 2.44 & .03 & -- & -- & -- & -- & -- & -- \\
\hline Pansexual & -3.88 & 2.98 & -.12 & -- & -- & -- & -- & -- & -- \\
\hline $\begin{array}{c}\text { Black/African } \\
\text { American }\end{array}$ & -- & -- & -- & 4.84 & 1.97 & $.21 *$ & -- & -- & -- \\
\hline Multiracial & -- & -- & -- & .44 & 1.59 & .02 & -- & -- & -- \\
\hline Volleyball & -- & -- & -- & -- & -- & -- & -4.91 & 2.11 & $-.22 *$ \\
\hline Soccer & -- & -- & -- & -- & -- & -- & -.32 & 1.66 & -.02 \\
\hline Softball & -- & -- & -- & -- & -- & -- & -3.62 & 1.58 & $-.23 *$ \\
\hline Ice Hockey & -- & -- & -- & -- & -- & -- & -.77 & 2.28 & -.03 \\
\hline $\begin{array}{l}\text { Sports with under } 9 \\
\text { respondents }\end{array}$ & - & -- & -- & -- & -- & -- & .26 & 1.52 & .02 \\
\hline
\end{tabular}

Note. $n=133 ;{ }^{*} p<.05$ 
Full scale NOS scores as outcome. Significant differences in full scale NOS scores were observed in the sample based on sexual orientation and year in school (see Table 11). Sexual orientation accounted for approximately $13 \%$ of the variance in NOS scores $\left(R^{2}=.17\right.$, adjusted $\left.R^{2}=.13, F(6,126)=4.24, p=.001\right)$. Mostly heterosexual athletes reported significantly lower levels of outness compared to lesbian/gay athletes. Bisexual participants also reported lower levels of outness relative to lesbian/gay participants, as did questioning participants. With regard to differences in NOS scores based on year in school, juniors and seniors reported significantly higher levels of outness than freshmen. Year in school did not account for a significant portion of variance in NOS scores $\left(R^{2}=.07\right.$, adjusted $R^{2}=.04, F(5,127)$ $=2.01, p=.081)$.

Table 11.

Summary of Demographic Predictors of Outness

\begin{tabular}{|c|c|c|c|c|c|c|}
\hline \multicolumn{7}{|l|}{ Variables } \\
\hline & \multicolumn{3}{|c|}{$\begin{array}{c}\frac{\text { Model } 1}{\text { Sexual Orientation }} \\
\text { adj } R^{2}=.13^{* *},(S E=2.12)\end{array}$} & \multicolumn{3}{|c|}{$\begin{array}{c}\frac{\text { Model 2 }}{\text { Year in School }} \\
\text { adj } R^{2}=.04,(S E=2.23)\end{array}$} \\
\hline & $B$ & $S E B$ & $\beta$ & $B$ & $S E B$ & $\beta$ \\
\hline $\begin{array}{l}\text { Mostly } \\
\text { heterosexual }\end{array}$ & -1.89 & .69 & $-.25 * *$ & -- & -- & -- \\
\hline Bisexual & -1.67 & .46 & $-.36 * *$ & -- & -- & -- \\
\hline Mostly lesbian/gay & .19 & .67 & .03 & -- & -- & -- \\
\hline Queer & -1.56 & 1.12 & -.12 & -- & -- & -- \\
\hline Questioning & -2.20 & .83 & $-.23 * *$ & -- & -- & -- \\
\hline Pansexual & .57 & 1.01 & .05 & -- & -- & -- \\
\hline Sophomore & -- & -- & -- & .76 & .59 & .13 \\
\hline Junior & -- & -- & -- & 1.20 & .54 & $.23 *$ \\
\hline Senior & -- & -- & -- & 1.51 & .53 & $.30 * *$ \\
\hline Fifth year & -- & -- & -- & .13 & 1.62 & .01 \\
\hline Grad student & -- & -- & -- & 2.38 & 1.62 & .13 \\
\hline
\end{tabular}

Note. $n=133 ; * p<.05 ; * * p<.01$ 
Retesting proposed models. To synthesize the findings from the previous sections, multiple regression analyses were performed to retest the supported mediation model while controlling for pertinent demographic variables.

Due to the role of racial identity and sport in predicting stress, both of these variables were tested in the first mediation model individually. First, a multiple regression was performed including AIMS scores, IHP-R scores, and racial identity as predictors of PSS scores (see Table 12). Adding racial identity into the model led to an increase in the variance explained in PSS scores $\left(\Delta R^{2}=.04, F(2,126)=3.15, p=.046\right)$, and did not change the significance of IHP-R scores as a predictor. No differences based on racial identity were observed. Table 12.

Summary of Multiple Regression Analyses with Perceived Stress as the Outcome Variable and Racial Identity as an Added Predictor

\begin{tabular}{|c|c|c|c|c|c|c|}
\hline \multicolumn{7}{|l|}{ Variables } \\
\hline & \multicolumn{3}{|c|}{$\begin{array}{c}\frac{\text { Model } 1}{\text { AIMS + IHP-R }} \\
\text { adj } R^{2}=.07^{* *},(S E=7.18)\end{array}$} & \multicolumn{3}{|c|}{ 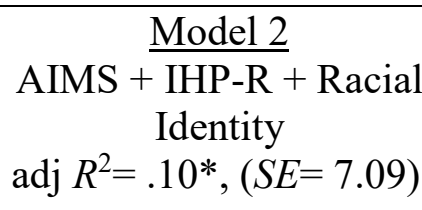 } \\
\hline & $B$ & $S E B$ & $\beta$ & $B$ & $S E B$ & $\beta$ \\
\hline AIMS & .19 & .10 & .16 & .16 & .10 & .13 \\
\hline IHP-R & .34 & .14 & $.21 *$ & .36 & .14 & $.22 *$ \\
\hline $\begin{array}{l}\text { Full scale } \\
\text { NOS }\end{array}$ & -- & -- & -- & -- & -- & -- \\
\hline $\begin{array}{c}\text { Black/African } \\
\text { American }\end{array}$ & -- & -- & -- & 3.12 & 2.31 & .12 \\
\hline Multiracial & -- & -- & -- & -3.50 & 1.81 & -.16 \\
\hline
\end{tabular}

Note. $n=133$; AIMS = Athletic Identity Measurement Scale; IHP-R= Revised Internalized Homophobia Scale. $* p<.05 ; * * p<.01$

When sport was tested as a predictor within the first mediation model, it did not account for significant variance in PSS scores $\left(\Delta R^{2}=.02, F(5,125)=.59, p=.71\right)$. However, controlling 
for sport did reestablish AI as a significant predictor, even when IH was included. No significant differences in PSS scores based on sport were observed. Results are shown in Table 13.

Table 13.

Summary of Multiple Regression Analyses with Perceived Stress as the Outcome Variable and Sport as an Added Predictor

\begin{tabular}{|c|c|c|c|c|c|c|}
\hline \multicolumn{7}{|l|}{ Variables } \\
\hline & \multicolumn{3}{|c|}{$\begin{array}{c}\text { Model 1 } \\
\text { AIMS + IHP-R } \\
\text { adj } R^{2}=.07^{*},(S E=7.18)\end{array}$} & \multicolumn{3}{|c|}{$\begin{array}{c}\frac{\text { Model 2 }}{\text { AIMS }+ \text { IHP-R }+ \text { Sport }} \\
\text { adj } R^{2}=.05,(S E=7.23)\end{array}$} \\
\hline & $B$ & $S E B$ & $\beta$ & $B$ & $S E B$ & $\beta$ \\
\hline AIMS & .19 & .10 & .16 & .24 & .11 & $.20 *$ \\
\hline IHP-R & .34 & .14 & $.21 *$ & .32 & .15 & $.19 *$ \\
\hline Volleyball & -- & -- & -- & 2.73 & 2.56 & .10 \\
\hline Soccer & -- & -- & -- & 1.21 & 2.00 & .06 \\
\hline Softball & -- & -- & -- & 2.87 & 1.93 & .15 \\
\hline Ice Hockey & -- & -- & -- & .05 & 2.73 & .002 \\
\hline $\begin{array}{l}\text { Sports with under } 9 \\
\text { respondents }\end{array}$ & -- & -- & -- & .75 & 1.80 & .04 \\
\hline
\end{tabular}

Note. $n=133$; AIMS= Athletic Identity Measurement Scale; IHP-R= Revised Internalized Homophobia Scale. $* p<.05$

An additional multiple regression was performed with racial identity and sport included simultaneously in the first mediation model (see Table 14). Although the overall model was not significant $\left(R^{2}=.16\right.$, adjusted $\left.R^{2}=.10, F(7,121)=1.61, p=.14\right)$, differences in PSS scores based on racial identity and sport were observed. When controlling for AI, IH, and sport, Multiracial participants endorsed less stress than White participants. In the same model, softball players reported significantly higher stress than basketball players. IHP-R scores maintained its status as a significant predictor. 
Table 14.

Summary of Multiple Regression Analysis with Perceived Stress as the Outcome Variable and Sport and Racial Identity as Added Predictors

\begin{tabular}{|c|c|c|c|}
\hline \multicolumn{4}{|l|}{ Variables } \\
\hline & \multicolumn{3}{|c|}{$\begin{array}{c}\text { Model } 1 \\
\text { AIMS }+ \text { IHP-R }+ \text { Racial } \\
\text { Identity }+ \text { Sport } \\
\text { adj } R^{2}=.10,(S E=7.10)\end{array}$} \\
\hline & $B$ & $S E B$ & $\beta$ \\
\hline AIMS & .21 & .11 & .18 \\
\hline IHP-R & .33 & .15 & $.20 *$ \\
\hline Full scale NOS & -- & -- & -- \\
\hline $\begin{array}{c}\text { Black / African } \\
\text { American }\end{array}$ & 4.08 & 2.38 & .15 \\
\hline Multiracial & -4.02 & 1.86 & $-.19 *$ \\
\hline Volleyball & 2.80 & 2.63 & .10 \\
\hline Soccer & 2.46 & 1.98 & .12 \\
\hline Softball & 3.97 & 1.96 & $.21 *$ \\
\hline Ice Hockey & .79 & 2.72 & .03 \\
\hline $\begin{array}{l}\text { Sports with under } 9 \\
\text { respondents }\end{array}$ & .84 & 1.79 & .05 \\
\hline
\end{tabular}

Note. $n=133$; AIMS= Athletic Identity Measurement Scale; IHP-R= Revised Internalized Homophobia Scale.

$* p<.05$

\section{Summary}

The present study yielded numerous results pertaining to the queer female athlete experience. The first mediation model was supported, with IH mediating the relationship between AI and perceived stress. The second mediation model, with IH mediating the relationship between outness and perceived stress, was not supported. Exploratory analyses revealed significant demographic predictors for $\mathrm{IH}, \mathrm{AI}$, and outness. Various comparisons between groups (e.g., White athletes and athletes of color) were also observed. A predictive model for IH was supported, with AI, sexual orientation, and religiosity as the predictors. 
Finally, racial identity and sport were integrated into the first mediation model separately and together. While racial identity added to the predictive power of the model and did not affect the mediation, sport appeared to impede the role of IH as a mediator between AI and perceived stress.

In the subsequent chapter, implications of the reported findings are discussed. Study limitations are presented, followed by applications and directions for future research. 


\section{Chapter 4: Discussion}

The purpose of the present study was to understand well-being and identity among queer female athletes (i.e., female athletes who identify with a minoritized sexual identity). To that end, a sample of athletes participating in the NCAA were surveyed about their levels of outness, internalized heterosexism, athletic identity, and perceived stress. Given the centrality of internalized heterosexism in the findings, conclusions about its relevance to the present sample are summarized first. Interpretations related to the hypothesized mediation models are presented next, using additional results to clarify variable relationships. Study limitations, applications of findings, and recommendations for future research are also discussed.

\section{Understanding Internalized Heterosexism}

Internalized heterosexism $(\mathrm{IH})$ has been examined among people with minoritized sexual identities for more than two decades. Researchers have established a connection between IH and negative outcomes, including psychache, PTSD symptoms, lower self-esteem, and internalizing mental health problems (e.g., Bourn, Frantell, \& Miles, 2018; Herek, Gillis, \& Cogan, 2009; Newcomb \& Mustanski, 2010). Studies including queer women in particular have demonstrated the role of IH in predicting PTSD symptoms, depression, suicidal ideation, anxiety, and global psychological distress (e.g., Straub, McConnell, \& Messman-Moore, 2018; Szymanski \& Kashubeck-West, 2008; Szymanski, Kashubeck-West, \& Meyer, 2008). Despite the richness of these findings, research capturing the impact of IH on the mental health of queer female athletes is largely nonexistent. The present study was an attempt to initiate this line of inquiry using quantitative methodology. Consistent with previous literature examining $\mathrm{IH}$ in queer populations, IH was related to higher levels of reported stress among the athletes in the present sample. Even when controlling for other variables, IH maintained its relationship to stress. 
Given the strength of IH as a predictor of stress, factors predicting IH were also examined. Religiosity, athletic identity (AI), sexual orientation, and outness were all significant predictors. The connection between religiosity and IH are discussed first, while the remaining variables are mentioned in the context of the proposed mediation models.

Internalized heterosexism and religiosity. Researchers have studied religiosity among queer people, noting some association with negative outcomes (e.g., Foster, Brewster, Velez, Eklund, \& Keum, 2017; Meladze \& Brown, 2015). However, a few researches observed a distinction between the effects of positive and negative religious coping on the impact of IH on mental health. For example, Bourn et al. (2018) found that negative religious coping mediated the relationship between IH and psychache. Additionally, Brewster, Velez, Foster, Esposito, and Robinson (2016) found that positive religious coping actually weakened the negative relationship between IH and psychological well-being. These findings point to the nuanced impact of religious beliefs and practices on $\mathrm{IH}$.

In the present study, religiosity was captured broadly, making it difficult to understand within group differences among queer religious athletes. However, the relationship between religious identification and $\mathrm{IH}$ in the present sample suggests that what it means to be religious among athletes may involve negative attitudes toward minoritized sexual identities. Reviewing the dominant religious athletic organizations present on college campuses could provide some clues into this connection. One such organization is the Fellowship of Christian Athletes (FCA), which is devoted to promoting Christianity among athletes and coaches worldwide. The widespread presence of FCA in the U.S. is apparent, given its reported 14,521 chapters on middle school, high school, and college campuses (FCA, 2018). Included on the FCA (2018) website is the following statement about sex and marriage: 
We believe God's design for sexual intimacy is to be expressed only within the context of marriage. God instituted marriage between one man and one woman as the foundation of the family and the basic structure of human society. For this reason, we believe that marriage is exclusively the union of one man and one woman (Statement of Faith, para.

8).

In light of the popularity of FCA and its public endorsement of committed heterosexual relationships, it is not surprising that identifying as a religious person may coincide with $\mathrm{IH}$ among queer female athletes. Such conclusions are highly speculative, however, and further research is needed to determine the form, meaning, and expression of religiosity among athletes and sporting cultures.

In addition to religiosity, three other predictors (AI, outness, and sexual orientation) of IH were identified in the present study that may help clarify its role and presence in the lives of queer female athletes. Athletic identity is discussed next, within the context of the first mediation model.

\section{Mediation Model with Athletic Identity as the Predictor Variable}

Internalized heterosexism and athletic identity. As part of the first mediation model, AI was expected to predict IH. Although never studied before, this hypothesis was supported, suggesting that queer female athletes with strong athletic identities possess negative attitudes about their sexual identity. The reasons behind this association are unclear. One explanation could be rooted in the history of oppression of queer identities in athletic spaces. For women, the stereotype of the lesbian athlete gained prominence in the $20^{\text {th }}$ century, as women became more involved in the traditionally masculine world of athletics (Cahn, 1993). Cahn described the criticism female athletes endured for their gender nonconformity and the societal pressure they 
received to assert feminine heterosexuality. With this historical backdrop, it is conceivable that female sporting spaces would emphasize a rejection of minoritized sexual identities (DavisDelano, 2014). As such, socialization of young women might involve an instillation of fear about being viewed as "mannish" or deviant if they participate in athletics. It is possible that heterosexual athletes try to remedy this by overtly rejecting queer people, creating a culture of silence around sexual diversity and limiting opportunities for ameliorating IH.

Cahn (1993) also noted an important paradox related to the lesbian athlete stereotype. Although female athletes were often pressured to prove their heterosexuality, queer women did find their way into sports. Thus, female sporting spaces served as a path to greater connectedness with other queer women. It is possible, then, that greater sexual identity acceptance might also occur in the midst of social scrutiny. Similarly, Davis-Delano (2014) concluded that sport both nurtures and thwarts same-sex attraction and relationships among female athletes. After interviewing 56 women, she found that homophobia and perceptions of masculinity were primary hindrances to sexual identity exploration and acceptance. At the same time, sport appeared to nurture same-sex attractions and relationships through sex segregation, bonding through time and emotional investment, and less heteronormative climates. Even so, the connection between athletic identity and IH in the present study suggests that dominant cultural and historical messages still maintain negative perceptions of minoritized sexual identities in sport.

Additional explanations for the connection between IH and AI could be derived from considering the other variables of this study. Given that sexual orientation, outness, and religiosity also predicted $\mathrm{IH}$, the relationship between $\mathrm{AI}$ and $\mathrm{IH}$ is likely linked to these and 
other factors. In other words, having a strong athletic identity may be more predictive of IH in conjunction with the influence of athlete sexual orientation, outness, and religious beliefs.

Internalized heterosexism as a mediator. As hypothesized, $\mathrm{IH}$ mediated the relationship between $\mathrm{AI}$ and perceived stress. This finding suggests that $\mathrm{IH}$ is the main agent of stress in this population, rather than athletic identity alone. Gender norms and socialization may partially explain this relationship. Women with strong athletic identities deviate from traditional feminine norms due to their sport participation and the demands placed on their bodies to be fit and strong in presumably masculine ways (Cahn, 1993). Queer women also deviate from traditional femininity, in light of their attraction to women. On its own, the nonconformity represented in being an athlete and having a minoritized sexual identity may not be distressing. However, in the context of elevated $\mathrm{IH}$, queer women in sports may experience greater gender role stress related to the incongruence of their identities and socialized womanhood. This would follow a similar trend in the literature observed by Szymanski et al. (2008b), which suggests that $\mathrm{IH}$ is related to a belief in traditional gender norms. Future research is needed to explore the connection between IH, AI, gender role beliefs, gender role conflict, and stress among female athletes.

Another possible explanation for the role of IH in mediating athletic identity and stress is related to the pressure athletes experience to perform in their sport. Athletes with strong athletic identities are likely concerned about maintaining their sport performance and commitment (Brewer et al., 1993). Greater stress may result from having to manage IH while maintaining a high level of sport involvement. Furthermore, given that AI is socially informed (Brewer et al., 1993), greater IH could instill a fear of social consequences based on sexual identity related to 
reputation or relational discord. It is therefore conceivable that queer female athletes experience more stress as athletes through the perceived implications of their sexual identities.

Extant literature regarding identity salience and exploration offers potential insight about how queer female athletes manage their athletic and sexual identities. For example, the salience of one identity may coincide with the minimization or devaluing of another, based on environmental demands (Hogg \& Terry, 2000). In the present sample, high athletic identity might be related to less sexual identity exploration, given external pressures to perform and the focus devoted to one's sport. Consequently, high AI could serve to maintain athletes' levels of $\mathrm{IH}$, promoting stress.

Additional findings from the present study may clarify the role of $\mathrm{IH}$ as a mediator between athletic identity and perceived stress. Interestingly, the mediation of athletic identity and stress by IH was no longer significant when controlling for sport. This could mean that IH only mediates AI and stress for athletes participating in certain sports. Thus, high AI and IH may be more harmful in certain sporting cultures compared to others. This interpretation is consistent with current literature, although determining which sports and teams produce friendlier climates for queer women is difficult to surmise. There is some evidence that more queer women are represented in basketball, softball, and soccer (Davis-Delano, 2014). In the present study, basketball, softball, soccer, volleyball, and ice hockey players were most highly represented. However, the number of queer female athletes in these sports does not necessarily mean that they promote affirming and friendly environments. Davis-Delano (2014) found that softball was considered the most nurturing of minoritized sexual identities among her interviewees, while basketball and soccer were deemed somewhat nurturing. Alternatively, Cahn (1993) discussed the ways in which women's basketball and softball were the target of 
anti-lesbianism in the 1950s, due to their heightened masculine association. It is possible that this history still negatively affects the way basketball and softball players are perceived and treated. More research is needed to understand the differences between sporting cultures and team environments in terms of sexual diversity acceptance.

Including racial identity in the mediation model also yielded significant results.

Controlling for AI, IH and racial identity, softball players endorsed more stress than basketball players. When controlling for AI, IH, and sport, multiracial participants endorsed less stress than White participants. Taken together, racial identity and sport appear related to the impact of AI and $\mathrm{IH}$ on perceived stress for queer female athletes. More research is needed to understand the unique experiences of athletes based on sport and racial identity. Fortunately, findings related to athletic identity in the present study offer some interesting insights.

Factors related to athletic identity. Differences in athletic identity were apparent based on racial identity, sport, and sexual identity. Black and African American athletes reported greater athletic identity than White athletes, which bears some consistency with the theoretical and empirical literature. Many authors have pointed to the role of oppression in shaping the experiences of Black athletes. For example, Cooper (2016) noted how institutions often over emphasize Black male student athletes' athletic identities, leading to limited identity integration and exploration. Additionally, sport can afford opportunities to Black athletes who might not otherwise have access to education and economic mobility, making sport performance of even greater import (Cooper \& Cooper, 2015). Given these trends, it is understandable that many Black athletes would endorse heightened levels of athletic identity.

With regard to differences by sport, basketball players reported higher athletic identity than volleyball and softball players. This may point to the popularity of college basketball 
nationwide and the greater opportunity to play basketball professionally. Lesbian/gay participants endorsed greater AI than bisexual participants, which suggest that bisexual athletes may not value sport as highly. One possible explanation could be that bisexuality is considered a less rigid approach to sexuality, by societal standards. Similarly, bisexual athletes' athletic identity might be more fluid or state-dependent.

In sum, racial identity, sport, and sexual identity appear relevant to athletic identity among queer female athletes, and may therefore influence the proposed mediation model. Practically, coaches and administrators may want to pay close attention to the experiences of Black/African American athletes, lesbian/gay athletes, and basketball players, given that they tend to endorse greater levels of athletic identity. Although not definitive, these athletes may be at risk for IH and stress. Additional clues as to which queer female athletes may be vulnerable to stress are apparent in the findings related to outness.

\section{Outness}

Outness, sexual orientation, and internalized heterosexism. Sexual orientation was a significant predictor of outness in the present study. Mostly heterosexual, bisexual, and questioning participants reported significantly less outness than lesbian/gay participants. Extant research provides clarification regarding the differences in outness between bisexual and lesbian/gay individuals. Several authors have noted that bisexual individuals face unique problems of visibility and oppression, including dual discrimination from heterosexuals and lesbian/gay people (Balsam \& Mohr, 2007; Dyar, Feinstein, \& London, 2015; Koh \& Ross, 2006). Brewster and Moradi (2010) presented common myths about bisexuality, including the belief that bisexuals are promiscuous or on a path of eventually declaring themselves as heterosexual or gay. Bisexual individuals may therefore conceal their sexual identity to avoid 
these judgments. Furthermore, bisexual individuals are often assumed to be lesbian or heterosexual based on the sex of their partner (Dyar et al., 2015). Correcting this impression could feel unnecessary, tiring, or unsafe depending on the context. Notably, Feinstein, Dyar, Li, Whitton, Newcomb, and Mustanski (2018) found that increased outness had more negative consequences for bisexual individuals than lesbian/gay individuals.

Conclusions about the lower outness of mostly heterosexual and questioning participants is harder to surmise from the literature, given that most studies do not distinguish these identities from being lesbian/gay and bisexual. However, findings from the present study related to IH, outness, and sexual orientation may provide some insight. Consistent with some previous research (e.g., Herek et al., 1998; Szymanski et al., 2008b; Walch et al., 2016), less outness was predictive of greater IH in the present study, further suggesting that queer people with lower levels of outness may experience fewer opportunities to counteract internalized prejudice. Interestingly, outness no longer predicted $\mathrm{IH}$ when controlling for sexual orientation. One reason for this could be that sexual orientation is a proximal measure of outness. Mostly heterosexual and questioning athletes endorsed significantly more IH than lesbian/gay athletes. These athletes also reported the lowest levels of outness based on sexual orientation. It is somewhat not surprising that mostly heterosexual and questioning athletes endorsed the least amount of outness and the highest levels of IH. Individuals who are questioning their sexual orientation may be trying to understand their sexuality, which could activate IH that may not have been salient before. In addition, questioning individuals may not disclose their identity out of a fear of stigmatization. There is some evidence that questioning youth report more adverse outcomes than lesbian/gay and bisexual youth, including bullying and victimization (Birkett, Espelage, \& Koenig, 2009). Mostly heterosexual athletes might believe it unnecessary to 
disclose their sexual identity, in light of their tendency to engage in relationships with men. However, their endorsement of greater IH could also represent a fear of stigmatization similar to that faced by bisexual women. In this case, IH may serve to limit the sexual exploration of mostly heterosexual athletes. Taken together, it appears as though IH is most prevalent among athletes who identify as questioning or mostly heterosexual, and who endorse low levels of outness.

Year in school and outness. Differences in outness based on year in school were also apparent in the present sample. Juniors and seniors were more out than first years, suggesting that outness could be a developmental process. Some research indicates that older queer individuals endorse greater outness than their younger counterparts in college and community samples (e.g., Brown, Baunach, \& Burgess, 2015; Solomon, McAbee, Åsberg, \& McGee, 2015). However, differences between college level cohorts are less documented. Additional research is needed to explore the differences in outness based on athletes' year in school in particular.

Taken together, it is possible that mostly heterosexual, bisexual, questioning, and first year students are the least out among queer female athletes. The impact of lower levels of outness on these athletes warrants further study. Nonetheless, the connection between outness and IH may signify that this subset of female athletes is at greater risk for negative outcomes. Although perceived stress was not predicted by outness in the present study, there may be reason to further explore their connection. In the subsequent section, possible explanations for their non-significant relationship in the present sample are presented.

Outness and perceived stress. Other researchers have demonstrated that less outness is associated with greater IH (Herek et al., 1998; Singh, Dew, Hays, \& Gailis, 2006; Szymanski et al., 2008b), concluding that concealing one's minoritized sexual identity can limit opportunities 
for acceptance and support. Similarly, athletes with lower levels of outness may experience greater IH due to a lack of support and closeness within their teams and athletic departments. Due to the association between outness and IH in the present study, one might presume that outness would also predict stress. One potential reason why this connection was not established may have to do with the current state of sport cultures. It is possible that athletic spaces are too variable in their level of queer friendliness that the impact of outness is difficult to identify definitively. This interpretation is consistent with those of other researchers, who have described outness as a complex construct that is highly contextual (Frost \& Meyer, 2009; Legate et al., 2012; Ryan et al., 2015), making generalizable conclusions difficult. Furthermore, there is evidence from previous research that outness is more connected to mental health through other variables (Feldman \& Wright, 2013; Lehavot \& Simoni, 2011; Lewis, Milletich, Mason, \& Derlega, 2014). Outness might also be linked to outcomes other than stress for athletes. Future research is needed to identify what other variables connect outness to measures of psychological well-being for this population.

\section{Limitations}

Although the results of the present study are informative, it is important to consider its limitations. One limitation was the absence of a comparison group including heterosexual athletes or participants of other genders. Although a strength of this study was the inclusion of multiple types of queer female athletes, additional identity-based comparisons could be informative. Future research could capture the differences in perceived stress, athletic identity, and attitudes towards minoritized sexual identities between athletes and non-athletes, heterosexual athletes and queer athletes, men and women, or transgender athletes and cisgender athletes. 
Another limitation of the present sample is that it may not be representative of the queer female athlete population in college. It was unclear how successful participant recruitment would be for the present quantitative inquiry, given the small samples of queer female athletes in previous research. Thus, recruitment was approached with a balance of practicality and a desire to acquire participants from a variety of institutions and identity statuses. As such, it is likely that participant recruitment was affected by selection bias, given that all of the athletes surveyed were accessible via email. Furthermore, the athletes who opted to participate may have unique characteristics compared to those who did not. For example, athletes may have chosen to participate due to the Starbucks gift card, which suggests that they have access to Starbucks and would want to go there. The present sample also lacked diversity in terms of racial identity, school religious affiliation, and sport. Future research would benefit from larger and more diverse samples.

Another limitation of this study is the broad definition that was used for religiosity. It can only be speculated that what it means to be "religious" is related to heterosexist views about sexuality for the athletes sampled in this study. Future research may want to assess religiosity and spirituality in more complex and varied ways, to better understand how such aspects of human experience relate to $\mathrm{IH}$.

Finally, the present study largely focused on the challenges queer athletes face. Much of the research involving those with minoritized identities places an emphasis on deficits rather than strength and resilience. Research that focuses on what contributes to the success and well-being of queer athletes could be both informative and uplifting for this population. 


\section{Application and Future Research}

The present findings may be useful for identifying queer female athletes who are at risk for greater IH and stress. For instance, the mostly heterosexual, bisexual, and questioning athletes of this study endorsed lower levels of outness and greater IH. As such, it may be important to increase acknowledgement and validation of these identities within athletic spaces. In addition, mental health professionals working with mostly heterosexual, bisexual, and questioning female athletes may want to provide space for them to explore and navigate their identities openly, in the event that it is not safe to do so on their teams. Oswalt and Vargas (2012) found that coaches viewed bisexuality as less stable than lesbian identity, perhaps highlighting a lack of understanding or affirmation of bisexual athletes. Given that bisexual participants were the most numerous but among the least out in the present study, it is possible that bisexual athletes are more invisible than their prevalence might suggest. Additional research is needed to understand the unique experiences of oppression that bisexual athletes face, along with protective factors.

Due to the lower levels of outness endorsed by first year athletes, it might also be important for coaches, clinicians, and athletics staff to be attentive to the needs of this population regarding sexual identity development. Normalizing minoritized sexual identities early and often could be important to fostering positive adjustment for new team members. Additional research could be done on the impact of older queer teammates on younger athletes. Some research has demonstrated that positive role models are important to identity development and acceptance (Gomillion \& Giuliano, 2011).

This study also illuminates the potential relevance of religion in sporting spaces. Although religiosity was associated with greater $\mathrm{IH}$ in this study, more research is needed to 
understand the nuances of religious influence among queer female athletes. It may be that the dominant religious affiliations in collegiate sports promote more hostile attitudes regarding queer identities. If this is the case, more dialogue and intervention are necessary to make athletic spaces more inclusive. Common Ground is one such effort put forth by the NCAA. Its mission is to promote inclusive athletic spaces for individuals of all sexual identities, genders, and religious beliefs through dialogue and practical action steps (NCAA, 2018). Efforts such as these may improve athletes' experiences of both religion and sexuality. Furthermore, given that religious coping can have positive mental health benefits for individuals with minoritized sexual identities (Brewster et al., 2016), research regarding the ways in which religion can benefit queer athletes might also be fruitful. Given that religiosity was a relevant feature of this study, it is recommended that mental health professionals assess the experiences athlete clients may have with religion and spirituality. It may be beneficial to explore the potential areas of strength and harm of these factors to promote well-being.

The relationships between $\mathrm{AI}, \mathrm{IH}$, and stress in the present study suggest that athletes with high AI could be at risk for greater IH and stress. Black/African American and lesbian/gay athletes endorsed the greatest AI in the present study. Basketball players also endorsed the highest AI compared to athletes in other sports. Additional research is needed to better understand how AI impacts these athletes and if intervention is appropriate or possible. Drawing from theory and research about identity development and intersectionality, it is recommended that sport psychologists and mental health clinicians facilitate conversations with minoritized athletes about being an athlete and balancing other identities. Similarly, fostering a more holistic appreciation for athletes in sporting spaces could promote healthy identity integration. 


\section{Conclusion}

In conclusion, the present study was intended to illuminate the experiences of queer female athletes, a population that has not been studied using quantitative methodology. Athletes' levels of internalized heterosexism, athletic identity, outness, and perceived stress were examined. Significant relationships among study variables were identified. Findings related to participant demographics were also noted, which may provide coaches, mental health professionals, and university administrators with information about the needs of different queer female athletes. It is hoped that this research will promote a commitment to understanding the experiences of athletes with minoritized sexual identities, in order to better serve and support them in university contexts. 


\section{References}

Allen, D., \& Oleson, T. (1999). Shame and internalized homophobia in gay men. Journal of Homosexuality, 37(3), 33-43. doi:10.1300/J082v37n03_03

American Psychological Association. (2012). Guidelines for psychological practice with lesbian, gay, and bisexual clients. American Psychologist, 67(1), 10-42. doi:10.1037/a0024659

Anderson, E. (2002). Openly gay athletes: Contesting hegemonic masculinity in a homophobic environment. Gender and Society, 16(6), 860-877. doi:10.1177/089124302237892

Anderson, E., Magrath, R., \& Bullingham, R. (2016). Out in sport: The experiences of openly gay and lesbian athletes in competitive sport. New York, NY: Routledge.

Antshel, K. M., VanderDrift, L. E., \& Pauline, J. S. (2016). The role of athletic identity in the relationship between difficulty thinking or concentrating and academic service use in NCAA student-athletes. Journal of Clinical Sport Psychology, 10(4), 309-323. doi:10.1123/jcsp.2015-0028

Associated Press. (2007, February 6). Penn State coach, ex-player reach settlement. ESPN. Retrieved from http://www.espn.com/ncw/news/story?id=2755039

Asta, E. L., \& Vacha-Haase, T. (2013). Heterosexual ally development in counseling psychologists: Experiences, training, and advocacy. The Counseling Psychologist, 41(4), 493-529. doi:10.1177/0011000012453174

Balsam, K. F., \& Mohr, J. J. (2007). Adaptation to sexual orientation stigma: A comparison of bisexual and lesbian/gay adults. Journal of Counseling Psychology, 54, 306-319. doi:10.1037/0022-0167.54.3.306 
Bandura, A. (1977). Self-efficacy: Toward a unifying theory of behavioral change. Psychological Review, 84(2), 191-215. doi:10.1037/0033-295X.84.2.191

Baron, R. M., \& Kenny, D. A. (1986). The moderator-mediator variable distinction in social psychological research: Conceptual, strategic, and statistical considerations. Journal of Personality and Social Psychology, 51(6), 1173-1182. doi:10.1037/0022-3514.51.6.1173

Barnes, D. M., \& Meyer, I. H. (2012). Religious affiliation, internalized homophobia, and mental health in lesbians, gay men, and bisexuals. The American Journal of Orthopsychiatry, 82(4), 505-515. doi:10.1111/j.1939-0025.2012.01185.x

Bayer, V., Robert-McComb, J. J., Clopton, J. R., \& Reich, D. A. (2017). Investigating the influence of shame, depression, and distress tolerance on the relationship between internalized homophobia and binge eating in lesbian and bisexual women. Eating Behaviors, 24, 39-44. doi:10.1016/j.eatbeh.2016.12.001

Beamon, K. (2012). "I'm a baller": Athletic identity foreclosure among African-American former student athletes. Journal of African American Studies, 16, 195-208. doi:10.1007/s12111-012-9211-8

Bell, A. P., \& Weinberg, T. S. (1978). Homosexualities: A study of diversity among men and women. New York: Simon \& Schuster.

Bimper, A. J. (2014). Game changers: The role athletic identity and racial identity play on academic performance. Journal of College Student Development, 55(8), 805-807. doi:10.1353/csd.2014.0078

Birkett, M., Espelage, D. L., \& Koenig, B. (2009). LGB and questioning students in schools: The moderating effects of homophobic bullying and school climate on negative outcomes. Journal of Youth and Adolescence, 38(7), 989-1000. 
doi:10.1007/s10964-008-9389-1

Blinde, E. M., \& Taub, D. E. (1992). Women athletes as falsely accused deviants: Managing the lesbian stigma. The Sociologist Quarterly, 33(4), 521-533. doi:10.1111/j.1533 8525.1992.tb00141.x

Bostwick, W. B., Boyd, C. J., Hughes, T. L., West, B. T., \& McCabe, S. E. (2014). Discrimination and mental health among lesbian, gay, and bisexual adults in the United States. American Journal of Orthopsychiatry, 84(1), 35-45. doi:10.1037/h0098851

Bourn, J. R., Frantell, K. A., \& Miles, J. R. (2018). Internalized heterosexism, religious coping, and psychache in LGB young adults who identify as religious. Psychology of Sexual Orientation and Gender Diversity, 5(3), 303-312. doi:10.1037/sgd0000274

Brewer, B. W., \& Cornelius, A. E. (2001). Norms and factorial invariance of the Athletic Identity Measurement Scale. Academic Athletic Journal, 15, 103-113. doi: $10.1037 / \mathrm{t} 15488-000$

Brewer, B. W., Cornelius, A. E., Stephan, Y., \& Van Raalte, J. (2010). Self-protective changes in athletic identity following anterior cruciate ligament reconstruction. Psychology of Sport and Exercise, 11(1), 1-5. doi:10.1016/j.psychsport.2009.09.005

Brewer, B. W., Van Raalte, J. L., \& Linder, D. E. (1993). Athletic identity: Hercules' muscles or Achilles' heel? International Journal of Sport Psychology, 24, 237-254. doi:10.1177/104973239800800506

Brewster, M. E., \& Moradi, B. (2010). Perceived experiences of anti-bisexual prejudice: Instrument development and dvaluation. Journal of Counseling Psychology, 57(4), 451 -468. doi:10.1037/a0021116 
Brewster, M. E., Velez, B. L., Foster, A., Esposito, J., \& Robinson, M. A. (2016). Minority stress and the moderating role of religious coping among religious and spiritual sexual minority individuals. Journal of Counseling Psychology, 63(1), 119-126. doi:10.1037/cou0000121

Brown, M., Baunach, D. M., \& Burgess, E. O. (2015). Sexual disclosure among college students in the American deep South: Toward a "sexuality as structure" approach. Journal of Child and Adolescent Behavior, 3(4), 1-9. doi:10.4172/2375-4494.1000227

Brown, J., \& Trevethan, R. (2010). Shame, internalized homophobia, identity formation, attachment style, and the connection to relationship status in gay men. American Journal of Men's Health, 4(3), 267-276. doi:10.1177/1557988309342002

Burn, S. M., Kadlec, K., \& Rexer, R. (2005). Effects of subtle heterosexism on gays, lesbians, and bisexuals. Journal of Homosexuality, 49(2), 23-38. doi:10.1300/J082v49n02

Burton, A., Burgess, C., Dean, S., Koutsopoulou, G. Z., \& Hugh-Jones, S. (2017). How effective are mindfulness-based interventions for reducing stress among healthcare professionals? A systematic review and meta-analysis. Stress and Health: Journal of the International Society for the Investigation of Stress, 33(1), 3-13. doi:10.1002/smi.2673

Cahn, S. K. (1993). From the "muscle moll" to the "butch" ballplayer: Mannishness, lesbianism, and homophobia in U.S. women's sport. Feminist Studies, 19(2), 343-68. doi: $10.2307 / 3178373$

Cass, V. C. (1979). Homosexual identity formation: A theoretical model. Journal of Homosexuality, 4(3), 219-235. doi:10.1300/J082v04n03_01

Casson, R. J., Farmer, L. D. (2014). Understanding and checking the assumptions of linear regression: A primer for medical researchers. Clinical and Experimental Ophthalmology, 42, 590-596. doi:10.1111/ceo.12358 
Chiu, Y., Lu, F.J., Lin, J., Nien, C., Hsu, Y., \& Liu, H. (2016). Psychometric properties of the Perceived Stress Scale (PSS): measurement invariance between athletes and non-athletes and construct validity. Peer J, 4, e2790. doi:10.7717/peerj.2790

Cochran, S. D. (2001). Emerging issues in research on lesbians' and gay men's mental health: Does sexual orientation really matter?. American Psychologist, 56(11), 931-47. doi:10.1037/0003-066X.56.11.931

Cohen, J. (1988). Statistical power analysis for the behavioral sciences (2nd ed.). Hillsdale, New Jersey: Lawrence Erlbaum Associates.

Cohen, S., Kamarck, T., \& Mermelstein, R. (1983). A global measure of perceived stress. Journal of Health and Social Behavior, 24, 385-396. doi:10.2307/2136404

Cohen, S., \& Williamson, G. M. (1988). Perceived stress in a probability sample of the United States. In S.Spacapan \& S.Oskamp (Eds.), The social psychology of health: Claremont Symposium on Applied Social Psychology (pp. 31-67). Newbury Park, CA: Sage.

Coito, W., Bodensteiner, J., Feyerherm, S., \& Snider, D. (n.d.). NCAA LGBTQ subcommittee statement of affirmation. Retrieved from http://www.ncaa.org/sites/default/files/NCAA -LGBTQ-subcommittee-Statement-edited.pdf

Cook, D. R., \& Weisberg, S. (1982). Residuals and influence in regression. New York: Chapman and Hall.

Cooper, J. N. (2016). Excellence beyond athletics: Best practices for enhancing Black male student athletes' educational experiences and outcomes. Equity and Excellence in Education, 49(3), 267-283. doi:10.1080/10665684.2016.1194097 
Cooper, J. N., \& Cooper, J. E. (2015). “I'm running so you can be happy and I can keep my scholarship": A comparative study of Black male college athletes' experiences with role conflict. Journal of Intercollegiate Sport, 8(2), 131-152. doi:10.1123/jis.2014-0120

Costa, P. A., Pereira, H., \& Leal, I. (2013). Internalized homonegativity, disclosure, and acceptance of sexual orientation in a sample of Portuguese gay and bisexual men, and lesbian and bisexual women. Journal of Bisexuality, 13(2), 229-244.

doi:10.1080/15299716.2013.782481

Critcher, C. R., \& Ferguson, M. J. (2014). The cost of keeping it hidden: Decomposing concealment reveals what makes it depleting. Journal of Experimental Psychology. General, 143(2), 721-735. doi:10.1037/a0033468

Curran, P. J., West, S., \& Finch, J. F. (1996). The robustness of test statistics to nonnormality and specification error in confirmatory factor analysis. Psychological Methods, 1(1), 16 -29. doi:10.1037//1082-989x.1.1.16

Curry, T. J., \& Weiss, O. (1989). Sport identity and motivation for sport participation: A comparison between American college athletes and Austrian student sport club members. Sociology of Sport Journal, 6, 257-268. doi:10.1123/ssj.6.3.257

Daltry, R. (2012). The impact of gender role conflict on the quality of life in female athletes. International Journal of Sport and Society, 3(2), 49-65. doi:10.18848/2152-7857/CGP/v03i02/53903

Davis-Delano, L. R. (2014). Sport as context for the development of women's same-sex relationships. Journal of Sport and Social Issues, 38(3), 263-285. doi:10.1177/0193723513520554 
Dragowski, E. A., Halkitis, P. N., Grossman, A. H., \& D’Augelli, A. R. (2011). Sexual orientation victimization and posttraumatic stress symptoms among lesbian, gay, and bisexual youth. Journal of Gay and Lesbian Social Services, 23, 226-249. doi:10.1080/10538720.2010.541028

Drescher, J. (2010). Queer diagnoses: Parallels and contrasts in the history of homosexuality, gender variance, and the Diagnostic and Statistical Manual. Archives of Sexual Behavior, 39(2), 427-460. doi:10.1007/s10508-009-9531-5

Dyar, C., Feinstein, B. A., \& London, B. (2015). Mediators of differences between lesbians and women in sexual identity and minority stress. Psychology of Sexual Orientation and Gender Diversity, 2(1), 43-51. doi:10.1037/sgd0000090

Everett, B. G., Onge, J. S., \& Mollborn, S. (2016). Effects of minority status and perceived discrimination on mental health. Population Research and Policy Review, 35(4), 445 -469. doi:10.1007/s11113-016-9391-3

Faul, F., Erdfelder, E., Buchner, A., \& Lang, A. G. (2009). Statistical power analyses using G*Power 3.1: Tests for correlation and regression analyses. Behavior Research Methods, 41(4), 1149-1160. doi:10.3758/brm.41.4.1149

Feinstein, B. A., Dyar, C., Li, D. H., Whitton, S. W., Newcomb, M. E., \& Mustanski, B. (2018). The longitudinal associations between outness and health outcomes among gay/lesbian versus bisexual emerging adults. Archives of Sexual Behavior, 48(4), 1111-1126. doi:10.1007/s10508-018-1221-8

Feinstein, B. A., Goldfried, M. R., \& Davila, J. (2012). The relationship between experiences of discrimination and mental health among lesbians and gay men: An examination of 
internalized homonegativity and rejection sensitivity as potential mechanisms. Journal of Consulting and Clinical Psychology, 80(5), 917-927. doi:10.1037/a0029425

Feldman, S. E., \& Wright, A. J. (2013). Dual impact: Outness and LGB identity formation on mental health. Journal of Gay and Lesbian Social Services: The Quarterly Journal of Community and Clinical Practice, 25(4), 443-464. doi:10.1080/10538720.2013.833066

Fellowship of Christian Athletes. (2018). Statement of faith. Retrieved from https://www.fca.org/aboutus/who-we-are/statement-of-faith

Fernald, J. L. (1995). Interpersonal heterosexism. In B. Lott \& D. Maluso (Eds.), The social psychology of interpersonal discrimination (pp. 80-117). New York, NY, US: Guilford Press.

Fingerhut, A. W., Peplau, L. A., \& Gable, S. L. (2010). Identity, minority stress and psychological well-being among gay men and lesbians. Psychology and Sexuality, 1(2), 101-114. doi:10.1080/19419899.2010.484592

Fink, J. S., Burton, L. J., Farrell, A. O., \& Parker, H. M. (2012). Playing it out: Female intercollegiate athletes' experiences in revealing their sexual identities. Journal for the Study of Sports and Athletes in Education, 6(1), 83-106. doi:10.1179/ssa.2012.6.1.83

Foster, A. B., Brewster, M. E., Velez, B. L., Eklund, A., \& Keum, B. T. (2017). Footprints in the sand: Personal, psychological, and relational profiles of religious, spiritual, and atheist LGB individuals. Journal of Homosexuality, 64(4), 466-487. doi:10.1080/00918369.2016.1191237

Friedman, C. K., \& Leaper, C. (2010). Sexual-minority women's experiences with discrimination during emerging adulthood: Relations with identity and collective action. Psychology of Women Quarterly, 34, 152-164. doi:10.1111/j.1471-6402.2010.01558.x 
Frock, S. D. (2000). The relationship between internalized homophobia and psychological distress in lesbians. Dissertation Abstracts International. Section B: Physical Sciences \& Engineering, 61(01), 529.

Frost, D. M., \& Meyer, I. H. (2009). Internalized homophobia and relationship quality among lesbians, gay men, and bisexuals. Journal of Counseling Psychology, 56(1), 97-109. doi:10.1037/a0012844

Fynes, J. M., \& Fisher, L. A. (2016). Is authenticity and integrity possible for sexual minority athletes? Lesbian student-athlete experiences of U.S. NCAA Division I sport. Women in Sport and Physical Activity Journal, 24(1), 60-69. doi:10.1123/wspaj.2014-0055

Gerber, M., Best, S., Meerstetter, F., Walter, M., Ludyga, S., Brand, S., ... Gustafsson, H.(2018). Effects of stress and mental toughness on burnout and depressive symptoms: A prospective study with young elite athletes. Journal of Science and Medicine in Sport, 21(12), 1200-1205. doi:10.1016/j.jsams.2018.05.018

Ghasemi, A., \& Zahediasl, S. (2012). Normality tests for statistical analysis: A guide for nonstatisticians. International Journal of Endocrinology and Metabolism, 10(2), 486-489. doi:10.5812/ijem.3505

Gill, D. L., \& Deeter, T. E. (1988). Development of the Sport Orientation Questionnaire. Research Quarterly for Exercise and Sport, 59(3), 191-202. doi:10.1080/02701367.1988.10605504

Gleeson, S. (2016, April 27). NCAA takes firmer stance against LGBT discrimination with new championship process. USA Today. Retrieved from https://www.usatoday.com/story/sports/college/2016/04/27/ncaa-anti-discrimination -process-championships-homophobia-transphobia/83622258/ 
Gogtay, N. J., \& Thatte, U. M. (2017). Principles of correlation analysis. Journal of The Association of Physicians of India, 65(3), 78-81. Retrieved from http://www.japi.org/

Gomillion, S. C., \& Giuliano, T. A. (2011). The influence of media role models on gay, lesbian, and bisexual identity. Journal of Homosexuality, 58(3), 330-354.

doi:10.1080/00918369.2011.546729

Goodman, D. J. (2011). Promoting diversity and social justice: Educating people from privileged groups ( $2^{\text {nd }}$ ed.). Routledge, Taylor \& Francis Group.

Greywolf, D. S. (2007). Social support, sexual identity development stage, internalized, and external homophobia in lesbian, gay, bisexual youth. Dissertation Abstracts International, 67, 6055.

Griffin, P.G. (1998). Strong women, deep closets: Lesbians and homophobia in sport. Champaign, IL: Human Kinetics

Griffin, P., \& Taylor, H. (2012). Champions of respect: Inclusion of LGBTQ student-athletes and staff in NCAA programs. Retrieved from http://www.ncaapublications.com/productdownloads/CRLGBTQ.pdf

Guilford, J. P. (1954). Psychometric methods (2nd ed.). New York: McGraw-Hill.

Gustafsson, H., Hassmén, P., \& Hassmén, N. (2011). Are athletes burning out with passion?. European Journal of Sport Science, 11(6), 387-395. doi:10.1080/17461391.2010.536573

Hair, J. F., Anderson, R. E., Tatham, R. L., \& Black, W. C. (1995). Multivariate data analysis. Englewood Cliffs, NJ: Prentice-Hall. 
Haldeman, D. C. (1994). The practice and ethics of sexual orientation conversion therapy. Journal of Consulting and Clinical Psychology, 62(2), 221-227. doi:10.1037/0022-006X.62.2.221

Harbaugh, E., \& Lindsey, E. W. (2015). Attitudes toward homosexuality among young adults: Connections to gender role identity, gender-typed activities, and religiosity. Journal of Homosexuality, 62(8), 1098-1125. doi:10.1080/00918369.2015.1021635

Hatzenbuehler, M. L., Pachankis, J. E., \& Wolff, J. (2012). Religious climate and health risk behaviors in sexual minority youths: A population-based study. American Journal of Public Health, 102(4), 657-663. doi:10.2105/AJPH.2011.300517

Havlicek, L. L., \& Peterson, N. L. (1976). Robustness of the Pearson correlation against violations of assumptions. Perceptual and Motor Skills, 43(3), 1319-1334. doi:10.2466/pms.1976.43.3f.1319

Herek, G. M. (1990). The context of anti-gay violence: Notes on cultural and psychological heterosexism. Journal of Interpersonal Violence, 5(3), 316-333. doi:10.1177/088626090005003006

Herek, G. M. (2009). Hate crimes and stigma-related experiences among sexual minority adults in the United States: Prevalence estimates from a national probability sample. Journal of Interpersonal Violence, 24, 54-74. doi:10.1177/0886260508316477.

Herek, G. M., Cogan, J. C., Gillis, J. R., \& Glunt, E. K. (1998). Correlates of internalized homophobia in a community sample of lesbians and gay men. Journal of the Gay and Lesbian Medical Association, 2(1), 17-25. doi:10.1300/j082v43n02_05 
Herek, G. M., Gillis, J. R., \& Cogan, J. C. (2009). Internalized stigma among sexual minority adults: Insights from a social psychological perspective. Journal of Counseling Psychology, 56(1), 32-43. doi:10.1037/a0014672

Herz, M., \& Johansson, T. (2015). The normativity of the concept of heteronormativity. Journal of Homosexuality, 62(8), 1009-1020. doi:10.1080/00918369.2015.1021631

Hinrichs, D. W., \& Rosenberg, P. J. (2002). Attitudes toward gay, lesbian, and bisexual persons among heterosexual liberal arts students. Journal of Homosexuality, 43(1), 61-84. doi:10.1300/J082v43n01_04

Hoang, M., Holloway, J., \& Mendoza, R. H. (2011). An empirical study into the relationship between bisexual identity congruence, internalized biphobia and infidelity among bisexual women. Journal of Bisexuality, 11(1), 23-38.

doi:10.1080/15299716.2011.545285

Hogg, M. A., \& Terry, D. J. (2000). Social identity and self-categorization processes in organizational contexts. Academy of Management Review, 25(1), 121-140. doi:10.5465/AMR.2000.2791606

Hong, J. S., Woodford, M. R., Long, L. D., \& Renn, K. A. (2016). Ecological covariates of subtle and blatant heterosexist discrimination among LGBQ college students. Journal of Youth and Adolescence, 45(1), 117-131. doi:10.1007/s10964-015-0362-5

Houle, J. W., \& Kluck, A. S. (2015). An examination of the relationship between athletic identity and career maturity in student-athletes. Journal of Clinical Sport Psychology, 9(1), 24-40. doi:10.1123/jcsp.2014-0027 
Ibrahim, M., Thearle, M. S., Krakoff, J., \& Gluck, M. E. (2016). Perceived stress and anhedonia predict short-and long-term weight change, respectively, in healthy adults. Eating Behaviors, 21214-219. doi:10.1016/j.eatbeh.2016.03.009

Jewell, L. M., \& Morrison, M. A. (2012). Making sense of homonegativity: Heterosexual men and women's understanding of their own prejudice and discrimination toward gay men. Qualitative Research in Psychology, 9(4), 351-370. doi:10.1080/14780887.2011.586098

Karam, F., Berard, A., Sheehy, O., Huneau, M., Briggs, G., Chambers, C., . . OTIS Research Committee. (2012). Reliability and validity of the 4-item Perceived Stress Scale among pregnant women: Results from the OTIS antidepressants study. Research in Nursing and Health, 35, 363-375. doi:10.1002/nur.21482

Kauer, K. J., \& Krane, V. (2006). "Scary dykes" and "feminine queens": Stereotypes and female collegiate athletes. Women in Sport and Physical Activity Journal, 15(1), 42-55. doi:10.1123/wspaj.15.1.42

Kaysen, D. L., Kulesza, M., Balsam, K. F., Rhew, I. C., Blayney, J. A., Lehavot, K., \& Hughes, T. L. (2014). Coping as a mediator of internalized homophobia and psychological distress among young adult sexual minority women. Psychology of Sexual Orientation and Gender Diversity, 1(3), 225-233. doi:10.1037/sgd0000045

Kilianski, S. E. (2003). Explaining heterosexual men's attitudes toward women and gay men: The theory of exclusively masculine identity. Psychology of Men \& Masculinity, 4(1), 37-56. doi:10.1037/1524-9220.4.1.37 
King, M., Semlyen, J., Tai, S. S., Killaspy, H., Osborn, D., Popelyuk, D., \& Nazareth, I. (2008). A systematic review of mental disorder, suicide, and deliberate self harm in lesbian, gay and bisexual people. BMC Psychiatry, 8, 1-17. doi:10.1186/1471-244X-8-70

Koh, A. S., \& Ross, L. K. (2006). Mental health issues: A comparison of lesbian, bisexual and heterosexual women. Journal of Homosexuality, 51, 33-57. doi:10.1300/J082v51n01_03

Kosciw, J. G., Palmer, N. A., \& Kull, R. M. (2015). Reflecting resiliency: Openness about sexual orientation and/or gender identity and its relationship to well-being and educational outcomes for LGBT students. American Journal of Community Psychology, 55(1-2), 167 -178. doi:10.1007/s10464-014-9642-6

Krane, V. (2016). Inclusion to exclusion: Sport for LGBT athletes. In R. J. Schinke, K. R. McGannon, B. Smith, R. J. Schinke, K. R. McGannon, B. Smith (Eds.), Routledge international handbook of sport psychology (pp. 238-247). New York, NY, US: Routledge/Taylor \& Francis Group.

Krane, V., \& Barber, H. (2003). Lesbian experiences in sport: A social identity perspective. Quest, 55(4), 328-346. doi:10.1080/00336297.2003.10491808

Kroshus, E., \& Davoren, A. K. (2016). Mental health and substance use of sexual minority college athletes. Journal of American College Health, 64(5), 371-379. doi:10.1080/07448481.2016.1158179

Kuerbis, A., Mereish, E. H., Hayes, M., Davis, C. M., Shao, S., \& Morgenstern, J. (2017). Testing cross-sectional and prospective mediators of internalized heterosexism on heavy drinking, alcohol problems, and psychological distress among heavy drinking men who have sex with men. Journal of Studies on Alcohol and Drugs, 78(1), 113-123. doi:10.15288/jsad.2017.78.113 
Kwag, K. H., Martin, P., Russell, D., Franke, W., \& Kohut, M. (2011). The impact of perceived stress, social support, and home-based physical activity on mental health among older adults. International Journal of Aging and Human Development, 72(2), 137-154. doi:10.2190/AG.72.2.c

Legate, N., Ryan, R. M., \& Weinstein, N. (2012). Is coming out always a 'good thing'? Exploring the relations of autonomy support, outness, and wellness for lesbian, gay, and bisexual individuals. Social Psychological and Personality Science, 3(2), 145-152. doi:10.1177/1948550611411929

Lehavot, K., \& Simoni, J. M. (2011). The impact of minority stress on mental health and substance use among sexual minority women. Journal of Consulting and Clinical Psychology, 79(2), 159-170. doi:10.1037/a0022839

Lewis, R. J., Derlega, V. J., Berndt, A., Morris, L. M., \& Rose, S. (2001). An empirical analysis of stressors for gay and lesbians. Journal of Homosexuality, 42(1), 63. doi:10.1300/J082v42n01_04

Lewis, R. J., Milletich, R. J., Mason, T. B., \& Derlega, V. J. (2014). Pathways connecting sexual minority stressors and psychological distress among lesbian women. Journal of Gay and Lesbian Social Services: The Quarterly Journal of Community and Clinical Practice, 26(2), 147-167. doi:10.1080/10538720.2014.891452

Louderback, L. A., \& Whitley Jr, B. E. (1997). Perceived erotic value of homosexuality and sex role attitudes as mediators of sex differences in heterosexual college students' attitudes toward lesbian and gay men. Journal of Sex Research, 34(2), 175. doi:10.1080/00224499709551882 
Ludvigson, C. (2014). Health risk behaviors of female student-athletes and the relationship to social support and athletic identity (Doctoral dissertation). Retrieved from ProQuest Dissertations and Theses Global. (UMI No. 3567863)

Mann, M., \& Krane, V. (2018). Inclusion and normalization of queer identities in women's college sport. Women in Sport and Physical Activity Journal, 26(2), 76-88. doi:10.1123/wspaj.2017-0033

Marcia, J. E. (1966). Development and validation of ego-identity status. Journal of Personality and Social Psychology, 3(5), 551-558. doi:10.1037/h0023281

Martin, J. L., \& Dean, L. L. (1988). The impact of AIDS on gay men: A research instrument. Unpublished technical report. New York, NY: Columbia University

Martin, E. M., \& Horn, T. S. (2013). The role of athletic identity and passion in predicting burnout in adolescent female athletes. Sport Psychologist, 27(4), 338-348. doi:10.1123/tsp.27.4.338

Mason, T. B., \& Lewis, R. J. (2015). Minority stress and binge eating among lesbian and bisexual women. Journal of Homosexuality, 62, 971-992. doi:10.1080/00918369.2015.1008285

Mason, T. B., Lewis, R. J., Winstead, B. A., \& Derlega, V. J. (2015). External and internalized heterosexism among sexual minority women: The moderating roles of social constraints and collective self-esteem. Psychology of Sexual Orientation and Gender Diversity, 2(3), 313-320. doi:10.1037/sgd0000115

Mathur, M. B., Epel, E., Kind, S., Desai, M., Parks, C. G., Sandler, D. P., \& Khazeni, N. (2016). Perceived stress and telomere length: A systematic review, meta-analysis, and 
methodologic considerations for advancing the field. Brain, Behavior, and Immunity, 54, 158-169. doi:10.1016/j.bbi.2016.02.002

McCarn, S R., \& Fassinger, R. (1996). Revisioning sexual minority identity formation: A new model of lesbian identity and its implications for counseling and research. The Counseling Psychologist, 24(3), 508-534. doi:10.1177/0011000096243011

McLaren, S. (2016). The interrelations between internalized homophobia, depressive symptoms, and suicidal ideation among Australian gay men, lesbians, and bisexual women. Journal of Homosexuality, 63(2), 156-168. doi:10.1080/00918369.2015.1083779

Meidlinger, P. C., \& Hope, D. A. (2014). Differentiating disclosure and concealment in measurement of outness for sexual minorities: The Nebraska Outness Scale. Psychology of Sexual Orientation and Gender Diversity, 1(4), 489-497. doi:10.1037/sgd0000080

Meladze, P., \& Brown, J. (2015). Religion, sexuality, and internalized homonegativity: confronting cognitive dissonance in the Abrahamic religions. Journal of Religion and Health, 54(5), 1950-1962. doi:10.1007/s10943-015-0018-5

Melton, E. N., \& Cunningham, G. B. (2012). When identities collide: Exploring minority stress and resilience among college athletes with multiple marginalized identities. Journal for the Study of Sports and Athletes in Education, 6(1), 45-66.

Meyer, I. H. (1995). Minority stress and mental health in gay men. Journal of Health and Social Behavior, 36(1), 38-56. doi:10.2307/2137286

Meyer, I. H. (2003). Prejudice, social stress, and mental health in lesbian, gay, and bisexual populations: Conceptual issues and research evidence. Psychological Bulletin, 129(5), 674-697. doi:10.1037/0033-2909.129.5.674 
Meyer, I. H., \& Dean, L. (1998). Internalized homophobia, intimacy, and sexual behavior among gay and bisexual men. In G. M. Herek (Ed.), Stigma and sexual orientation (pp. 160 -186). Thousand Oaks, CA: Sage

Mildner, C. A. (2001, November). Sexual minority identity formation and internalized homophobia in lesbians: A validation study of a new instrument and related variables. Dissertation Abstracts International, 62, 2494.

Mitchell, A. M., Crane, P. A., \& Kim, Y. (2008). Perceived stress in survivors of suicide: Psychometric properties of the Perceived Stress Scale. Research in Nursing and Health, 31(6), 576-585. doi:10.1002/nur.20284

Moen, F., Firing, K., \& Wells, A. (2016). The effects of attention training techniques on stress and performance in sports. International Journal of Applied Sports Sciences, 28(2), 213-225. doi:10.24985/ijass.2016.28.2.213

Mohr, J., \& Fassinger, R. (2000). Measuring dimensions of lesbian and gay male experience. Measurement and Evaluation in Counseling and Development, 33, 66-90.

Mohr, J. J., \& Kendra, M. S. (2011). Revision and extension of a multidimensional measure of sexual minority identity: The Lesbian, Gay, and Bisexual Identity Scale. Journal of Counseling Psychology, 58(2), 234-245. doi:10.1037/a0022858

Morandini, J. S., Blaszczynski, A., Ross, M. W., Costa, D. J., \& Dar-Nimrod, I. (2015). Essentialist beliefs, sexual identity uncertainty, internalized homonegativity and psychological wellbeing in gay men. Journal of Counseling Psychology, 62(3), 413-424. doi:10.1037/cou0000072 
Morris, J. F., Waldo, C. R., \& Rothblum, E. D. (2001). A model of predictors and outcomes of outness among lesbian and bisexual women. American Journal of Orthopsychiatry, 71, 61-71. doi:10.1037/0002-9432.71.1.61

Murphy, G. M., Petitpas, A. J., \& Brewer, B. W. (1996). Identity foreclosure, athletic identity, and career maturity in intercollegiate athletes. The Sport Psychologist, 10(3), 239-246. doi:10.1123/tsp.10.3.239

Nagoshi, J., Adams, K., Terrell, H., Hill, E., Brzuzy, S., \& Nagoshi, C. (2008). Gender differences in correlates of homophobia and transphobia. Sex Roles, 59(7-8), 521. doi:10.1007/s11199-008-9458-7

NCAA. (2018). Common Ground IV held November 2018 at Brigham Young University. Retrieved from http://www.ncaa.org/about/resources/inclusion/common-ground

Nefzger, M. D., \& Drasgow, J. (1957). The needless assumption of normality in Pearson's r. American Psychologist, 12(10), 623-625. doi:10.1037/h0048216

Newcomb, M. E., \& Mustanski, B. (2010). Internalized homophobia and internalizing mental health problems: A meta-analytic review. Clinical Psychology Review, 30(8), 1019-1029. doi:10.1016/j.cpr.2010.07.003

Oswalt, S. B., \& Vargas, T. M. (2013). How safe is the playing field? Collegiate coaches' attitudes towards gay, lesbian, and bisexual individuals. Sport in Society, 16(1), 120-132. doi:10.1080/17430437.2012.690407

Pachankis, J. E., \& Bränström, R. (2018). Hidden from happiness: Structural stigma, sexual orientation concealment, and life satisfaction across 28 countries. Journal of Consulting and Clinical Psychology, 86(5), 403-415. doi:10.1037/ccp0000299 
Pachankis, J. E., Goldfried, M. R., \& Ramrattan, M. E. (2008). Extension of the rejection sensitivity construct to the interpersonal functioning of gay men. Journal of Consulting and Clinical Psychology, 76, 306-317. 10.1037/0022-006X.76.2.306

Papathomas, A. (2016). Understanding athlete disordered eating: Critical gender comparisons. In R. J. Schinke, K. R. McGannon, B. Smith, R. J. Schinke, K. R. McGannon, B. Smith (Eds.), Routledge international handbook of sport psychology (pp. 176-183). New York, NY, US: Routledge/Taylor \& Francis Group.

Pearson, E.S. (1930), A further development of tests for normality, Biometrika, 22, 239-249. doi: $10.2307 / 2332073$

Pedhazur, E. J. (1982). Multiple regression in behavioral research: Explanation and prediction (2nd ed.). New York: Holt, Rinehart, and Winston.

Peterson, T., \& Gerrity, D. (2006). Internalized homophobia, lesbian identity development, and self-esteem in undergraduate women. Journal of Homosexuality, 50(4), 49-75. doi:10.1300/J082v50n04_03

Pew Research Center. (2013). A survey of LGBT Americans: Attitudes, experiences and values in changing times. Retrieved from http://www.pewsocialtrends.org/2013/06/13/a-survey -of-lgbt-americans/

Potoczniak, D. J., Aldea, M. A., \& DeBlaere, C. (2007). Ego identity, social anxiety, social support, and self-concealment in lesbian, gay, and bisexual Individuals. Journal of Counseling Psychology, 54(4), 447-457. doi:10.1037/0022-0167.54.4.447

Puckett, J. A., Levitt, H. M., Horne, S. G., \& Hayes-Skelton, S. A. (2015). Internalized heterosexism and psychological distress: The mediating roles of self-criticism and 
community connectedness. Psychology of Sexual Orientation and Gender Diversity, 2(4), 426-435. doi:10.1037/sgd0000123

Puckett, J. A., Maroney, M. R., Levitt, H. M., \& Horne, S. G. (2016). Relations between gender expression, minority stress, and mental health in cisgender sexual minority women and men. Psychology of Sexual Orientation and Gender Diversity, 3(4), 489-498. doi:10.1037/sgd0000201

Puckett, J. A., Newcomb, M. E., Garofalo, R., \& Mustanski, B. (2016). The impact of victimization and neuroticism on mental health in young men who have sex with men: Internalized homophobia as an underlying mechanism. Sexuality Research and Social Policy: A Journal of the NSRC, 13(3), 193-201. doi:10.1007/s13178-016-0239-8

Puckett, J. A., Woodward, E. N., Mereish, E. H., \& Pantalone, D. W. (2015). Parental rejection following sexual orientation disclosure: Impact on internalized homophobia, social support, and mental health. LGBT Health, 2(3), 265-269. doi:10.1089/lgbt.2013.0024

Ram, N., Starek, J., \& Johnson, J. (2004). Race, ethnicity, and sexual orientation: Still a void in sport and exercise psychology? Journal of Sport and Exercise Psychology, 26(2), 250 -268. doi:10.1123/jsep.26.2.250

Ramírez, M., \& Hernanzez, R. (2007). Factor structure of the Perceived Stress Scale (PSS) in a sample from Mexico. The Spanish Journal of Psychology, 10, 199-206. doi:10.1017/S1138741600006466

Rankin, S. R. (1998). Heterosexism and the lesbian label in women's intercollegiate athletics. In R. L. Sanlo (Ed.), Working with lesbian, gay, bisexual, and transgender college students: A handbook for faculty and administrators (pp. 203-211). Westport, CT: Greenwood Press. 
Rankin, S. \& Merson, D. (2012). 2012 LGBTQ National College Athlete Report. Charlotte, NC: Campus Pride.

Reis, R. S., Hino, A. A. F., \& Rodriguez-Anez, C. R. R. (2010). Perceived Stress Scale: Reliability and validity study in Brazil. Journal of Health Psychology, 15, 107-114. doi: $10.1177 / 1359105309346343$

Riggle, E. B., Mohr, J. J., Rostosky, S. S., Fingerhut, A. W., \& Balsam, K. F. (2014). A multifactor Lesbian, Gay, and Bisexual Positive Identity Measure (LGBPIM). Psychology of Sexual Orientation and Gender Diversity, 1(4), 398-411. doi: $10.1037 /$ sgd0000057

Riggle, E. B., Rostosky, S. S., Black, W. W., \& Rosenkrantz, D. E. (2017). Outness, concealment, and authenticity: Associations with LGB individuals' psychological distress and well-being. Psychology of Sexual Orientation and Gender Diversity, 4(1), 54-62, doi:10.1037/sgd0000202

Roberti, J. W., Harrington, L. N., \& Storch, E. A. (2006). Further psychometric support for the 10-item version of the Perceived Stress Scale. Journal of College Counseling, 9(2), 135 -147. doi:10.1002/j.2161-1882.2006.tb00100.x

Roper, E. A., \& Halloran, E. (2007). Attitudes toward gay men and lesbians among heterosexual male and female student-athletes. Sex Roles, 57(11-12), 919-928. doi:10.1007/s11199-007-9323-0

Rostosky, S. S., \& Riggle, E.D.B. (2011). Marriage equality for same-sex couples: Counseling psychologists as social change agents. The Counseling Psychologist, 39, 956-972. doi: $10.1177 / 0011000011398398$ 
Ryan, W. S., Legate, N., \& Weinstein, N. (2015). Coming out as lesbian, gay, or bisexual: The lasting impact of initial disclosure experiences. Self and Identity, 14(5), 549-569. doi:10.1080/15298868.2015.1029516

Ryan, W. S., Legate, N., Weinstein, N., \& Rahman, Q. (2017). Autonomy support fosters lesbian, gay, and bisexual identity disclosure and wellness, especially for those with internalized homophobia. Journal of Social Issues, 73(2), 289-306. doi:10.1111/josi.12217

Sabat, I., Trump, R., \& King, E. (2014). Individual, interpersonal, and contextual factors relating to disclosure decisions of lesbian, gay, and bisexual individuals. Psychology of Sexual Orientation and Gender Diversity, 1(4), 431-440. doi:10.1037/sgd0000061

Sanders, E. K., \& Chalk, H. M. (2016). Predictors of psychological outcomes in nonheterosexual individuals. Psi Chi Journal of Psychological Research, 21(2), 100-110. doi:10.24839/2164-8204.JN21.2.100

Schober, P., Boer, C., \& Schwarte, L. A. (2018). Correlation coefficients: Appropriate use of interpretation. Anesthesia and Analgesia, 126 (5), 1763-1768. doi:10.1213/ANE.0000000000002864.

Shakthivel, N., Amarnath, V. M., Ahamed, F., Rath, R. S., Sethuraman, A. R., \& Suliankatchi, R. A. (2017). Level of perceived stress and coping strategies prevailing among 1st year medical undergraduate students: A cross-sectional study from South India. International Journal of Medicine and Public Health, 7(2), 111-115. doi:10.5530/ijmedph.2017.2.22

Shapiro, S. S., \& Wilk, M. B. (1965). An analysis of variance test for normality (complete samples). Biometrika, 52(3), 591-611. doi:10.2307/2333709 
Shavitt, S., Cho, Y. I., Johnson, T. P., Jiang, D., Holbrook, A., \& Stavrakantonaki, M. (2016). Culture moderates the relation between perceived stress, social support, and mental and physical health. Journal of Cross-Cultural Psychology, 47(7), 956-980. doi:10.1177/0022022116656132

Singh, A., Dew, B. J., Hays, D. G., \& Gailis, A. (2006). Relationships among internalized homophobia, sexual identity development, and coping resources of lesbian and bisexual women. Journal of LGBT Issues in Counseling, 1(3), 15-31. doi:10.1300/J462v01n03_03

Smith, K. J., Rosenberg, D. L., \& Timothy Haight, G. (2014). An assessment of the psychometric properties of the Perceived Stress Scale-10 ( PSS10) with business and accounting students. Accounting Perspectives, 13(1), 29-59. doi:10.1111/1911-3838.12023

Solomon, D., McAbee, J., Åsberg, K., \& McGee, A. (2015). Coming out and the potential for growth in sexual minorities: The role of social reactions and internalized homonegativity. Journal of Homosexuality, 62(11), 1512-1538. doi:10.1080/00918369.2015.1073032

Spielberger, C. D. (1983). Manual for the State-Trait Anxiety Inventory: STAI (Form T). Palo Alto, CA: Mind Garden.

Steinfeldt, M., \& Steinfeldt, J. A. (2012). Athletic identity and conformity to masculine norms among college football players. Journal of Applied Sport Psychology, 24(2), 115-128.

Stevens, J. P. (1984). Outliers and influential data points in regression analysis. Psychological Bulletin, 95(2), 334-344. https://doi-org.www.libproxy.wvu.edu/10.1037/00332909.95.2.334 
Stoelting, S. (2011). Disclosure as an interaction: Why lesbian athletes disclose their sexual identities in intercollegiate sport. Journal of Homosexuality, 58(9), 1187-1210. doi:10.1080/00918369.2011.605731

Storch, E. A., Kolsky, A. R., Silvestri, S. M., \& Storch, J. B. (2001). Religiosity of elite college athletes. Sport Psychologist, 15(3), 346. doi:10.1123/tsp.15.3.346

Straub, K. T., McConnell, A. A., \& Messman-Moore, T. L. (2018). Internalized heterosexism and posttraumatic stress disorder symptoms: The mediating role of shame proneness among trauma-exposed sexual minority women. Psychology of Sexual Orientation and Gender Diversity, 5(1), 99-108. doi:10.1037/sgd0000263

Sue, D. W. (2010b). Microaggressions, marginality, and oppression: An introduction. In D. W.Sue (Ed.), Microaggressions and marginality: Manifestation, dynamics, and impact (pp. 3-22). Hoboken, NJ: Wiley.

Sue, D. W., \& Sue, D. (2016). Counseling the culturally diverse: Theory and practice (7th ed.). Hoboken, NJ: John Wiley \& Sons Inc.

Surujlal, J., van Zyl, Y., \& Nolan, V. T. (2013). Perceived stress and coping skills of university student-athletes and the relationship with life satisfaction. African Journal for Physical, Health Education, Recreation and Dance, 19(4.2), 1047-1059.

Symons, C.M., O’sullivan, G.A., \& Polman, R. (2017). The impacts of discriminatory experiences on lesbian, gay and bisexual people in sport. Annals of Leisure Research, 20, 467-489. doi:10.1080/ 11745398.2016.1251327

Szymanski, D. M. (2005). A feminist approach to working with internalized heterosexism in lesbians. Journal of College Counseling, 8(1), 74-85. doi:10.1002/j.2161-1882.2005.tb00074.x 
Szymanski, D. M. (2006). Does internalized heterosexism moderate the link between heterosexist events and lesbians' psychological distress?. Sex Roles, 54(3-4), 227-234. doi:10.1007/s11199-006-9340-4

Szymanski, D. M., \& Chung, Y. B. (2003). Feminist attitudes and coping resources as correlates of lesbian internalized heterosexism. Feminism and Psychology, 13(3), 369-389. doi:10.1177/0959353503013003008

Szymanski, D. M., Chung, Y. B., \& Balsam, K. F. (2001). Psychosocial correlates of internalized homophobia in lesbians. Measurement and Evaluation in Counseling and Development, 34(1), 27-38. doi:10.1300/j155v07n01_08

Szymanski, D. M., Dunn, T. L., \& Ikizler, A. S. (2014). Multiple minority stressors and psychological distress among sexual minority women: The roles of rumination and maladaptive coping. Psychology of Sexual Orientation and Gender Diversity, 1(4), 412 -421. doi:10.1037/sgd0000066

Szymanski, D. M., \& Henrichs-Beck, C. (2014). Exploring sexual minority women's experiences of external and internalized heterosexism and sexism and their links to coping and distress. Sex Roles, 70(1-2), 28-42. doi:10.1007/s11199-013-0329-5

Szymanski, D. M., \& Ikizler, A. S. (2013). Internalized heterosexism as a mediator in the relationship between gender role conflict, heterosexist discrimination, and depression among sexual minority men. Psychology of Men and Masculinity, 14(2), 211-219. doi: $10.1037 / \mathrm{a} 0027787$

Szymanski, D. M., \& Kashubeck-West, S. (2008). Mediators of the relationship between internalized oppressions and lesbian and bisexual women's psychological distress. Counseling Psychologist, 36(4), 575-594. doi:10.1177/0011000007309490 
Szymanski, D. M., Kashubeck-West, S., \& Meyer, J. (2008a). Internalized heterosexism: A historical and theoretical overview. The Counseling Psychologist, 36(4), 510-524. doi:10.1177/0011000007309488

Szymanski, D. M., Kashubeck-West, S., \& Meyer, J. (2008b). Internalized heterosexism: Measurement, psychosocial correlates, and research directions. The Counseling Psychologist, 36(4), 525-574. doi:10.1177/0011000007309489

Szymanski, D. M., \& Mikorski, R. (2016). External and internalized heterosexism, meaning in life, and psychological distress. Psychology of Sexual Orientation and Gender Diversity, 3(3), 265-274. doi:10.1037/sgd0000182

Taylor, J. M. (2015). Psychometric analysis of the ten-item Perceived Stress Scale. Psychological Assessment, 27(1), 90-101. doi:10.1037/a0038100

Troiden, R. R. (1979). Becoming homosexual: A model of gay identity acquisition. Psychiatry: Journal for the Study of Interpersonal Processes, 42(4), 362-373. doi:10.1080/00332747.1979.11024039

Vaughan, M., \& Waehler, C. (2010). Coming out growth: Conceptualizing and measuring stress related growth associated with coming out to others as a sexual minority. Journal of Adult Development, 17(2), 94-109. doi:10.1007/s10804-009-9084-9

Veliz, P., Epstein-Ngo, Q., Zdroik, J., Boyd, C. J., \& McCabe, S. E. (2016). Substance use among sexual minority collegiate athletes: A national study. Substance Use and Misuse, 51(4), 517-532. doi:10.3109/10826084.2015.1126741

Wahlert, L. (2013). Anti-Love or Anti-“Lifestyle”: Historical reflections on reparative therapies for homosexuality. American Journal of Bioethics, 13(11), 36-38. doi:10.1080/15265161.2013.840869 
Walch, S. E., Ngamake, S. T., Bovornusvakool, W., \& Walker, S. V. (2016). Discrimination, internalized homophobia, and concealment in sexual minority physical and mental health. Psychology of Sexual Orientation and Gender Diversity, 3(1), 37-48. doi:10.1037/sgd0000146

Wampold, B. E., \& Freund, R. D. (1987). Use of multiple regression in counseling psychology research: A flexible data-analytic strategy. Journal of Counseling Psychology, 34(4), 372-382. doi:10.1037/0022-0167.34.4.372

Warner, M. (1991). Introduction: Fear of a queer planet. Social Text, 29, 3-17. doi:10.2307/2076123

Warriner, K., Nagoshi, C. T., \& Nagoshi, J. L. (2013). Correlates of homophobia, transphobia, and internalized homophobia in gay or lesbian and heterosexual samples. Journal of Homosexuality, 60(9), 1297-1314. doi:10.1080/00918369.2013.806177

Watson, J. C. (2005). College student-athletes' attitudes toward help-seeking behavior and expectations of counseling services. Journal of College Student Development, 46(4), 442 -449. doi:10.1353/csd.2005.0044

Watson, J. C. (2016). The effect of athletic identity and locus of control on the stress perceptions of community college student-athletes. Community College Journal of Research and Practice, 40(9), 729-738. doi:10.1080/10668926.2015.1072595

Williamson, I. R. (2000). Internalized homophobia and health issues affecting lesbians and gay men. Health Education Research, 15(1), 97-107. doi:10.1093/her/15.1.97

Wolanin, A., Hong, E., Marks, D., Panchoo, K., \& Gross, M. (2016). Prevalence of clinically elevated depressive symptoms in college athletes and differences by gender and sport. British Journal of Sports Medicine, 50(3), 167-171. 
doi:10.1136/bjsports-2015-095756

Woodford, M. R., Kulick, A., Sinco, B. R., \& Hong, J. S. (2014). Contemporary heterosexism on campus and psychological distress among LGBQ students: The mediating role of selfacceptance. The American Journal of Orthopsychiatry, 84(5), 519-529.

doi:10.1037/ort0000015

Woodford, M. R., Silverschanz, P., Swank, E., Scherrer, K. S., \& Raiz, L. (2012). Predictors of heterosexual college students' attitudes toward LGBT people. Journal of LGBT Youth, 9(4), 297-320. doi:10.1080/19361653.2012.716697

Worthen, M. F. (2014). Blaming the jocks and the Greeks? Exploring collegiate athletes' and fraternity/sorority members' attitudes toward LGBT individuals. Journal of College Student Development, 55(2), 168-195. doi:10.1353/csd.2014.0020

Wright, E. R., \& Perry, B. L. (2006). Sexual identity distress, social support, and the health of gay, lesbian, and bisexual youth. Journal of Homosexuality, 51(1), 81-110. doi:10.1300/J082v51n01_05

Yang, J., Peek-Asa, C., Corlette, J. D., Cheng, G., Foster, D. T., \& Albright, J. (2007). Prevalence of and risk factors associated with symptoms of depression in competitive collegiate student athletes. Clinical Journal of Sport Medicine, 17(6), 481-487. doi:10.1097/JSM.0b013e31815aed6b

Yopyk, D. A. (2007). The student-athlete: One identity or two separate identities? The role of identity salience and stereotype threat in athletic and academic performance. Dissertation Abstracts International, 67, 6774. 
Zhou, J., Heim, D., \& O'Brien, K. (2015). Alcohol consumption, athlete identity, and happiness among student sportspeople as a function of sport-type. Alcohol and Alcoholism, 50(5), 617-623. doi:10.1093/alcalc/agv030

Zuckerman, M., Eysenck, S., \& Eysenck, H. J. (1978). Sensation seeking in England and America: Cross-cultural, age, and sex comparisons. Journal of Consulting and Clinical Psychology, 46, 139-149. doi:10.1037/0022-006X.46.1.139 


\section{APPENDIX A}

IHP-R Scale

1. I have tried to stop being attracted to women in general.

Disagree strongly

Agree strongly

$\begin{array}{lllll}1 & 2 & 3 & 4 & 5\end{array}$

2. If someone offered me the chance to be completely heterosexual, I would accept the chance.

Disagree strongly

Agree strongly

$\begin{array}{lllll}1 & 2 & 3 & 4 & 5\end{array}$

3. I wish I weren't lesbian/bisexual/queer/etc.

Disagree strongly

Agree strongly

$\begin{array}{lllll}1 & 2 & 3 & 4 & 5\end{array}$

4. I feel that being lesbian/bisexual/queer/etc. is a personal shortcoming for me.

Disagree strongly

Agree strongly

$\begin{array}{lllll}1 & 2 & 3 & 4 & 5\end{array}$

5. I would like to get professional help in order to change my sexual orientation from lesbian/bisexual/queer/etc. to straight.

Disagree strongly

Agree strongly

$\begin{array}{lllll}1 & 2 & 3 & 4 & 5\end{array}$




\section{APPENDIX B}

Athletic Identity Measurement Scale (AIMS)

1. I consider myself an athlete.

Strongly disagree

Strongly agree

$\begin{array}{llllllll}1 & 2 & 3 & 4 & 5 & 6 & 7\end{array}$

2. I have many goals related to sport.

Strongly disagree

Strongly agree

$\begin{array}{llllllll}1 & 2 & 3 & 4 & 5 & 6 & 7\end{array}$

3. Most of my friends are athletes.

Strongly disagree

Strongly agree
12
3
4
$5 \quad 6$
7

4. Sport is the most important part of my life.

Strongly disagree

Strongly agree

$\begin{array}{lllllll}1 & 2 & 3 & 4 & 5 & 6 & 7\end{array}$

5. I spend more time thinking about sport than anything else.

Strongly disagree

Strongly agree

$\begin{array}{llllllll}1 & 2 & 3 & 4 & 5 & 6 & 7\end{array}$

6. I feel bad about myself when I do poorly in sport.

Strongly disagree

Strongly agree

$\begin{array}{lllllll}1 & 2 & 3 & 4 & 5 & 6 & 7\end{array}$

7. I would be very depressed if I were injured and could not compete in sport. Strongly disagree Strongly agree 


\section{APPENDIX C}

\section{Nebraska Outness Scale}

(NOS-D) What percent of the people in this group do you think are aware of your sexual orientation (meaning they are aware of whether you consider yourself straight, gay, etc)?

0\% $10 \% 20 \% 30 \% 40 \% 50 \% 60 \% 70 \% 80 \% 90 \% 100 \%$

Members of your immediate family (e.g., parents and siblings)

Members of your extended family (e.g., aunts, uncles, grandparents, cousins)

People you socialize with (e.g., friends, $\circ \quad \circ \quad \circ \quad \circ \quad \circ \quad \circ \quad \circ \quad \circ \quad \circ \quad \circ \quad \circ$ teammates, acquaintances)

People at your work/school (e.g., coaches, administrators, professors) Strangers (e.g., someone you have a casual conversation with in line at the store)

(NOS-C) How often do you avoid talking about topics related to or otherwise indicating your sexual orientation (e.g., not talking about your significant other, changing your mannerisms) when interacting with members of these groups?

Half

of the

Never Time

Members of your immediate family (e.g., $\circ \quad \circ \quad \circ \quad \circ \quad \circ \quad \circ \quad \circ \quad \circ \circ \circ \circ \circ$

parents and siblings)

Members of your extended family (e.g.,

aunts, uncles, grandparents, cousins)

People you socialize with (e.g., friends, teammates, acquaintances)

People at your work/school (e.g., coaches, administrators, professors)

Strangers (e.g., someone you have a casual conversation with in line at the store) 


\section{APPENDIX D}

\section{Perceived Stress Scale}

The questions in this scale ask you about your feelings and thoughts during the last month. In each case, you will be asked to indicate by circling how often you felt or thought a certain way.

$0=$ Never $1=$ Almost Never $2=$ Sometimes $3=$ Fairly Often $4=$ Very Often

1. In the last month, how often have you been upset because $\quad \begin{array}{llllll}0 & 1 & 2 & 3 & 4\end{array}$ of something that happened unexpectedly?

2. In the last month, how often have you felt that you were $\quad \begin{array}{llllll}0 & 1 & 2 & 3 & 4\end{array}$ unable to control the important things in your life?

3. In the last month, how often have you felt nervous and $\quad \begin{array}{llllll}0 & 1 & 2 & 3 & 4\end{array}$ "stressed"?

4. In the last month, how often have you felt confident about $\begin{array}{llllll}0 & 1 & 2 & 3 & 4\end{array}$ your ability to handle your personal problems?

5. In the last month, how often have you felt that things were $\begin{array}{llllll}0 & 1 & 2 & 3 & 4\end{array}$ going your way?

6. In the last month, how often have you found that you $\quad \begin{array}{lllllll}0 & 1 & 2 & 3 & 4\end{array}$ could not cope with all the things that you had to do?

7. In the last month, how often have you been able to control $\begin{array}{llllll}0 & 1 & 2 & 3 & 4\end{array}$ irritations in your life?

8. In the last month, how often have you felt that you were $\quad \begin{array}{llllll}0 & 1 & 2 & 3 & 4\end{array}$ on top of things?

9. In the last month, how often have you been angered

$\begin{array}{lllll}0 & 1 & 2 & 3 & 4\end{array}$
because of things that were outside of your control?

10. In the last month, how often have you felt difficulties

$0 \quad 1 \quad 2 \quad 3$
were piling up so high that you could not overcome them? 


\section{APPENDIX E}

\section{Demographic Questionnaire}

Age:

What is your gender identity?
a. Male
b. Female
c. Trans male/Trans man
d. Trans female/Trans woman
e. Genderqueer/Gender non-conforming
f. Indicate different answer

What is your sexual orientation?
a. Heterosexual
b. Mostly heterosexual
c. Lesbian/gay
d. Mostly lesbian
e. Bisexual
f. Queer
g. Questioning
h. Pansexual
i. Indicate different answer

What is your ethnicity?
a. Hispanic or Latino or Spanish Origin
b. Not Hispanic or Latino or Spanish Origin

What is your race? Select all that apply.
a. American Indian/Alaska Native
b. Asian
c. Black or African American
d. Native Hawaiian/Pacific Islander
e. White
f. Multiracial
g. Indicate different answer

What is your year in school?
a. First year
b. Sophomore
c. Junior
d. Senior
e. Fifth year
f. Indicate different answer 
What varsity collegiate sport do you play?
a. Basketball
b. Bowling
c. Cross Country
d. Fencing
e. Field Hockey
f. Golf
g. Gymnastics
h. Ice Hockey
i. Lacrosse
j. Rifle
k. Rowing
1. Skiing
m. Soccer
n. Softball
o. Swimming/Diving
p. Tennis
q. Track and Field
r. Volleyball
s. Water Polo
t. Indicate different answer

What NCAA division does your team participate in?
a. Division I
b. Division II
c. Division III

What is your school's religious affiliation?
a. None
b. Catholic/Jesuit
c. Protestant
d. Indicate different answer

Please indicate how much you agree or disagree with the following statement:

I consider myself a religious person.

1. Strongly disagree

2. Somewhat disagree

3. Neither agree nor disagree

4. Somewhat agree

5. Strongly agree 


\section{APPENDIX F}

\section{Study Advertisement}

Hello, My name is Olivia Scott and I am a doctoral candidate in Counseling Psychology at West Virginia University. Please consider taking part in my dissertation research to assess the experiences of sexual minority female athletes. Your participation in this project is greatly appreciated and will take approximately 10-15 minutes to fill out the online questionnaire (link below). All participants who complete the study will be awarded a $\$ 5$ Starbucks gift card. To participate, you must meet the following criteria:

a) be 18 years or older

b) identify as a woman

c) identify as lesbian, bisexual, queer, or any other non-heterosexual identity

d) play a varsity level collegiate sport at an NCAA institution

Whether you meet these criteria or not, please consider forwarding this study advertisement to any eligible athletes you may know. I will not ask any information that should lead back to your identity as a participant. Your participation is completely voluntary. You may skip any question that you do not wish to answer and you may discontinue at any time. West Virginia University's Institutional Review Board acknowledgement of this project is on file. Should you have any questions about this letter or the research project, please feel free to contact me at ocscott@mix.wvu.edu. You may also contact my supervisor, Dr. Lisa Platt at Lisa.Platt@mail.wvu.edu or 304-293-2176.

Thank you for your time, Olivia Scott

If you wish to participate, please click on the following link to access the survey: https://wvu.qualtrics.com/jfe/form/SV_1N3z0ctCHRAWMSN 


\section{APPENDIX G}

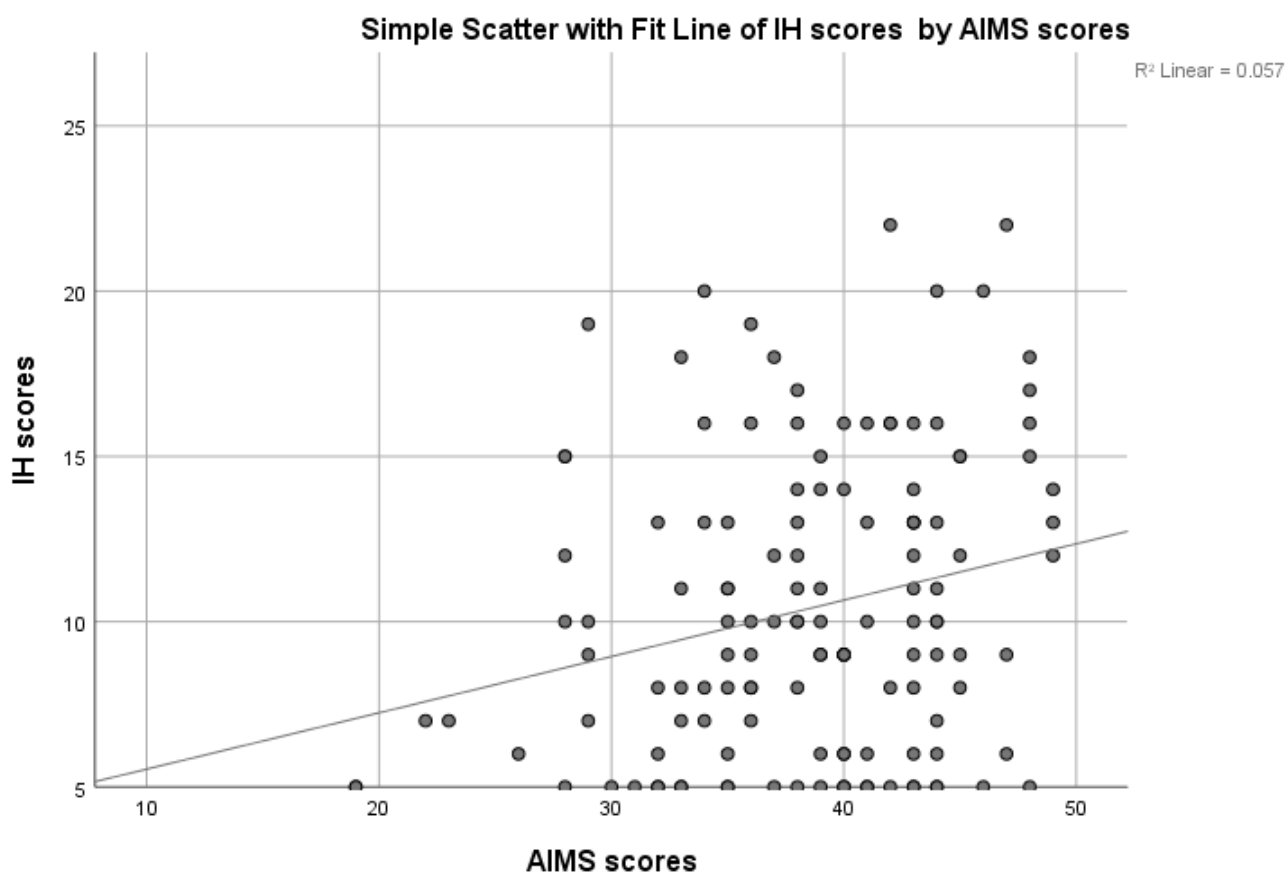

Figure 10. Scatterplot of internalized heterosexism and athletic identity values.

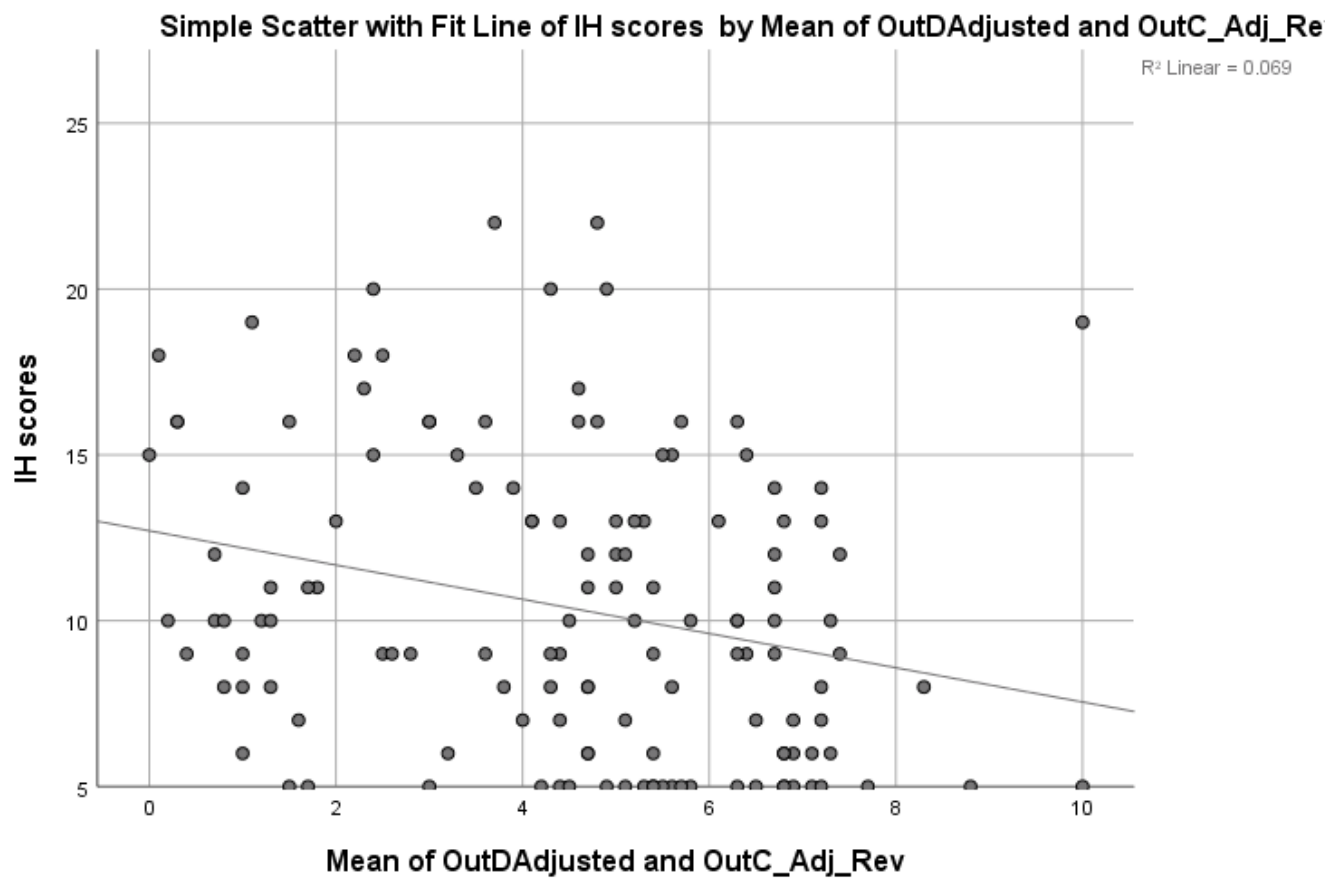

Figure 11. Scatterplot of internalized heterosexism and outness values. 


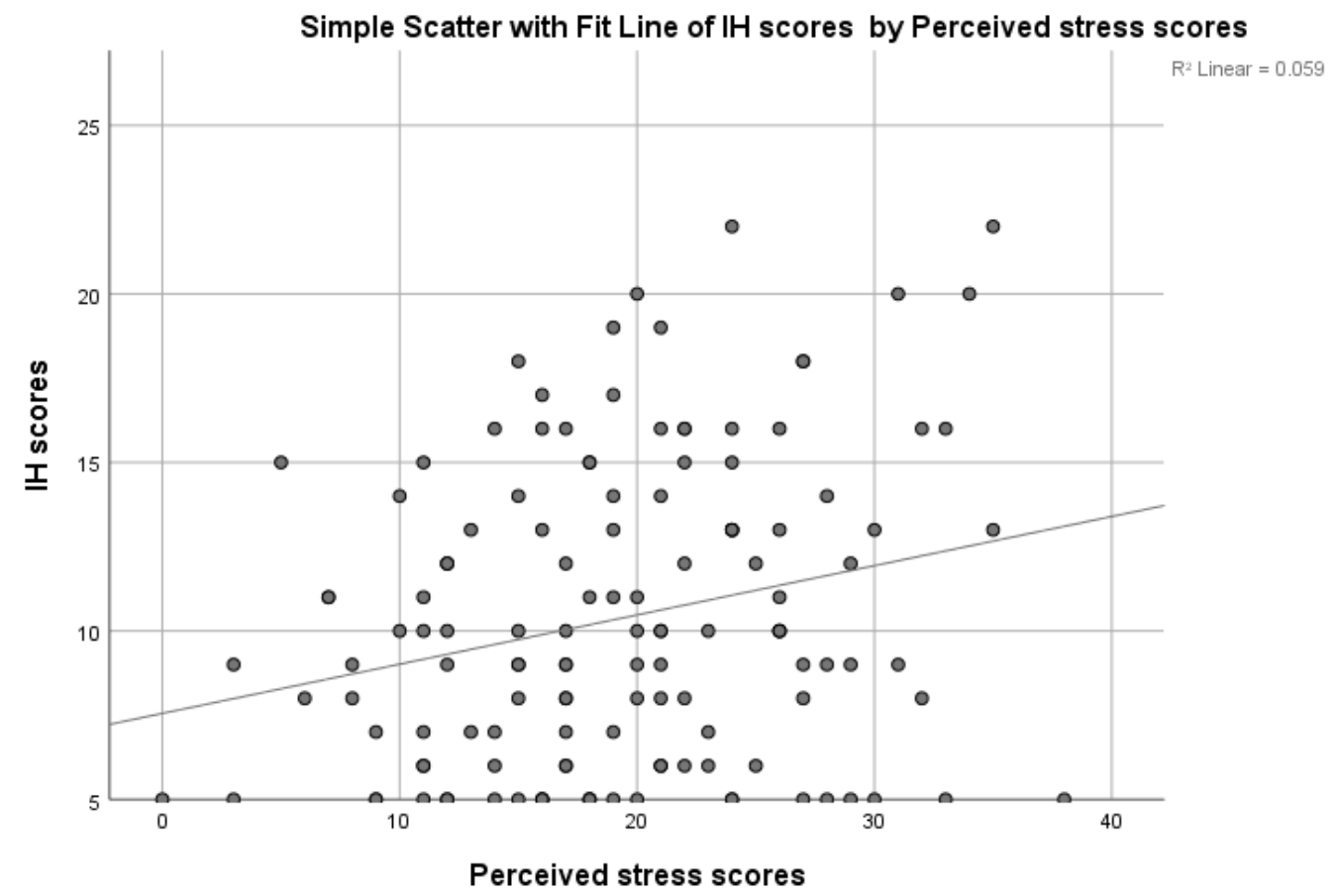

Figure 12. Scatterplot of internalized heterosexism and perceived stress values.

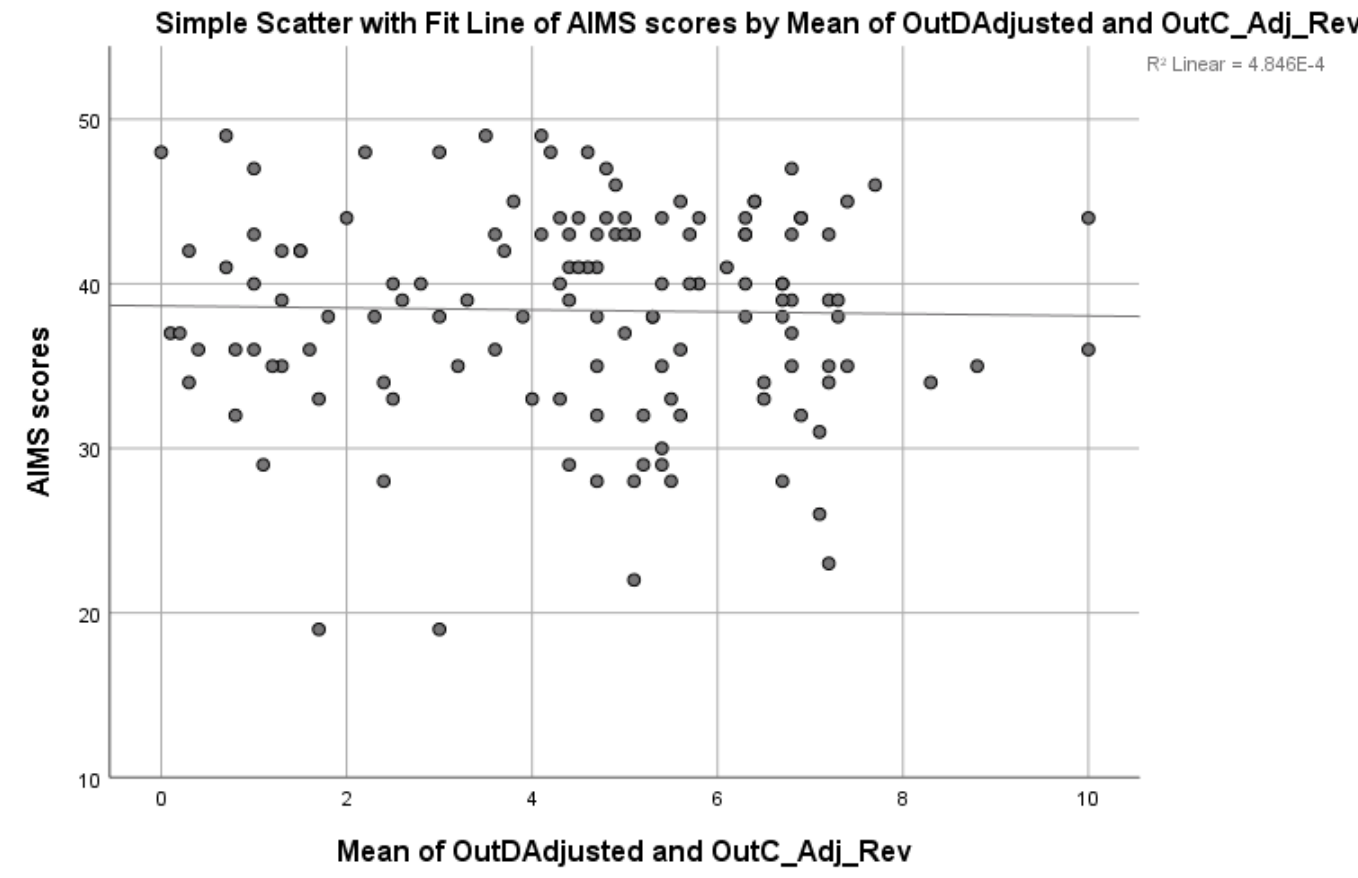

Figure 13. Scatterplot of athletic identity and outness values. 


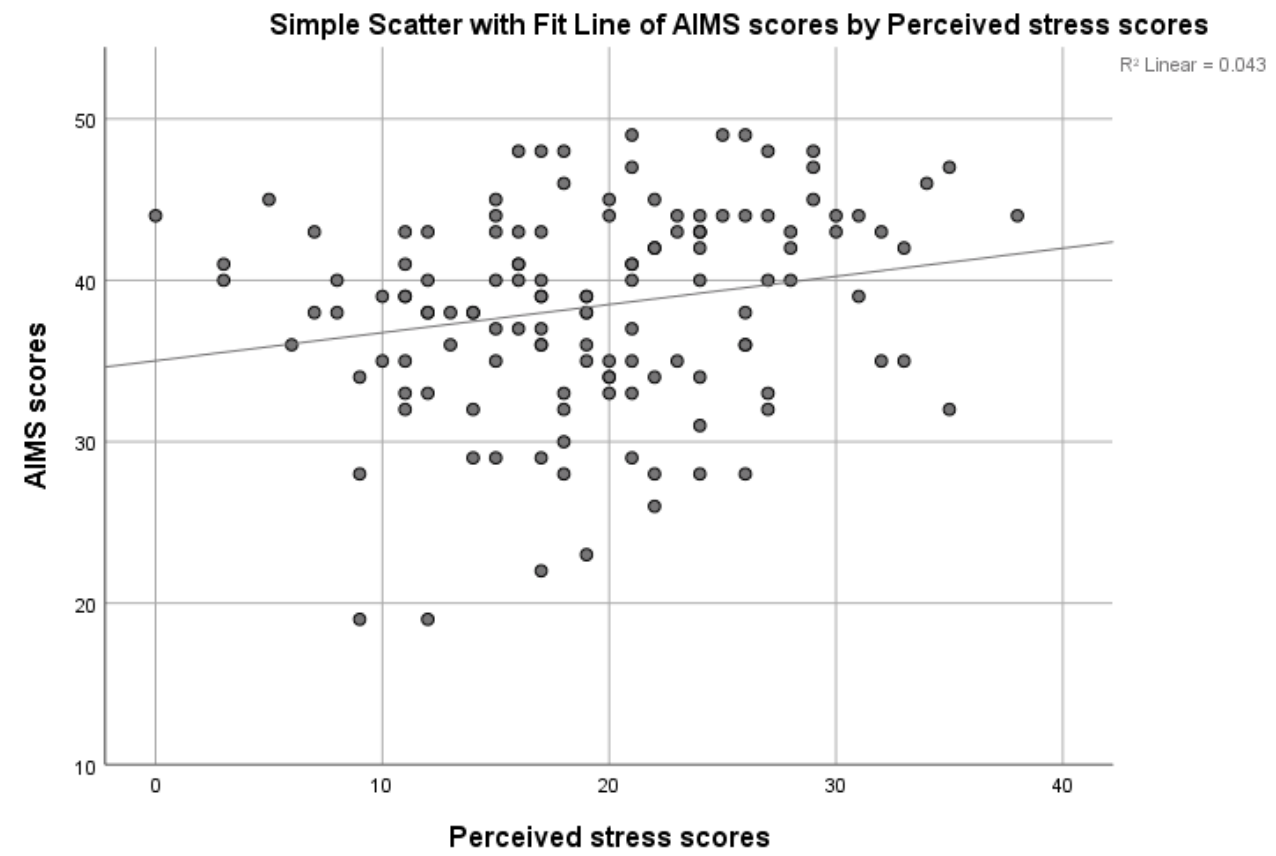

Figure 14. Scatterplot of athletic identity and perceived stress values.

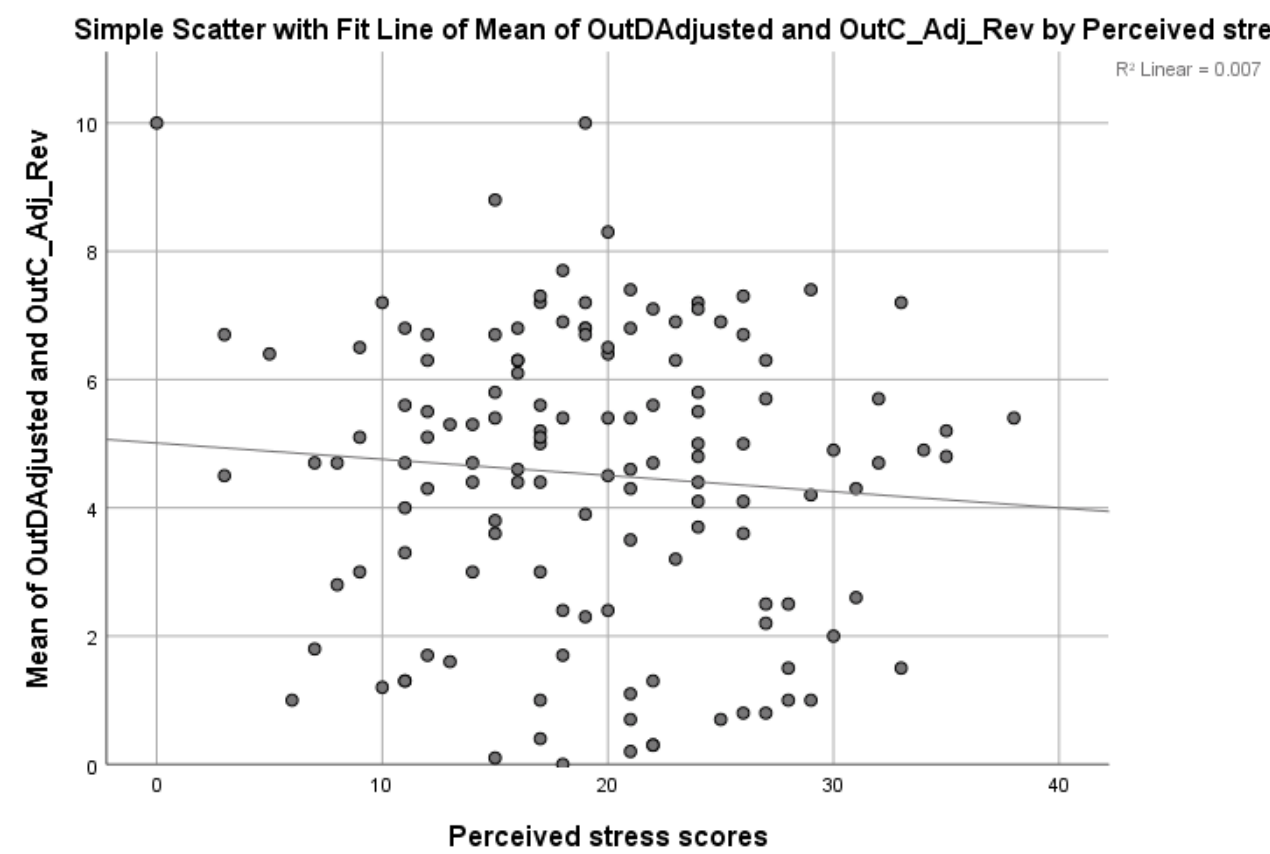

Figure 15. Scatterplot of outness and perceived stress values. 


\section{APPENDIX H}

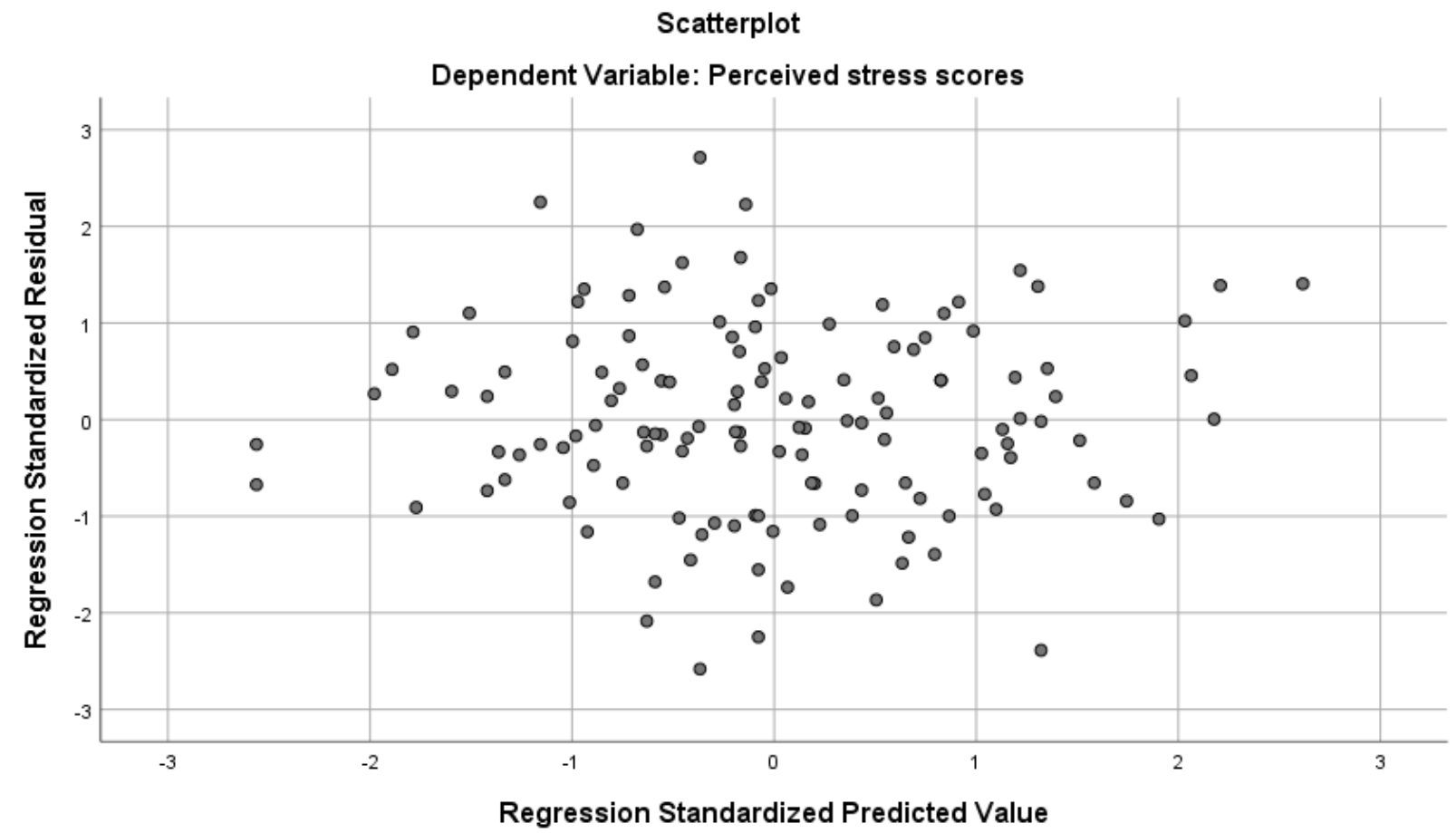

Figure 16. Plot of residuals and predicted values for mediation of athletic identity and perceived stress by internalized heterosexism.

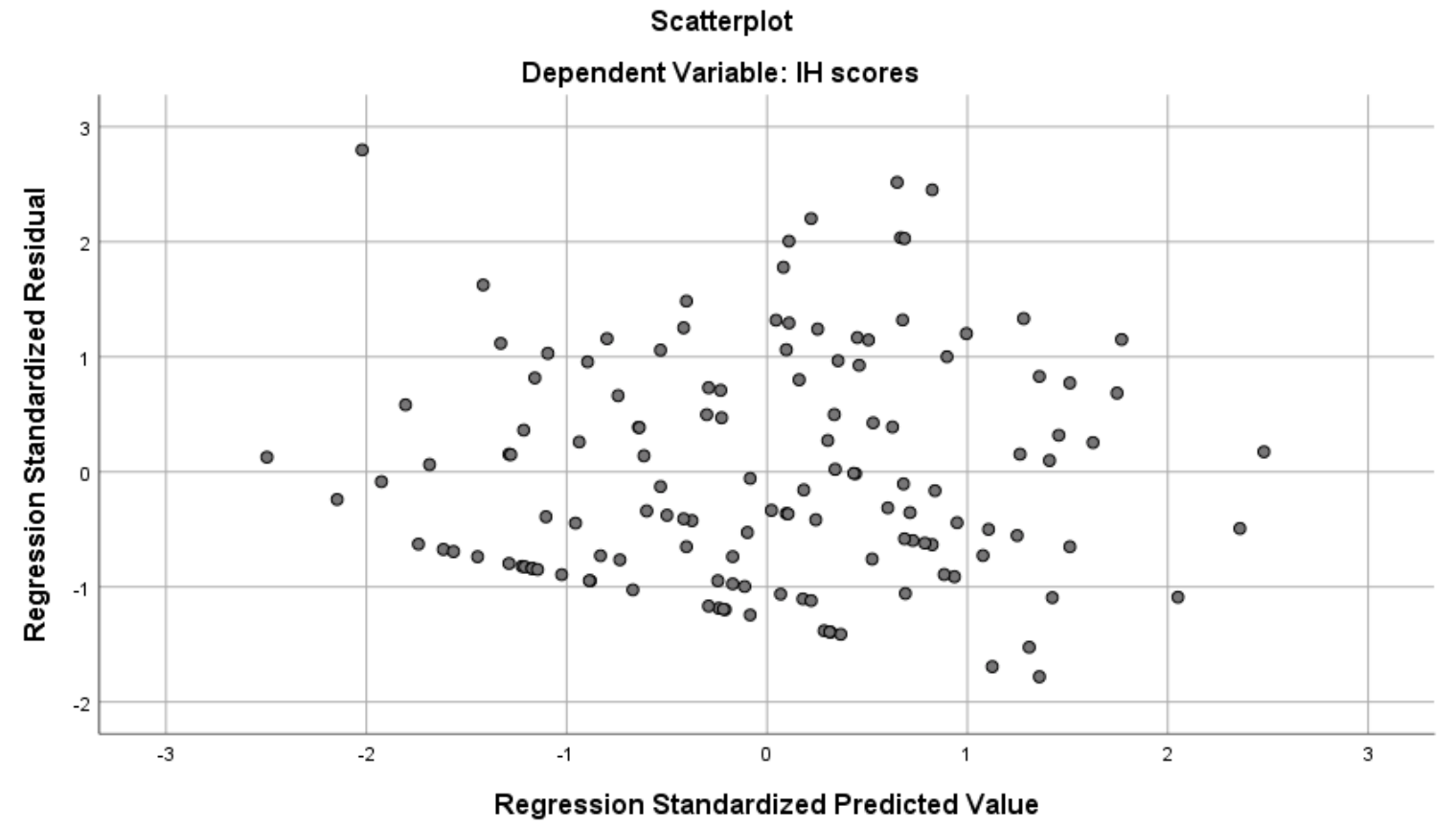

Figure 17. Plot of residuals and predicted values for regression with outness and athletic identity as predictors and internalized heterosexism as the outcome variable. 


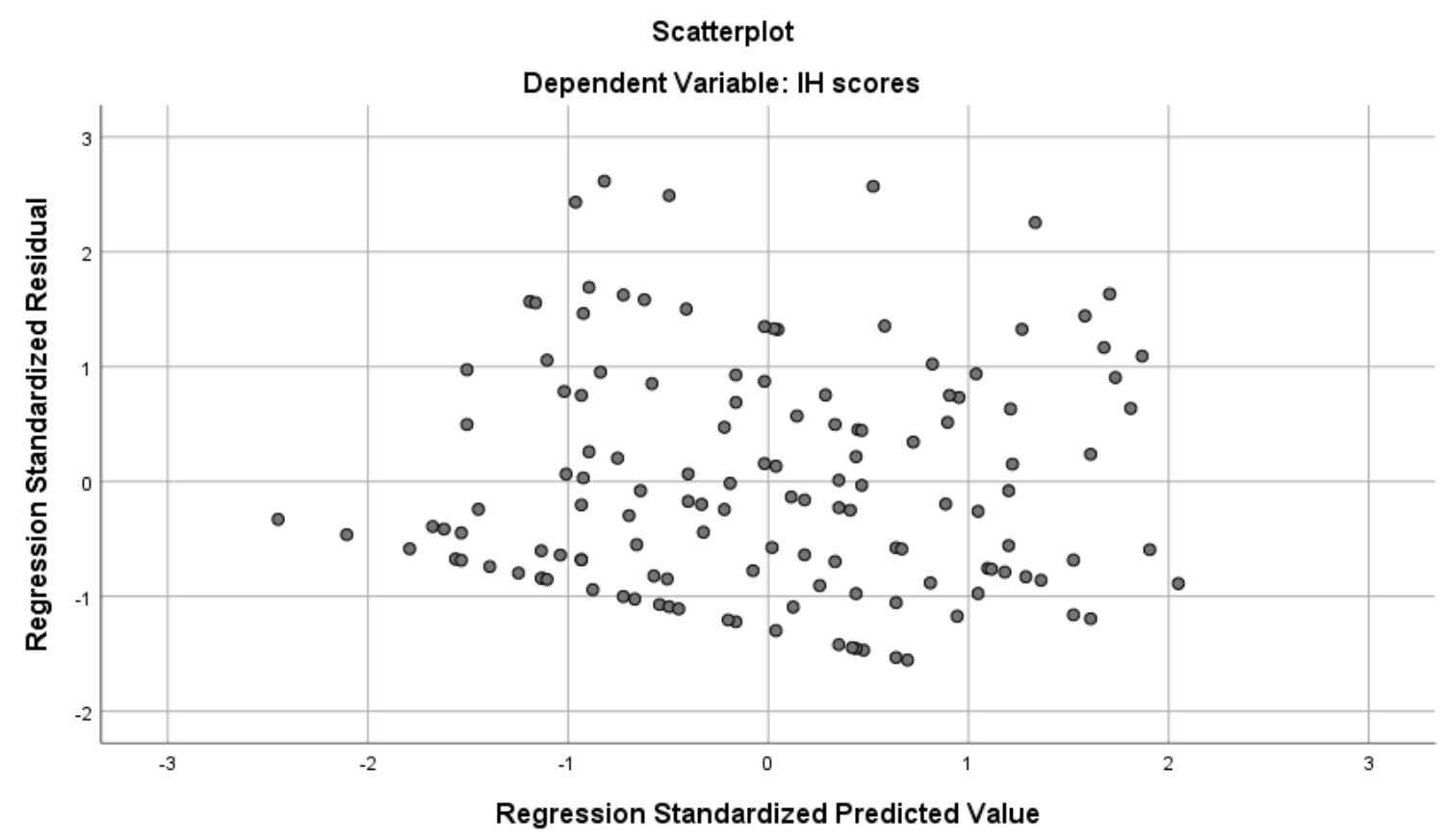

Figure 18. Plot of residuals and predicted values for regression with outness and religiosity as predictors and internalized heterosexism as the outcome variable.

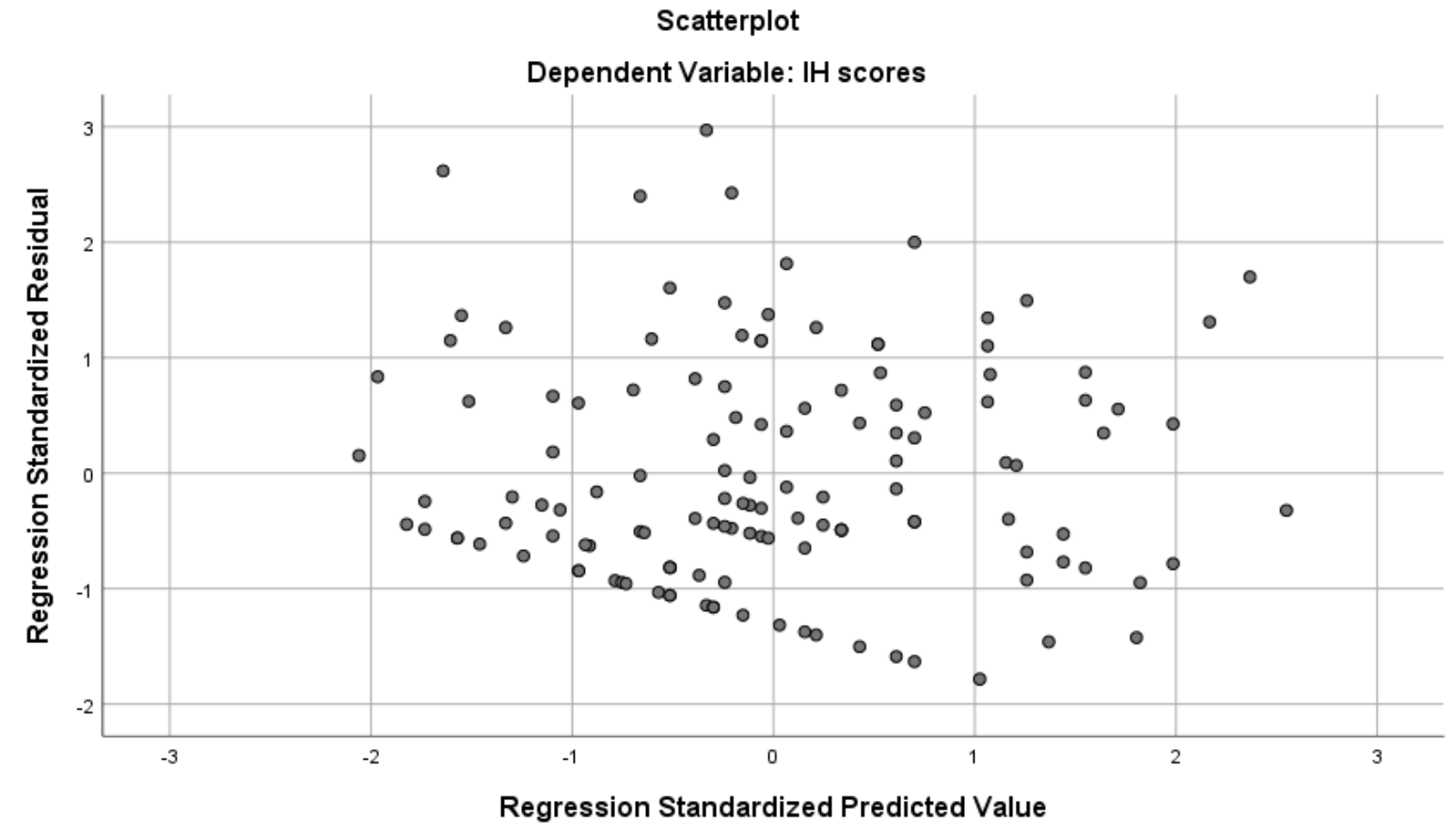

Figure 19. Plot of residuals and predicted values for regression with athletic identity and sexual orientation as predictors and internalized heterosexism as the outcome variable. 


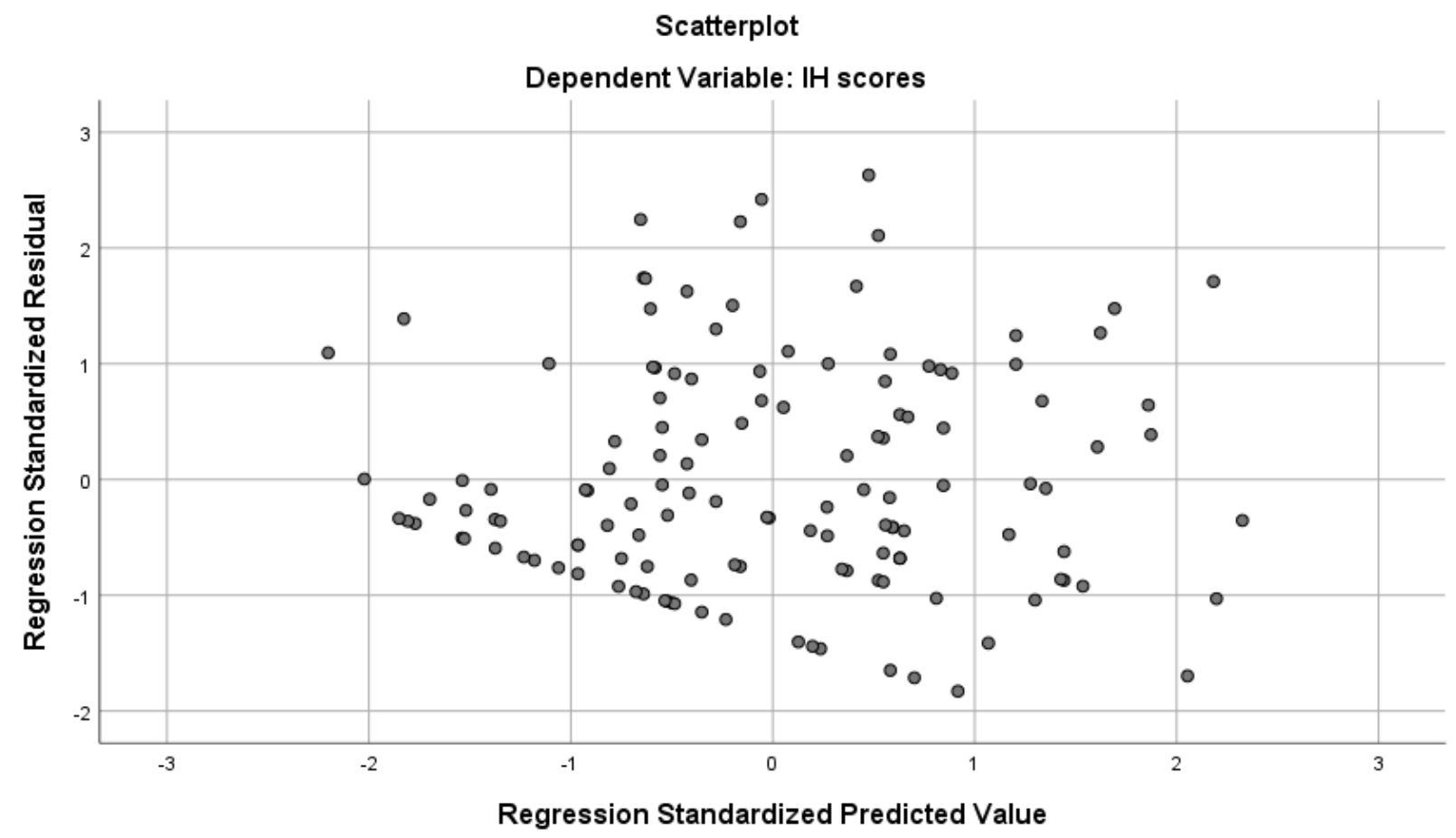

Figure 20. Plot of residuals and predicted values for regression with athletic identity, sexual orientation, and religiosity as predictors and internalized heterosexism as the outcome variable.

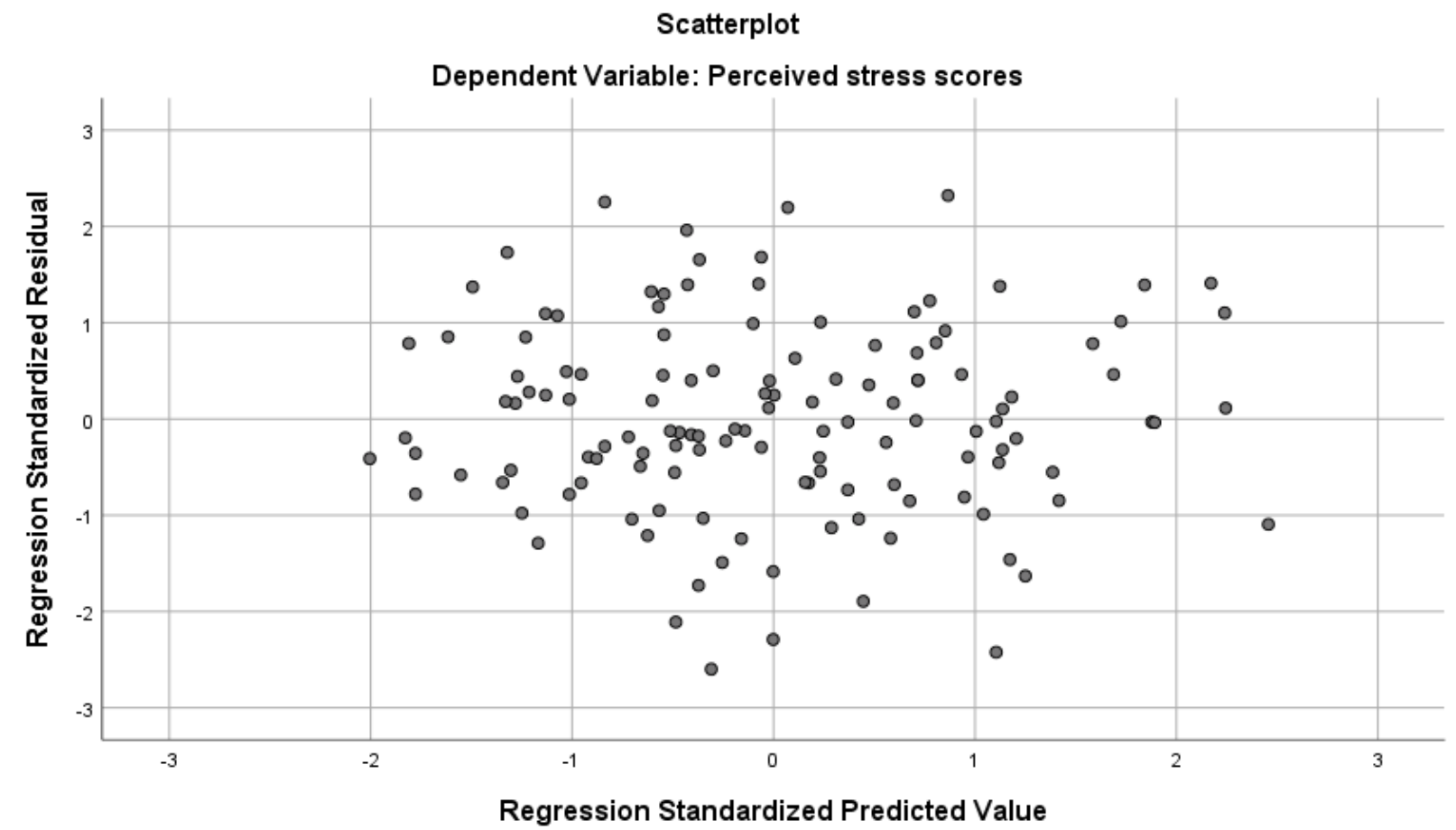

Figure 21. Plot of residuals and predicted values for regression with athletic identity, internalized heterosexism, and race as predictors and perceived stress as the outcome variable. 


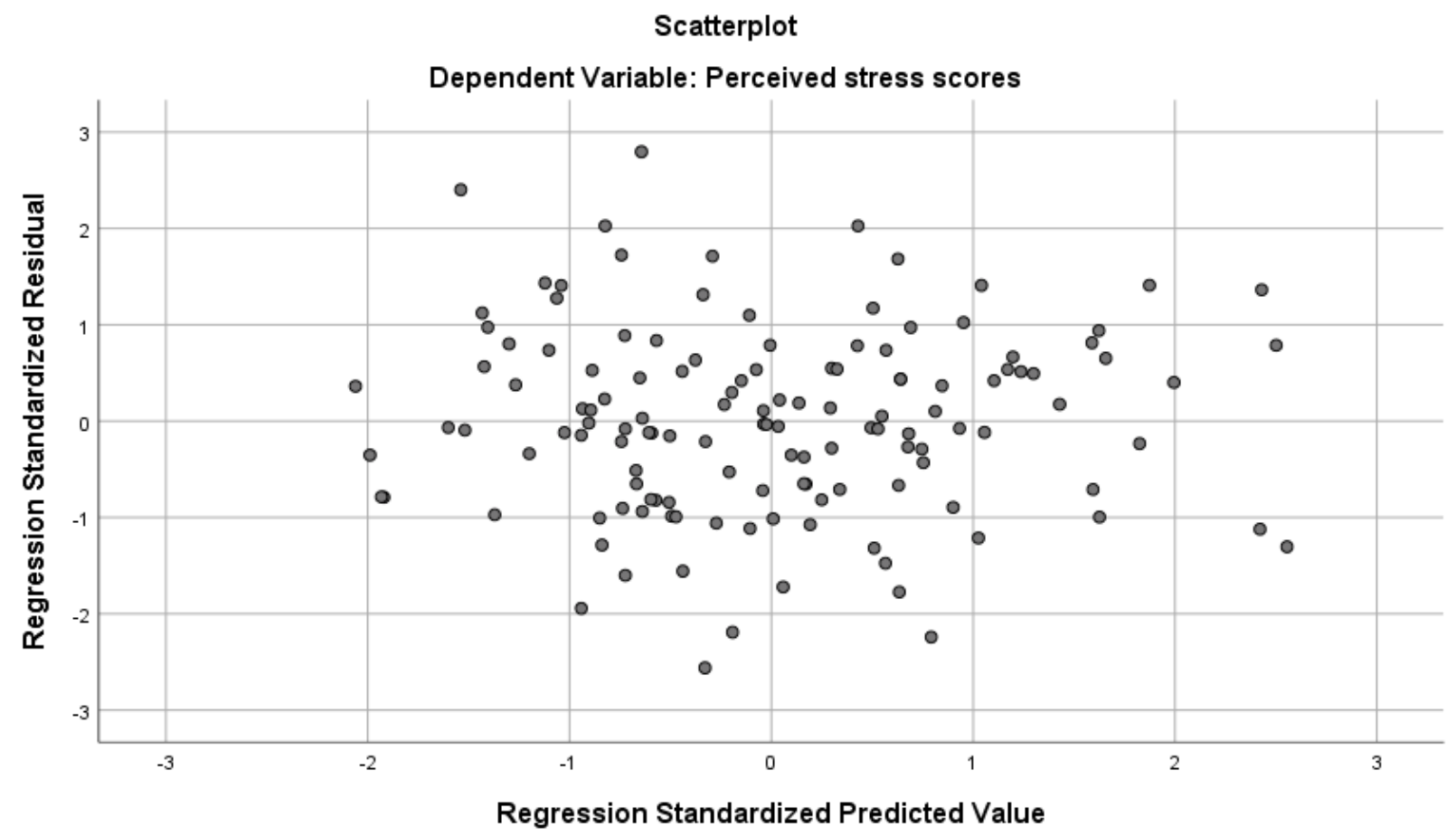

Figure 22. Plot of residuals and predicted values for regression with athletic identity, internalized heterosexism, and sport as predictors and perceived stress as the outcome variable.

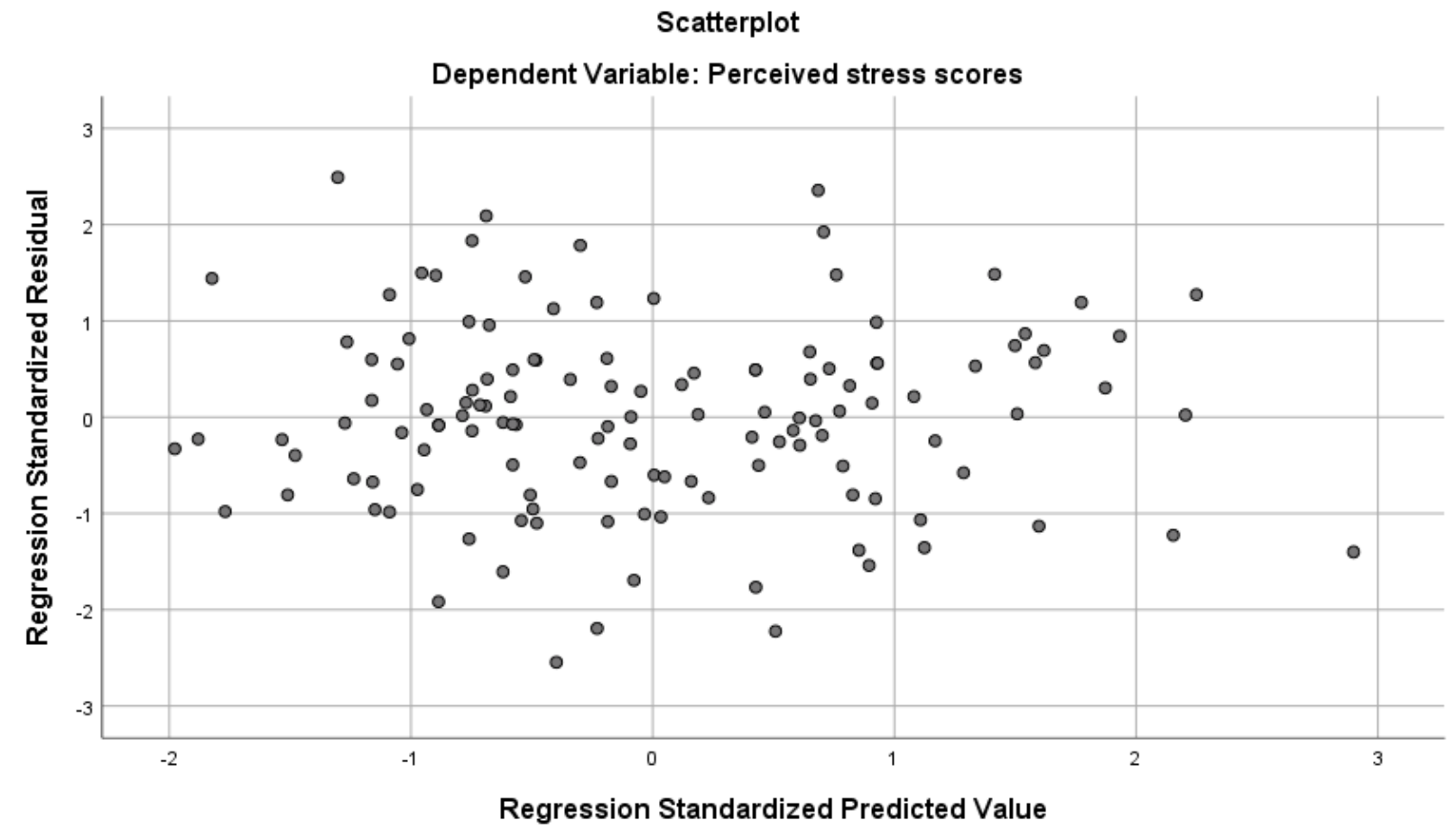

Figure 21. Plot of residuals and predicted values for regression with athletic identity, internalized heterosexism, race and sport as predictors and perceived stress as the outcome variable. 


\section{APPENDIX I}

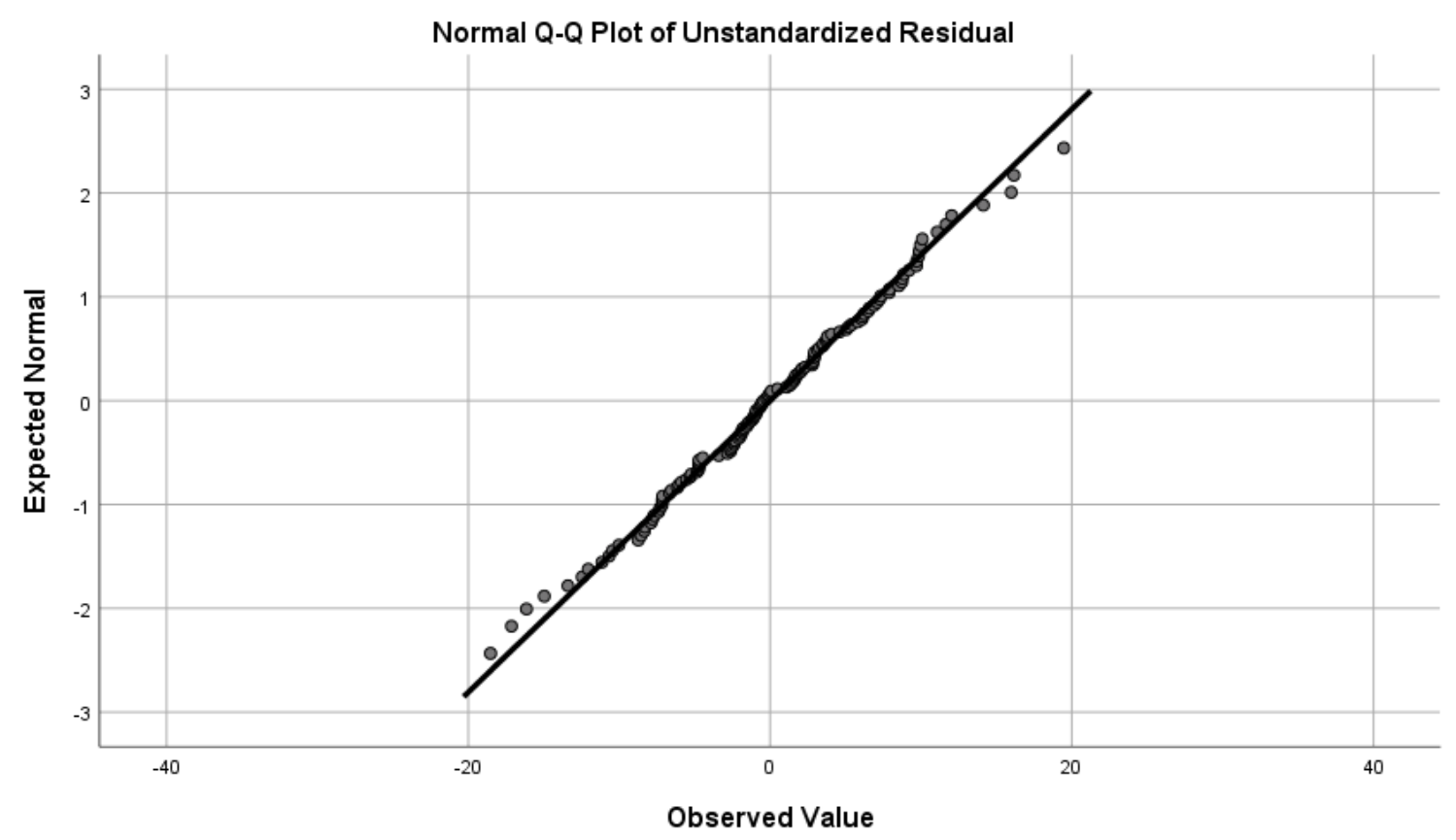

Figure 23. Plot of unstandardized residuals for mediation of athletic identity and perceived stress by internalized heterosexism.

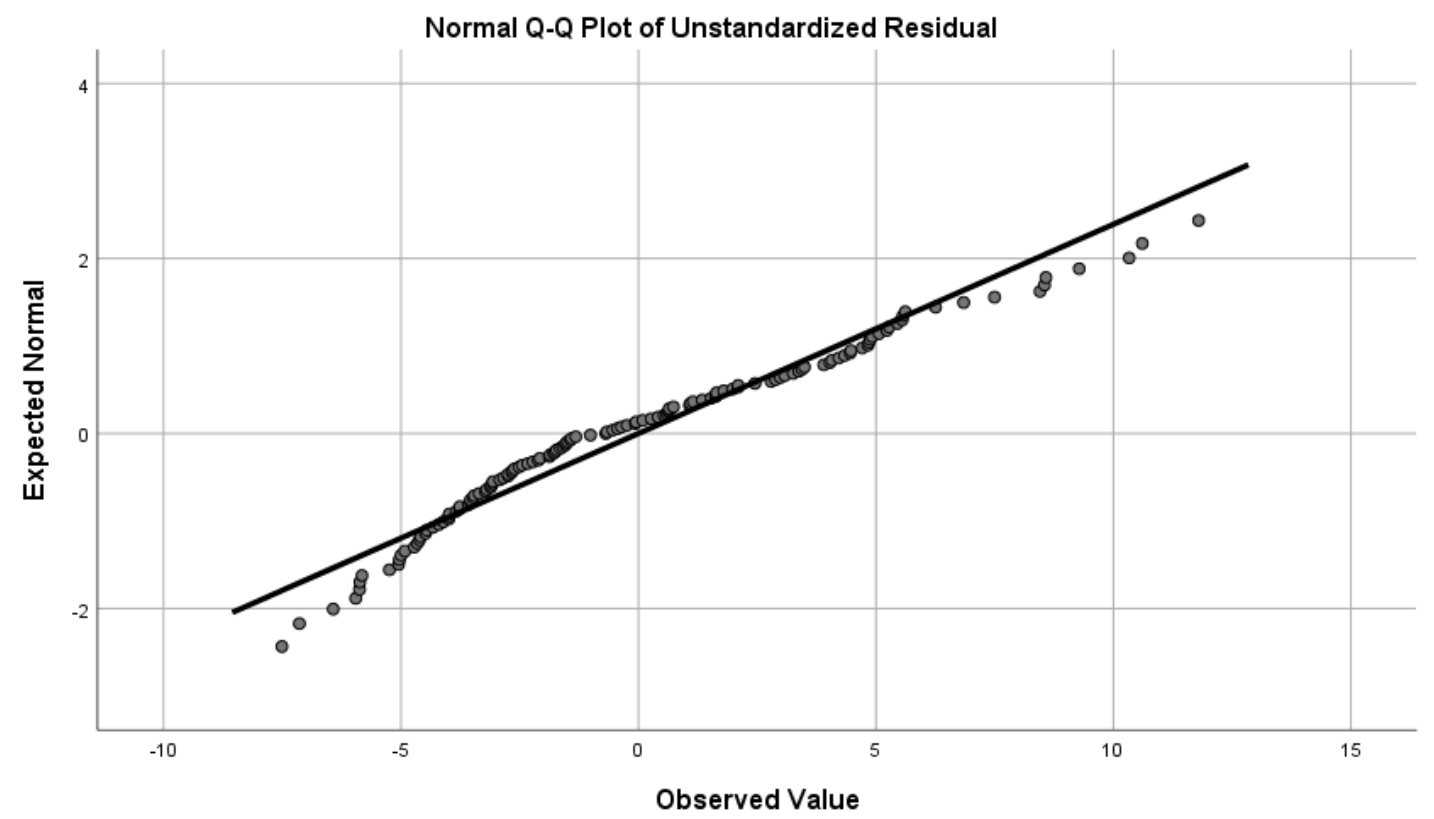

Figure 24. Plot of unstandardized residuals for regression with outness and athletic identity as predictors and internalized heterosexism as the outcome variable. 


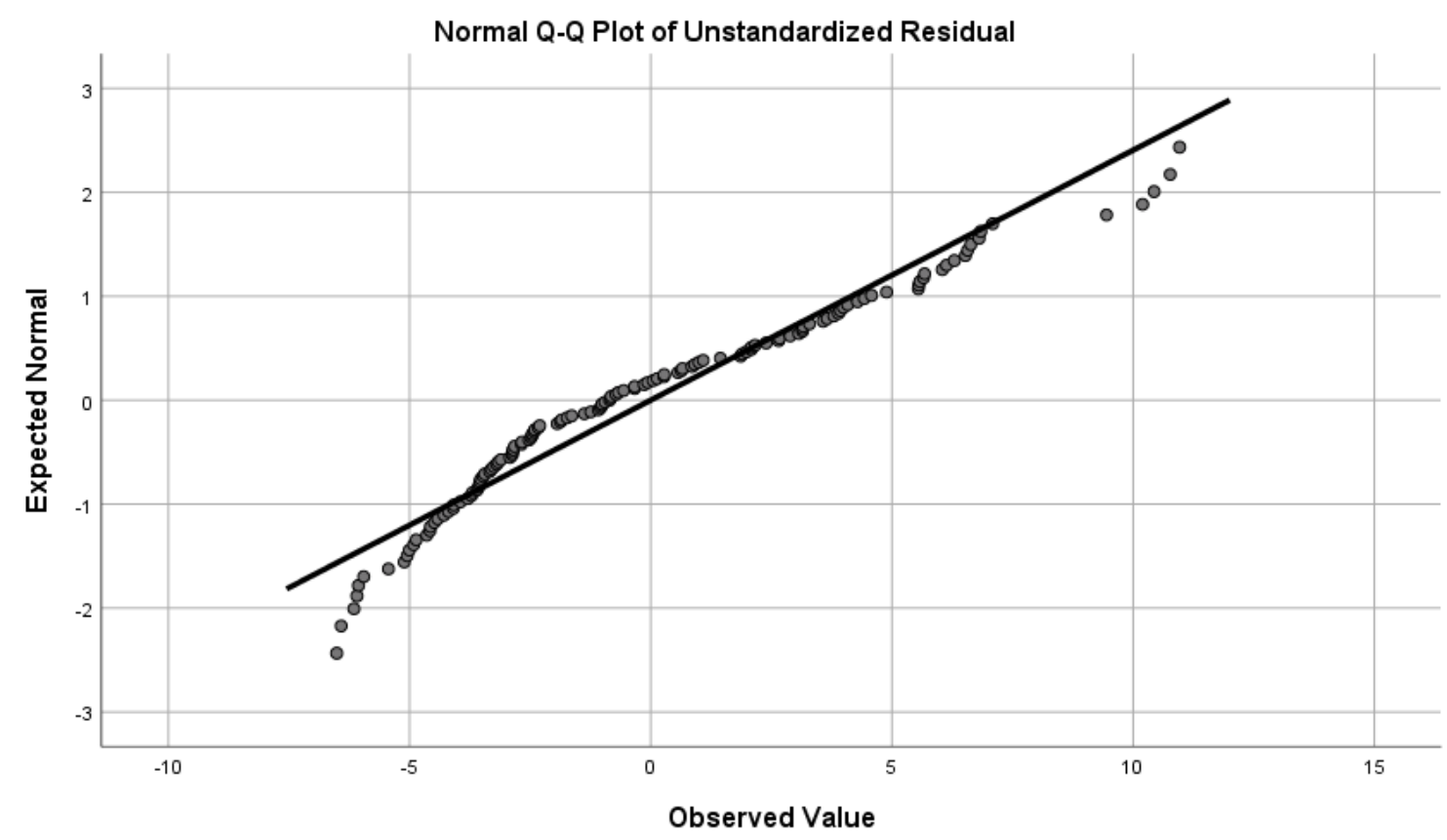

Figure 25. Plot of unstandardized residuals for regression with outness and religiosity as predictors and internalized heterosexism as the outcome variable.

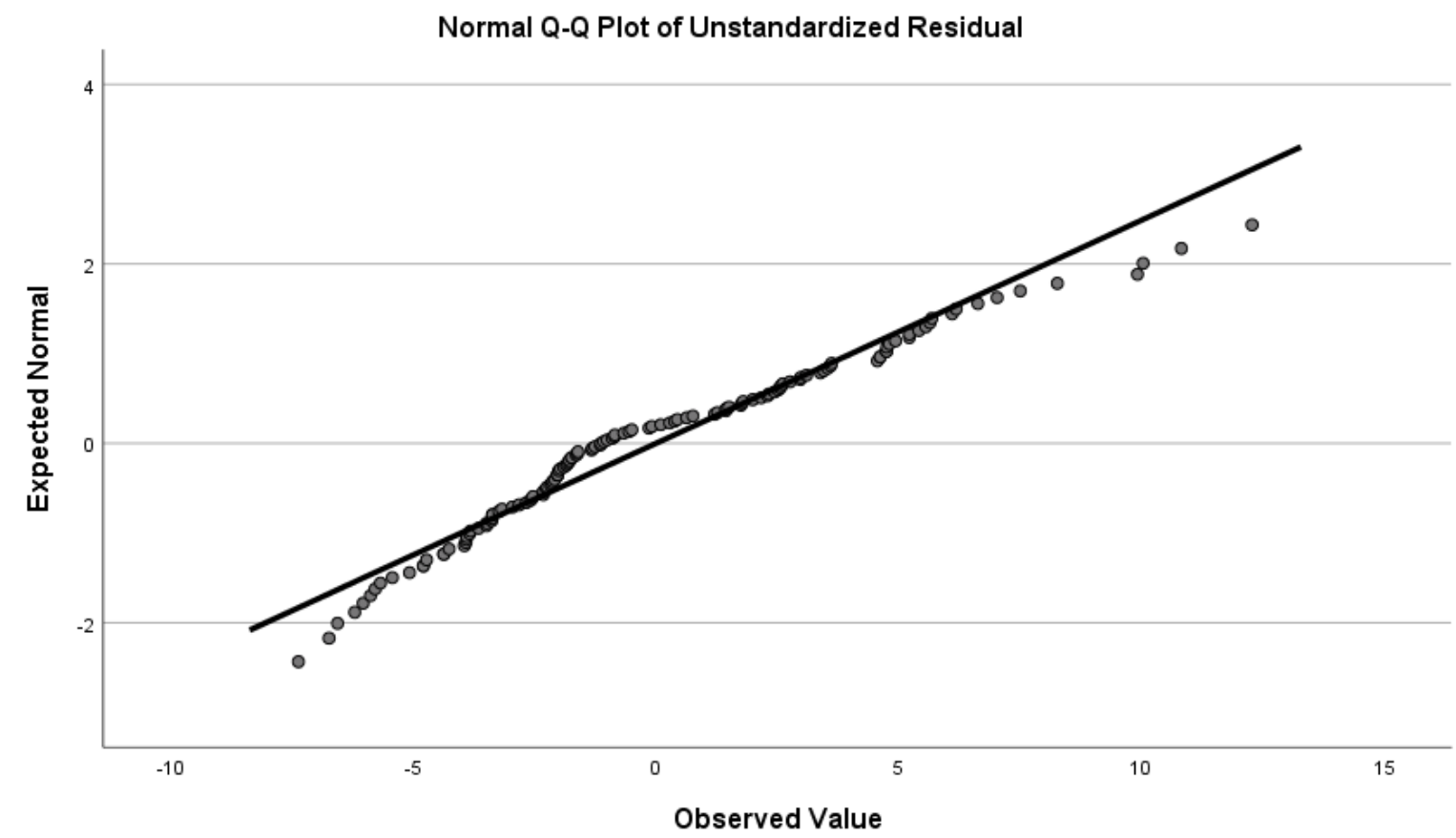

Figure 26. Plot of unstandardized residuals for regression with athletic identity and sexual orientation as predictors and internalized heterosexism as the outcome variable. 


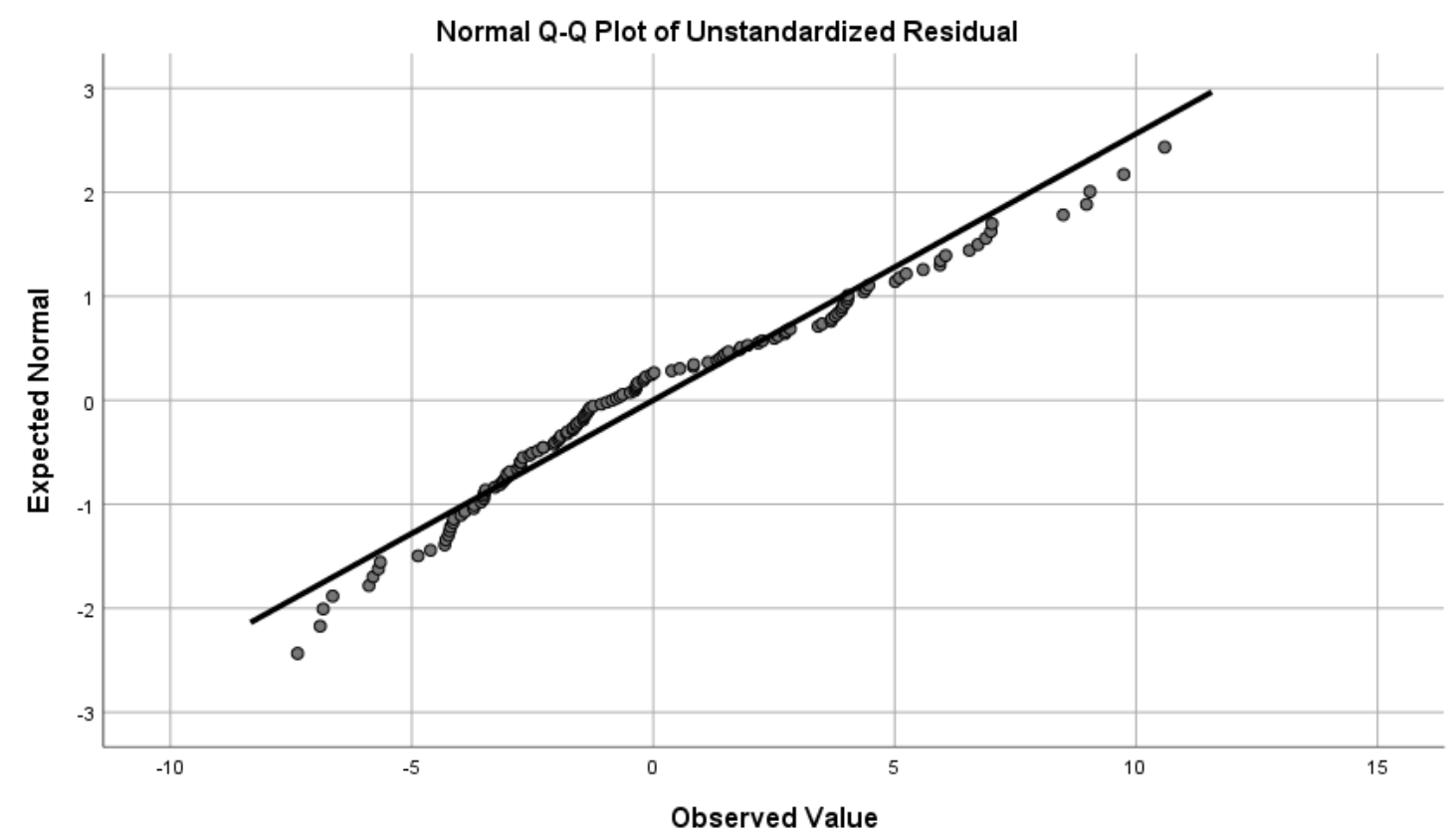

Figure 27. Plot of unstandardized residuals for regression with athletic identity, sexual orientation, and religiosity as predictors and internalized heterosexism as the outcome variable.

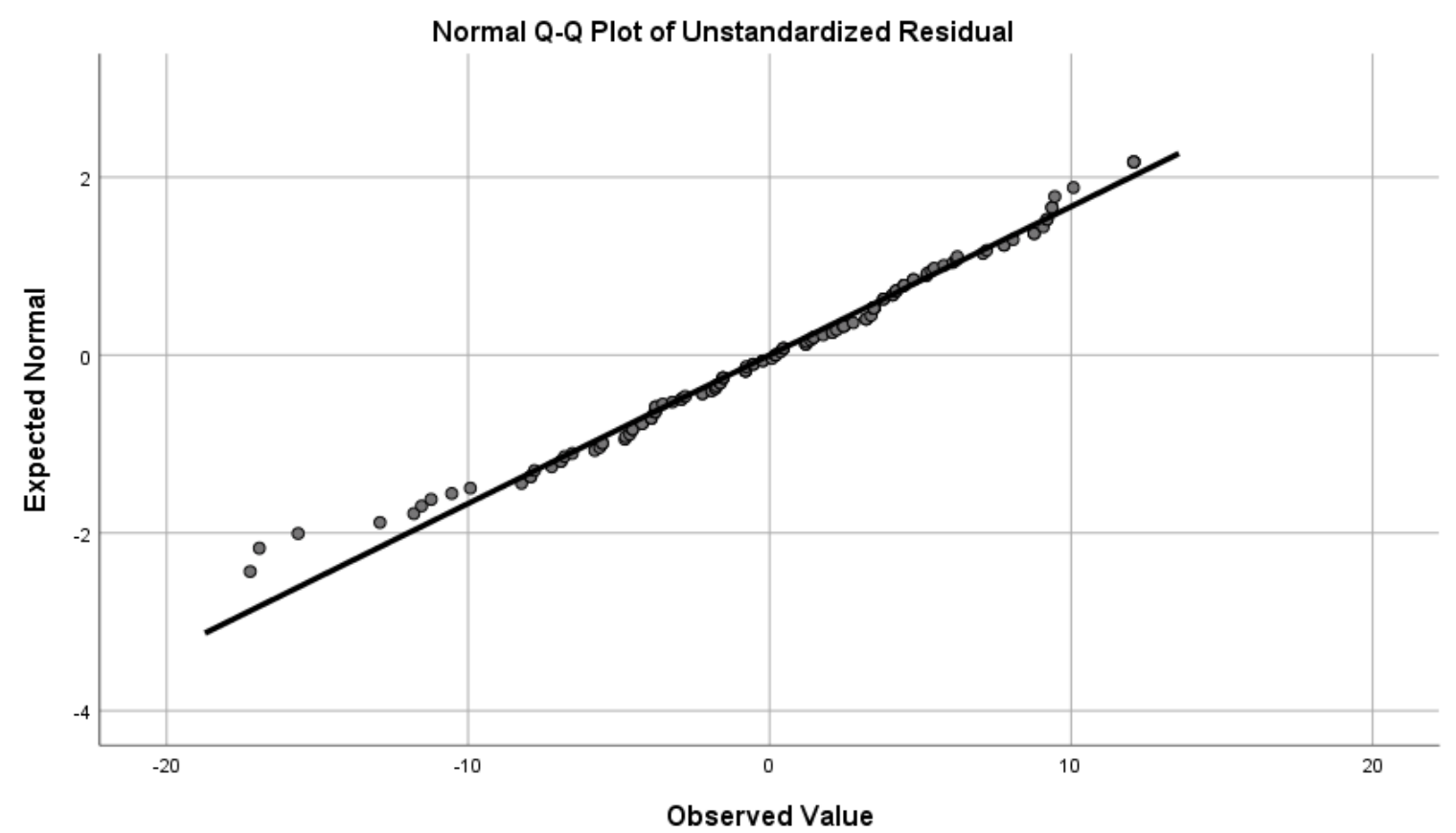

Figure 28. Plot of unstandardized residuals for regression with sport played as the predictor and athletic identity as the outcome variable. 


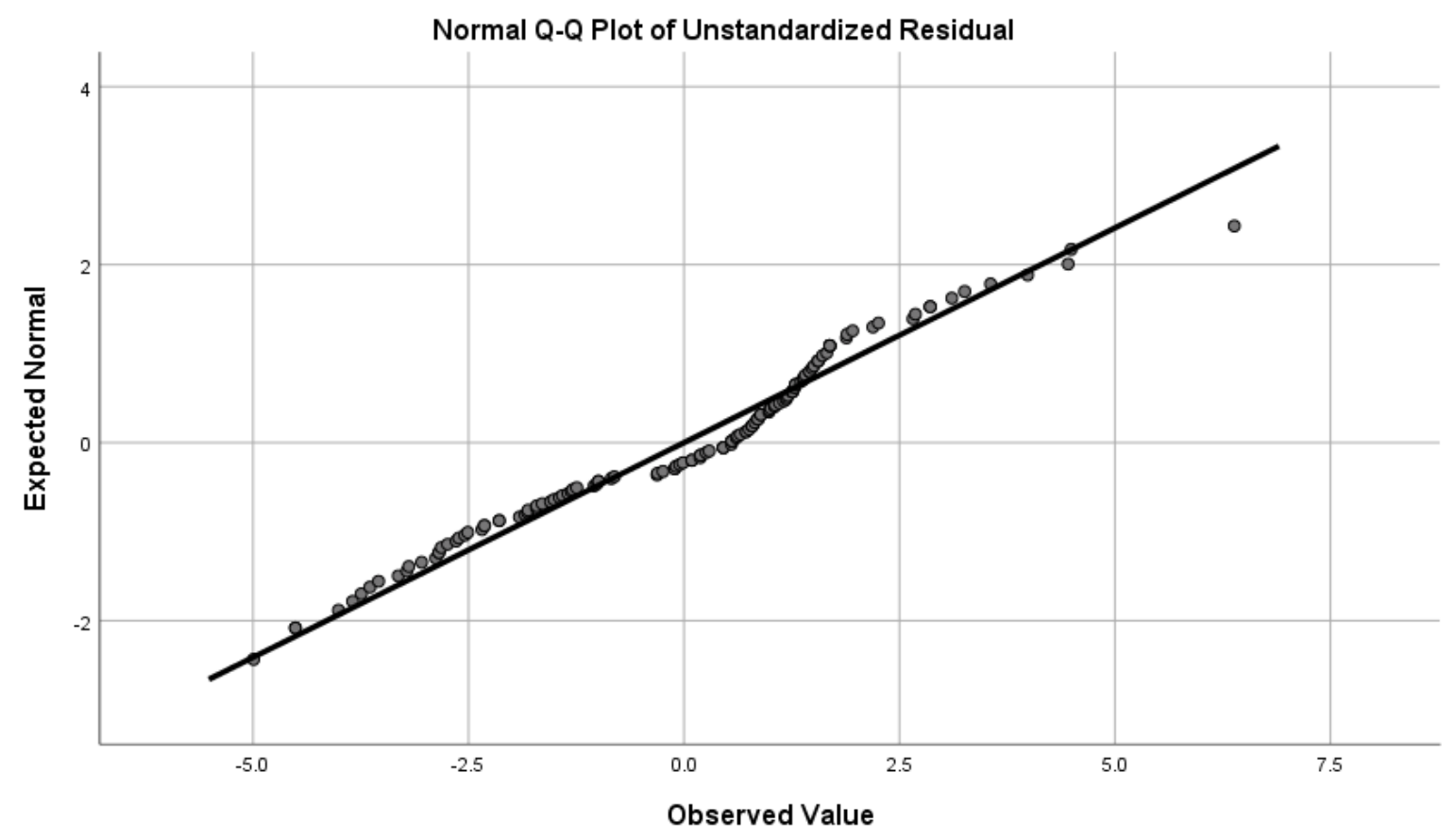

Figure 29. Plot of unstandardized residuals for regression with sexual orientation as the predictor and outness as the outcome variable.

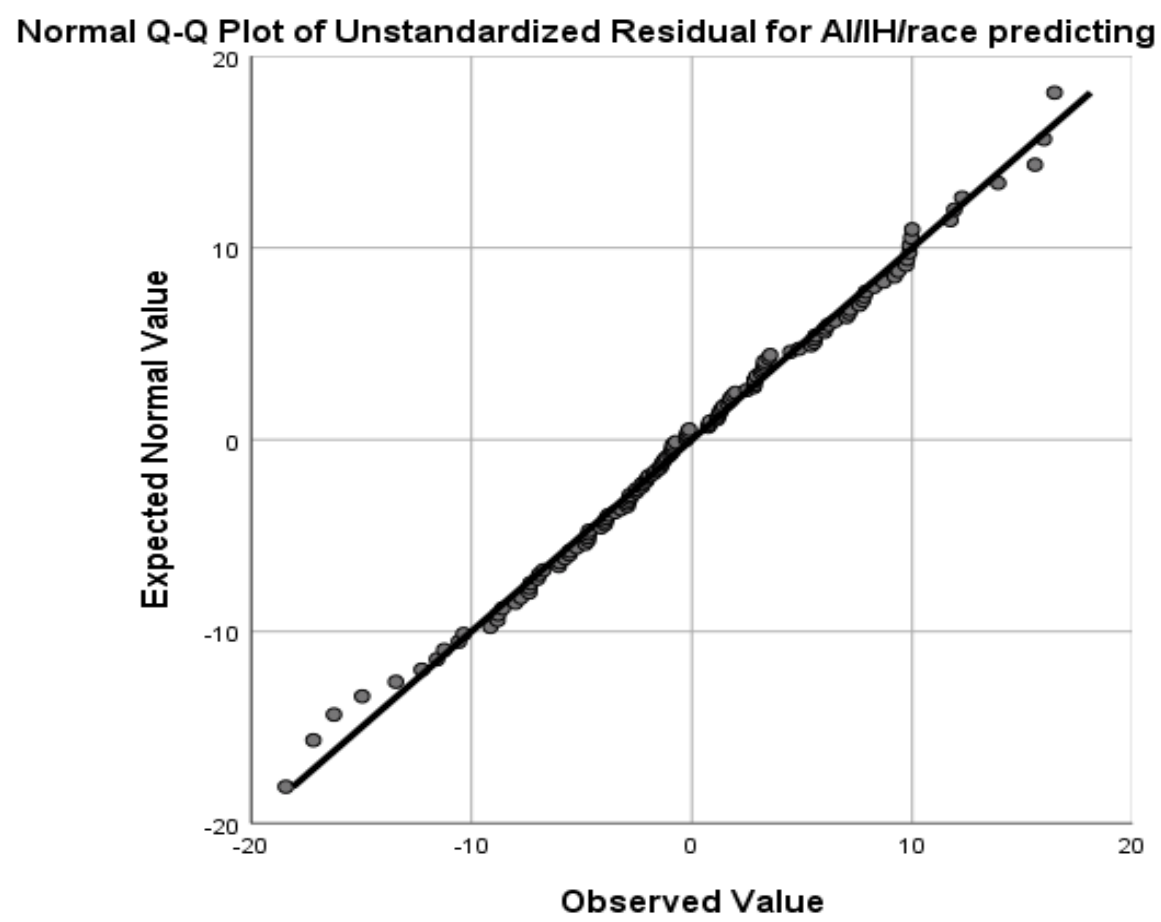

Figure 30. Plot of unstandardized residuals for regression with athletic identity, internalized heterosexism, and race as predictors and perceived stress as the outcome variable. 


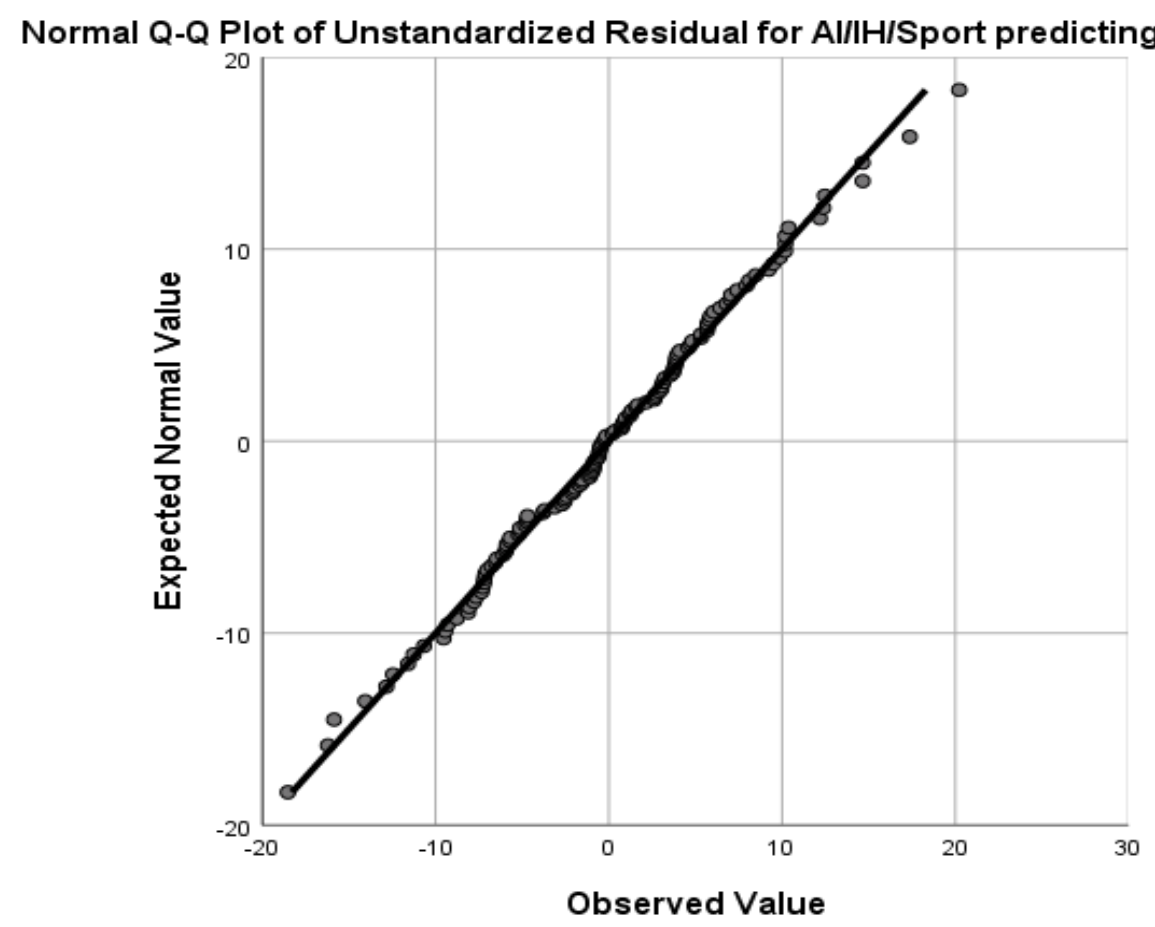

Figure 31. Plot of unstandardized residuals for regression with athletic identity, internalized heterosexism, and sport as predictors and perceived stress as the outcome variable.

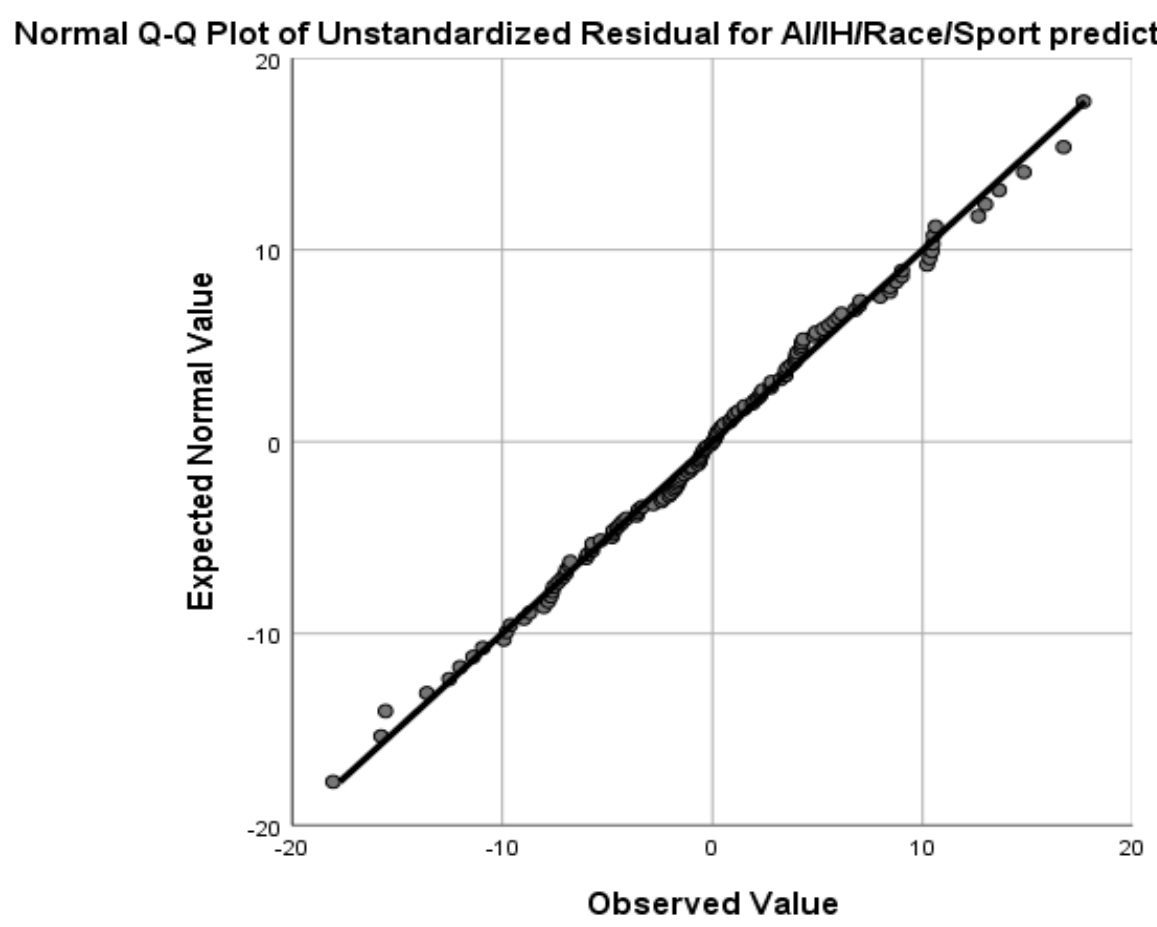

Figure 32. Plot of unstandardized residuals for regression with athletic identity, internalized heterosexism, race, and sport as predicotrs and perceived stress as the outcome variable. 


\section{APPENDIX J}

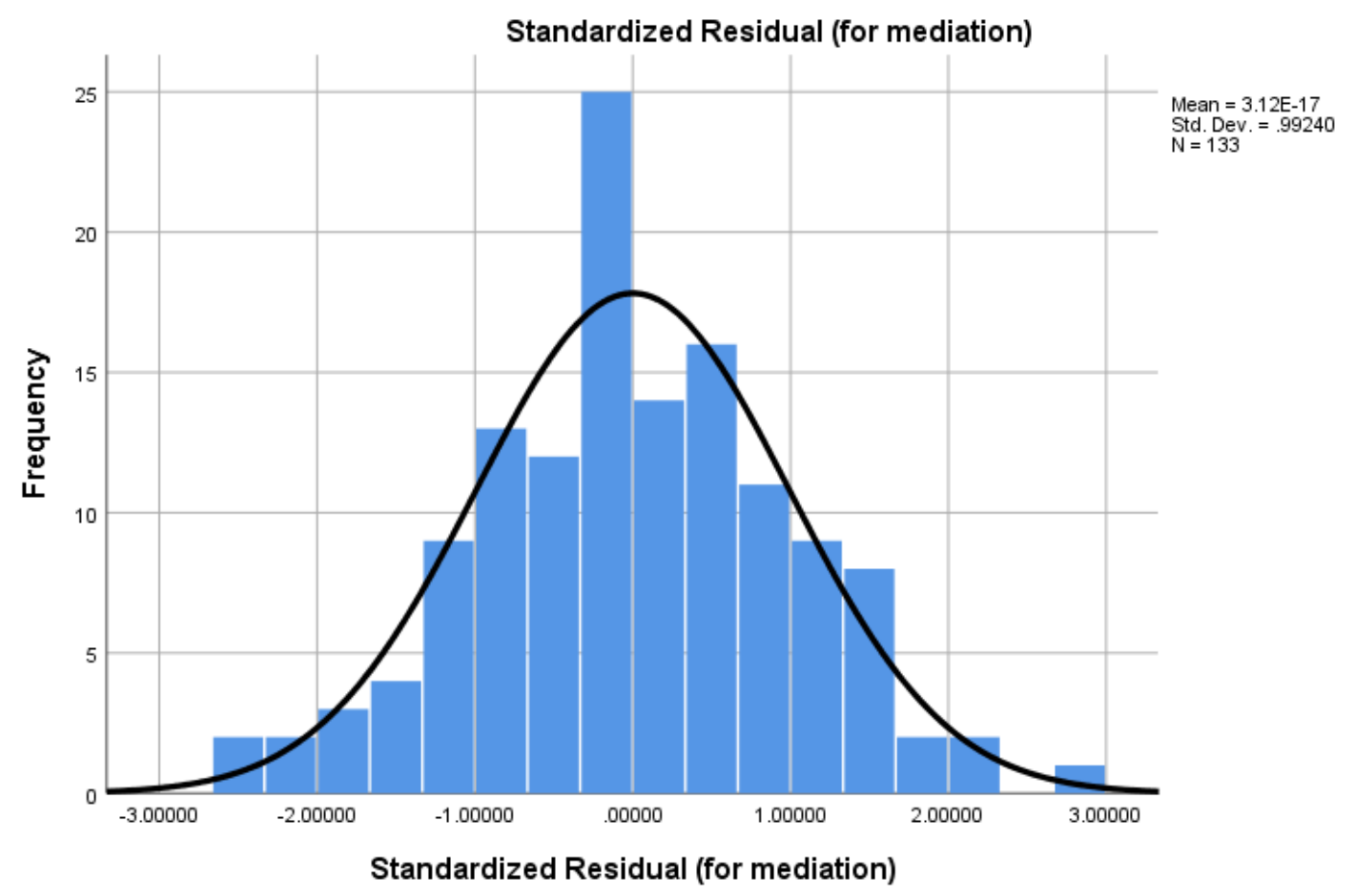

Figure 33. Histogram of standardized residuals for mediation of athletic identity and perceived stress by internalized heterosexism.

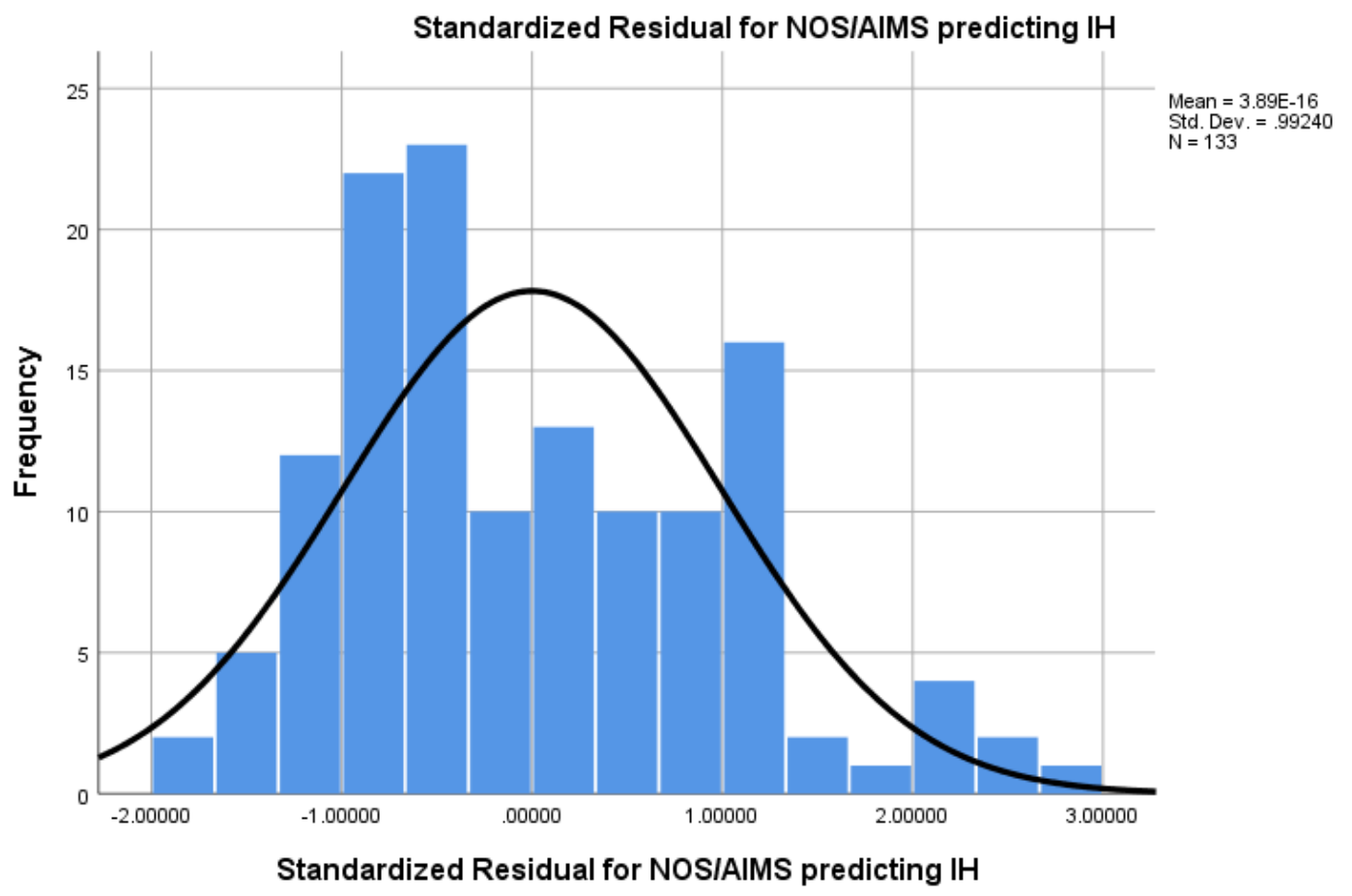

Figure 34. Histogram of standardized residuals for regression with outness and athletic identity as predictors and internalized heterosexism as the outcome variable. 


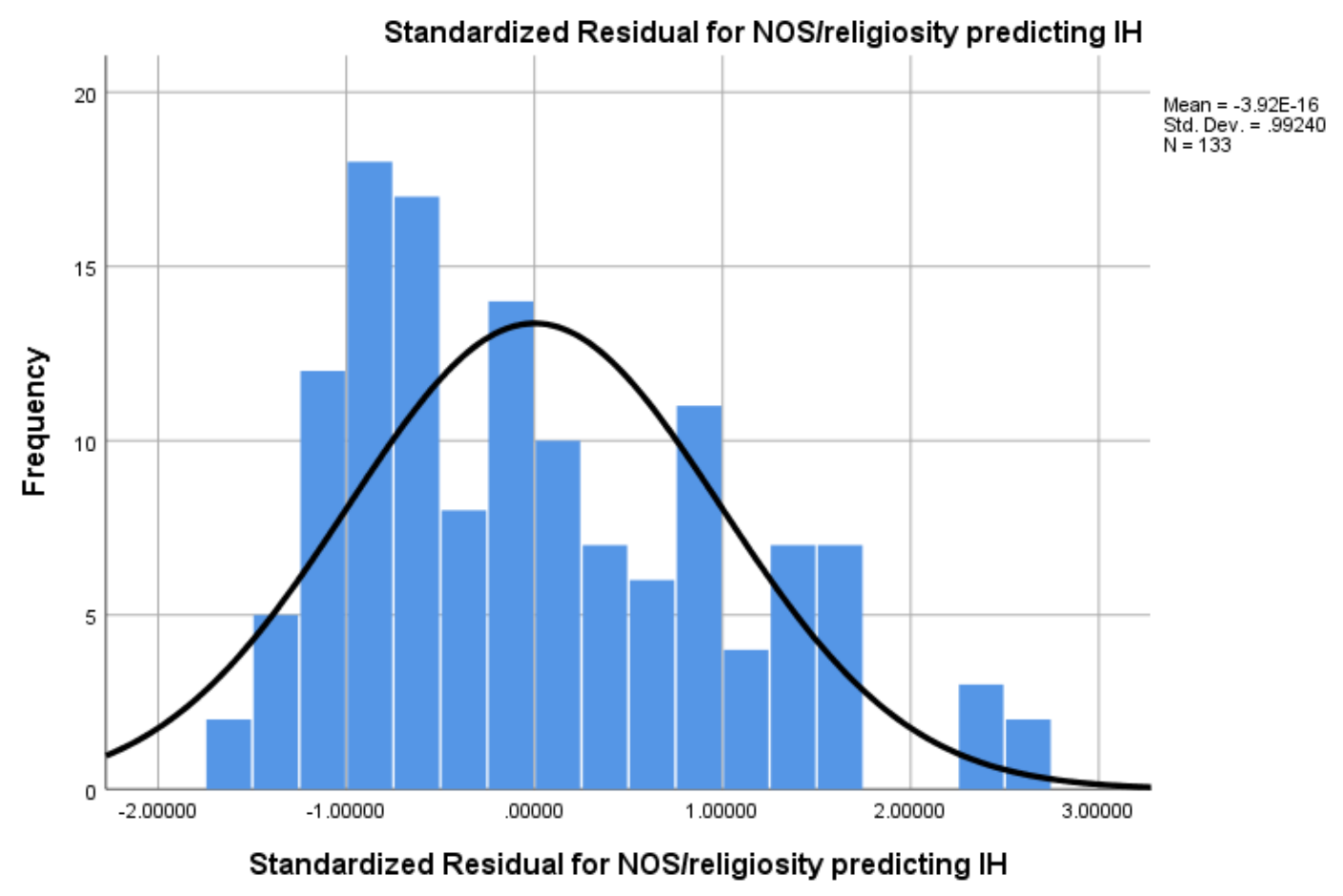

Figure 35. Histogram of standardized residuals for regression with outness and religiosity as predictors and internalized heterosexism as the outcome variable.

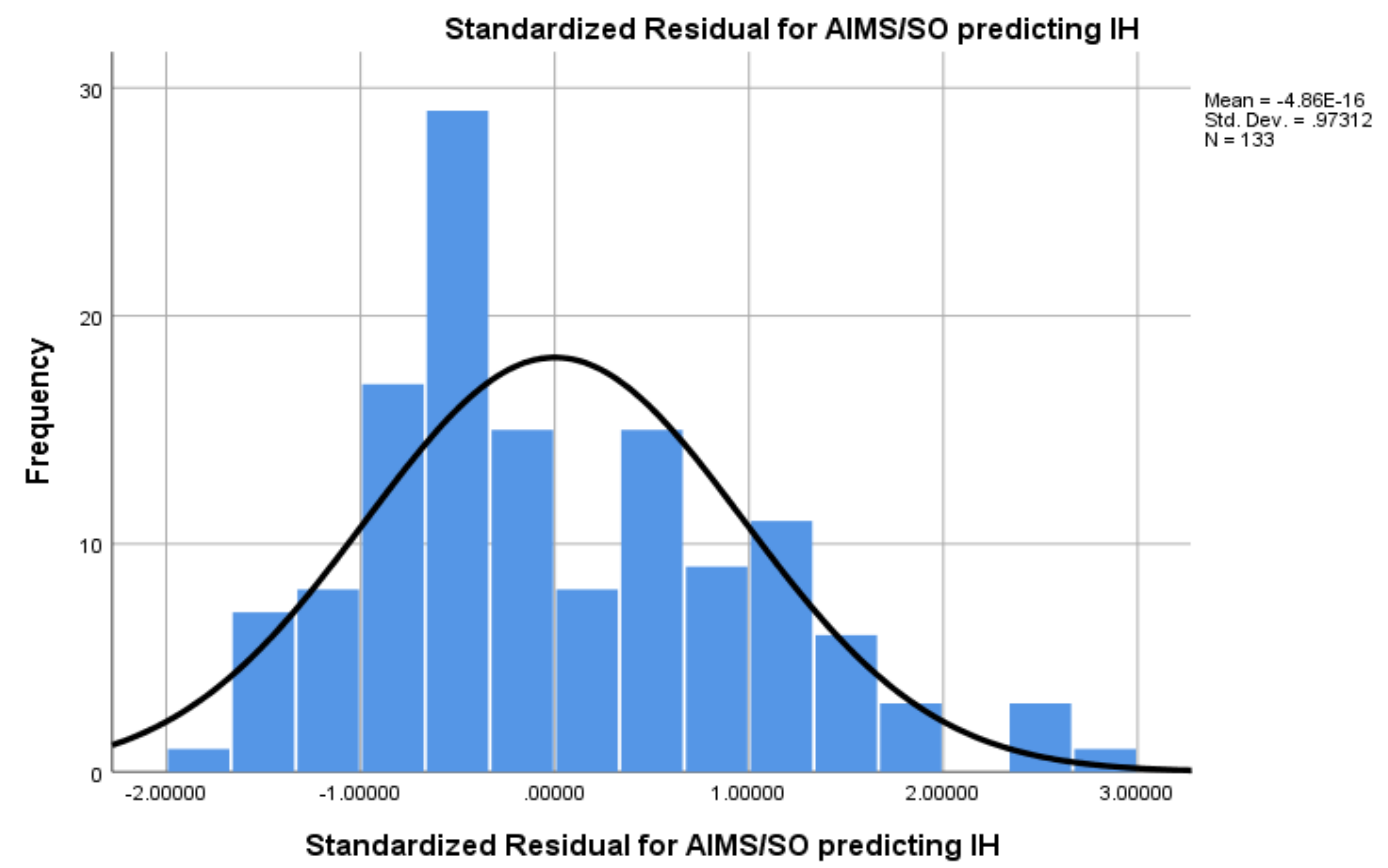

Figure 36. Histogram of standardized residuals for regression with athletic identity and sexual orientation as predictors and internalized heterosexism as the outcome variable. 


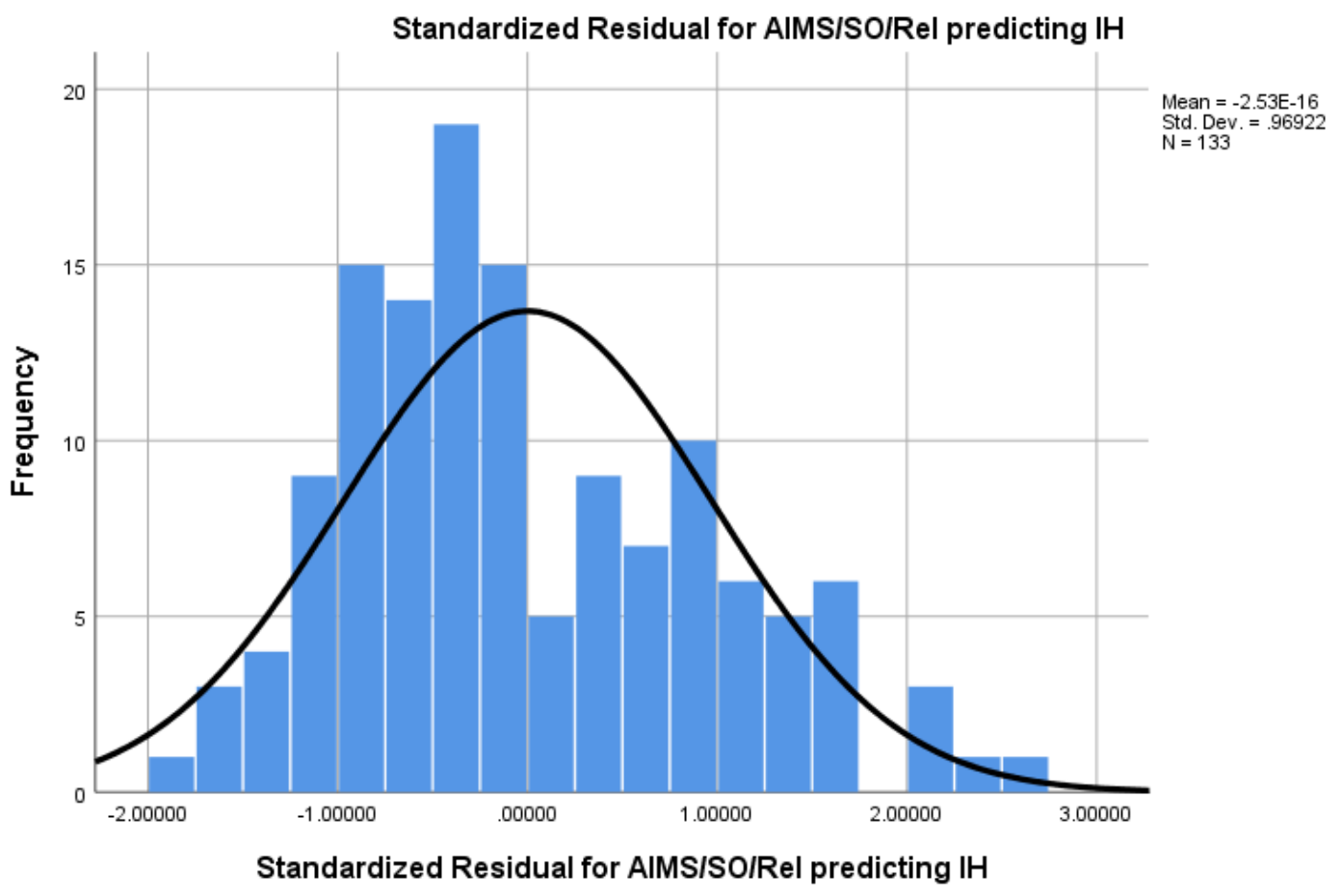

Figure 37. Histogram of standardized residuals for regression with athletic identity, sexual orientation, and religiosity as predictors and internalized heterosexism as the outcome variable.

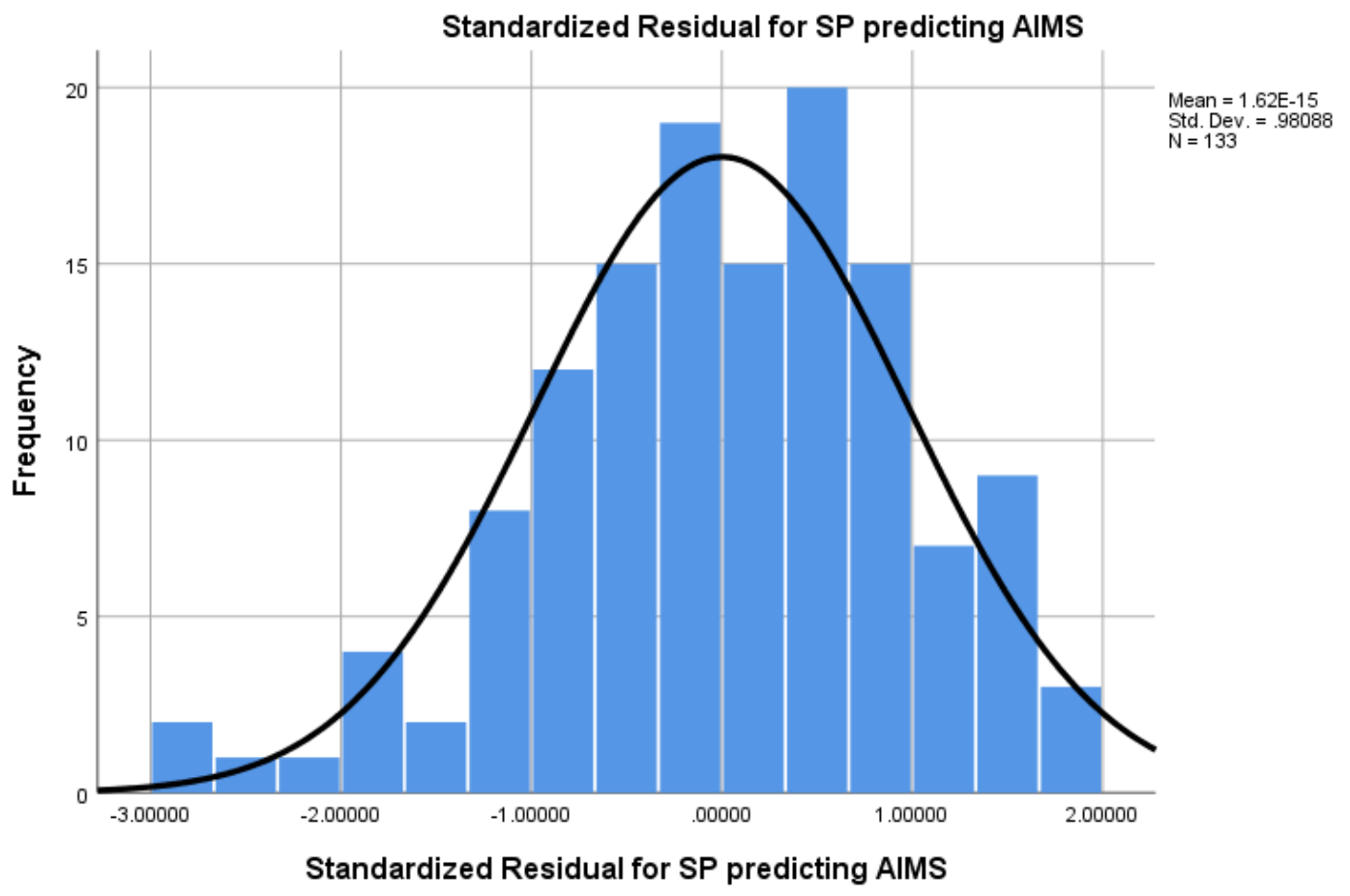

Figure 38. Histogram of standardized residuals for regression with sport played as the predictor and athletic identity as the outcome variable. 


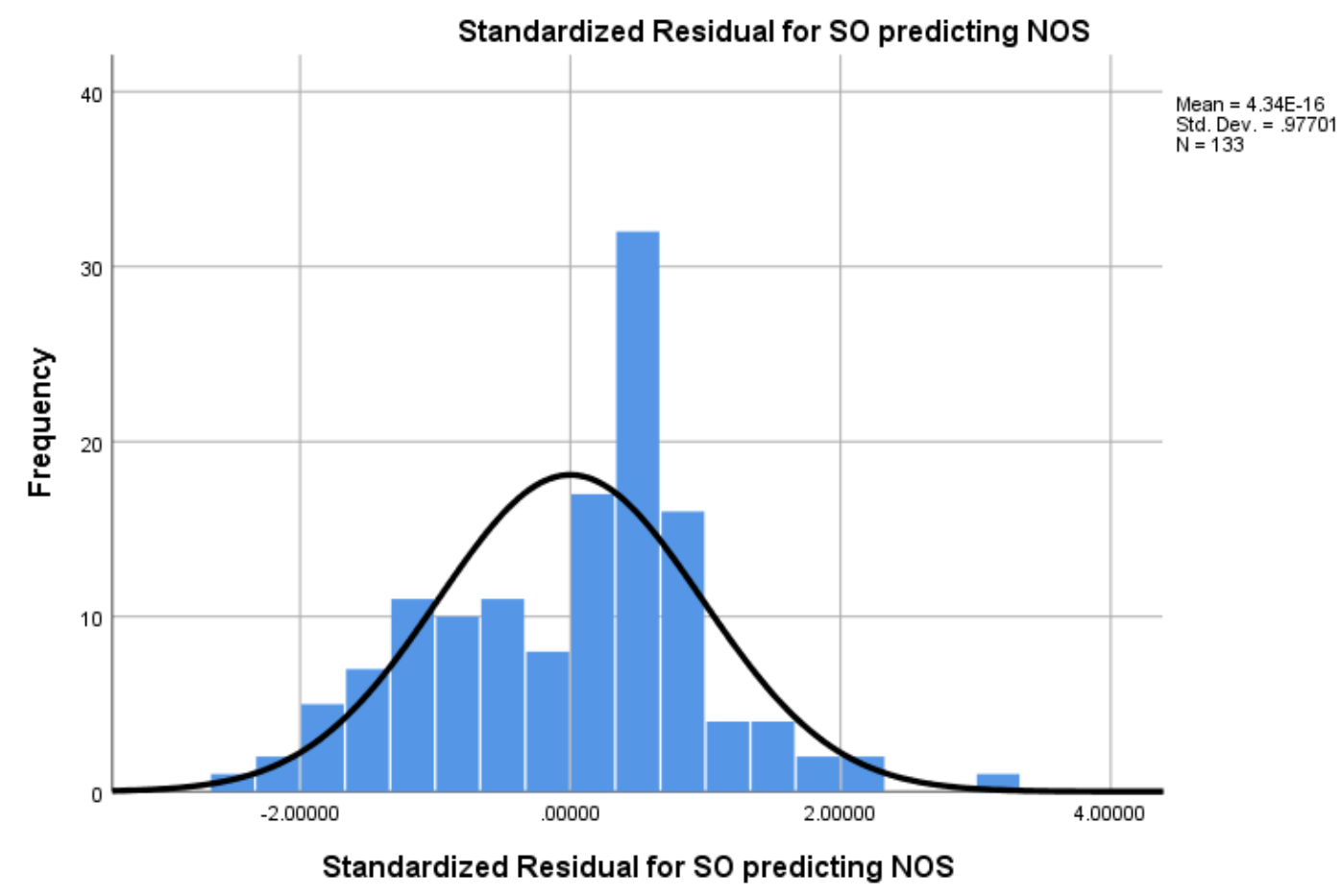

Figure 39. Histogram of standardized residuals for regression with sexual orientation as the predictor and outness as the outcome variable.

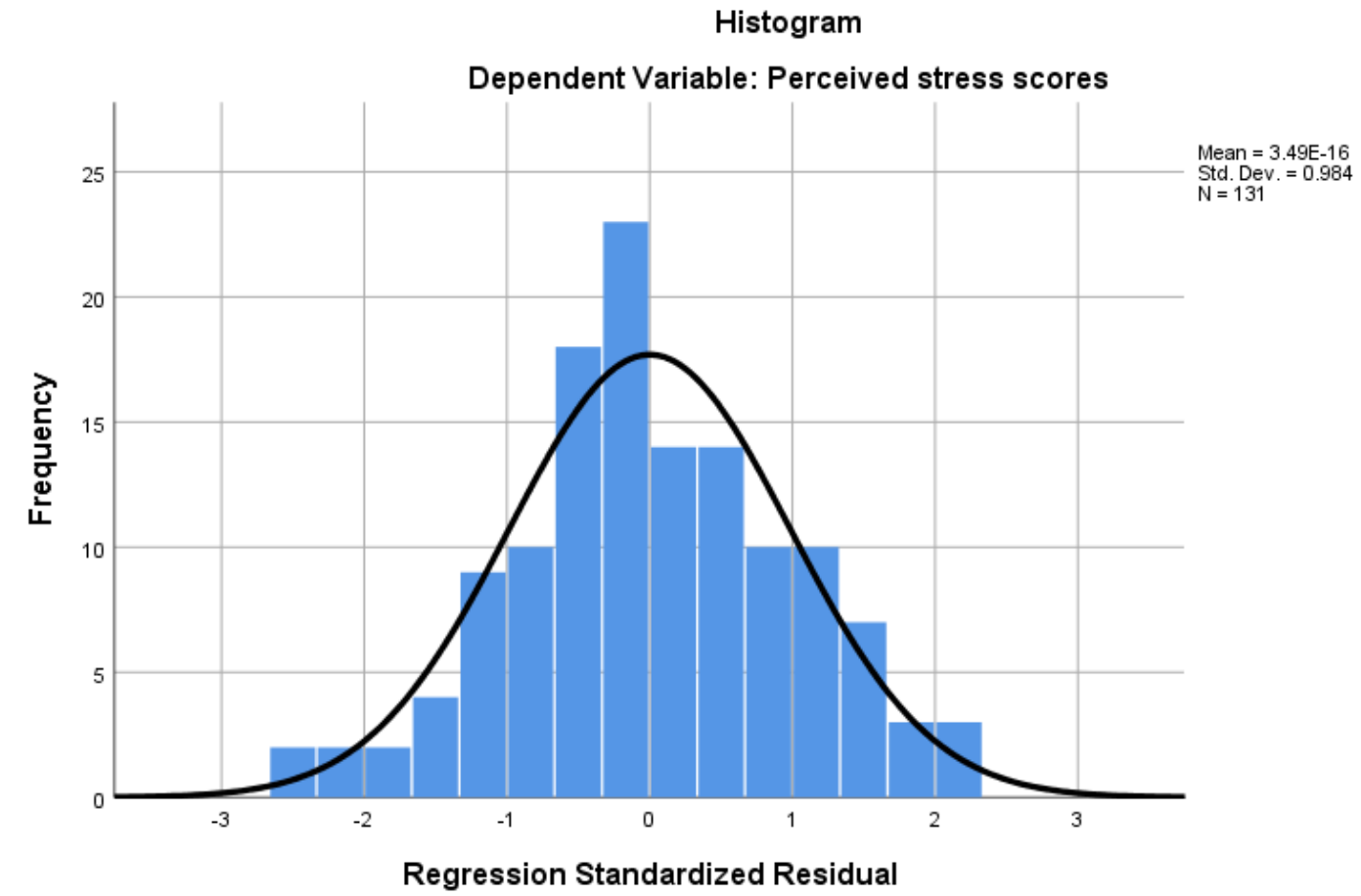

Figure 40. Histogram of standardized residuals for regression with athletic identity, internalized heterosexism, and race as predcitors and perceived stress as the outcome variable. 


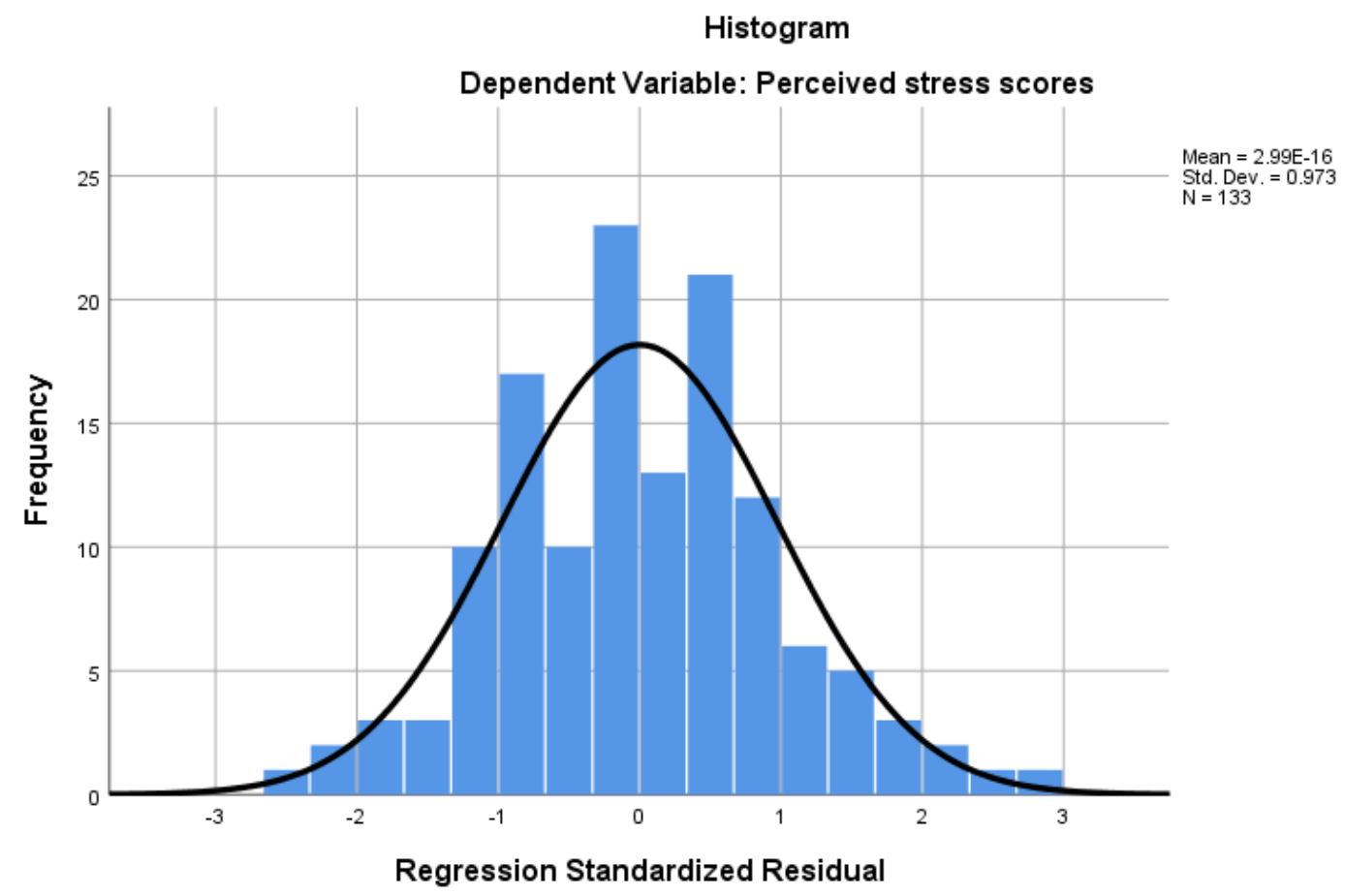

Figure 41. Histogram of standardized residuals for regression with athletic identity, internalized heterosexism, and sport as predictors and perceived stress as the outcome variable.

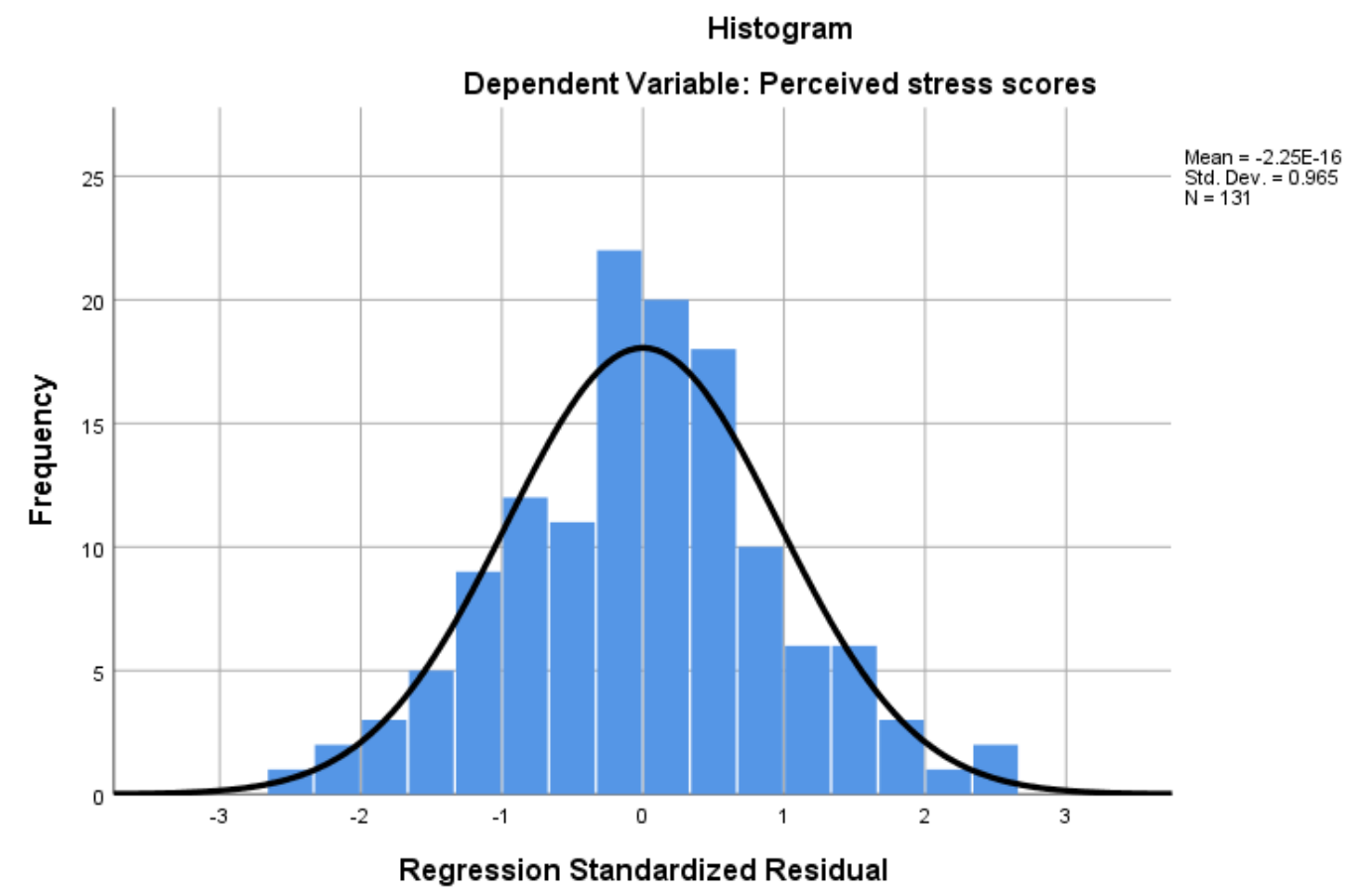

Figure 42. Histogram of standardized residuals for regression with athletic identity, internalized heterosexism, race, and sport as predictors and perceived stress as the outcome variable. 